INFLUÊNCIA DE QUEIMADAS NA REDUÇÃO DA INCIDÊNCIA DE RADIAÇÃO SOLAR OBSERVADA POR ESTAÇÕES DO PROJETO SONDA NO TERRITÓRIO BRASILEIRO

\author{
RELATÓRIO FINAL DE PROJETO DE INICIAÇÃO CIENTÍFICA \\ (PIBIC/INPE - CNPq/MCT)
}

\title{
PROCESSO $N^{\circ}$ 104234/2007-5
}

Rodrigo Brackmann - Bolsista PIBIC/INPE - CNPq/MCT

Laboratório de Recursos de Energias Renováveis

LRER/CRS/CIE/INPE - MCT

Centro Regional Sul de Pesquisas Espaciais

CRS/CIE/INPE - MCT

E-mail: rodrigob@lacesm.ufsm.br

Dr. Fernando Ramos Martins

Orientador

Divisão de Clima e Meio Ambiente

DMA/CPTEC/INPE - MCT

Instituto Nacional de Pesquisas Espaciais

INPE - MCT

E-mail: fernando@dge.inpe.br 
Relatório Final de Atividades, 2008

\title{
RELATÓRIO FINAL DE INICIAÇÃO CIENTÍFICA DO \\ PROGRAMA: PIBIC/INPE - CNPq/MCT
}

\author{
PROJETO
}

\section{INFLUÊNCIA DE QUEIMADAS NA REDUÇÃO DA INCIDÊNCIA DE RADIAÇÃO SOLAR OBSERVADA POR ESTAÇÕES DO PROJETO SONDA NO TERRITÓRIO BRASILEIRO}

\section{PROCESSO: 104234/2007-5}
Relatório elaborado por Rodrigo Brackmann relativas ao período de execução das atividades:
Rodrigo Brackmann - Bolsista PIBIC/INPE - CNPq/MCT E-mail: rodrigob@lacesm.ufsm.br

\section{Dr. Nelson Jorge Schuch - Co-Orientador Centro Regional Sul de Pesquisas Espaciais - CRS/CIE/INPE - MCT E-mail: njschuch@lacesm.ufsm.br}

Dr. Enio Bueno Pereira - Co-Orientador Divisão de Clima e Meio Ambiente DMA/CPTEC/INPE - MCT E-mail: <enio.pereira@cptec.inpe.br> 


\section{DADOS DE IDENTIFICAÇÃO}

Título: INFLUÊNCIA DE QUEIMADAS NA REDUÇÃO DA INCIDÊNCIA DE RADIAÇÃO SOLAR OBSERVADA POR ESTAÇÕES DO PROJETO SONDA NO TERRITÓRIO BRASILEIRO

Processo CNPq No: 104234/2007-5

\section{Aluno Bolsista:}

Rodrigo Brackmann

Curso de Engenharia Química

Centro de Tecnologia - CT/UFSM

Universidade Federal de Santa Maria - UFSM

\section{Orientador:}

\section{Dr. Fernando Ramos Martins}

Divisão de Clima e Meio Ambiente - DMA/ CPTEC/INPE - MCT

Centro de Previsão do Tempo e Estudos Climáticos - CPTEC/INPE - MCT Instituto Nacional de Pesquisas Espaciais - INPE - MCT

\section{Co-Orientadores:}

\section{Dr. Nelson Jorge Schuch}

Centro Regional Sul de Pesquisas Espaciais - CRS/CIE/INPE - MCT

Dr. Enio Bueno Pereira

Divisão de Clima e Meio Ambiente - DMA/CPTEC/INPE

\section{Colaboradores:}

Me. Eng. Ricardo A. Guarnieri - DMA/CPTEC/INPE - MCT 
Daniel Vinícius Fiorin - Estagiário LRER/CRS/CIE/INPE-MCT e Graduando do curso de Engenharia Química da UFSM

Márcio Ceconi - Bolsista I.C. e Graduando do curso de Física Bacharelado da UFSM

Alexandre Ceretta Dalla Favera - Estagiário do Curso de Automação Industrial CTISM/UFSM

\section{Locais de Trabalho/Execução do Projeto:}

Laboratório de Recursos de Energias Renováveis - CRS/CIE/INPE - MCT

Observatório Espacial do Sul - OES/CRS/CIE/INPE - MCT

Trabalho desenvolvido no âmbito da Parceria: INPE/MCT - UFSM, através do Laboratório de Ciências Espaciais de Santa Maria - LACESM/CT UFSM. 
Relatório Final de Atividades, 2008

\section{DIRETÓRIO DOS GRUPOS DE PESQUISA}

\section{Grupo de Pesquisa \\ Ciências Atmosféricas - Ozônio x Radiação - Energias Renováveis}

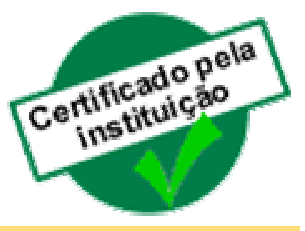

Identificacão

Recursos Humanos

Linhas de Pesquisa

Indicadores do Grupo

Identificação
Dados básicos

Nome do grupo: Ciências Atmosféricas - Ozônio x Radiação - Energias Renováveis

Status do grupo: certificado pela instituição

Ano de formação: 1992

Data da última atualização: 18/06/2008 11:32

Líder (es) do grupo: Nelson Jorge Schuch - nelson.schuch@pq.cnpq.br

Damaris Kirsch Pinheiro - damaris@lacesm.ufsm.br

Área predominante: Ciências Exatas e da Terra; Geociências

Instituição: Instituto Nacional de Pesquisas Espaciais - INPE

Órgão: Coordenação de Gestão Científica - CIE Unidade: Centro Regional Sul de Pesquisas Espaciais - CRS

$\begin{array}{ll}\text { Endereço } & \\ \text { Logradouro: Caixa Postal } 5021 & \text { CEP: } 97110970 \\ \text { Bairro: Camobi } & \text { UF: RS } \\ \text { Cidade: Santa Maria } & \text { Fax: } 33012030 \\ \text { Telefone: } 33012026 & \text { Home page: http:// } \\ \text { E-mail: } \text { njschuch@lacesm.ufsm.br } & \end{array}$

\section{Repercussões dos trabalhos do grupo}

O Grupo de Pesquisa - Ciências Atmosféricas - Ozônio x Radiação - Energias Renováveis, do Centro Regional Sul de Pesquisas Espaciais - CRS/CIE/INPE-MCT, em Santa Maria, e Observatório Espacial do Sul -

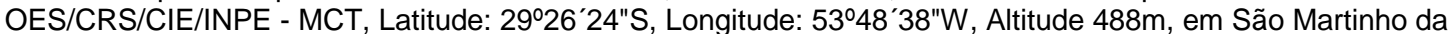
Serra, RS, colabora com pesquisadores do INPE (CEA e CPTEC), da USP(DM/ICB e IAG), do DBG/CB-UFRN, do LACESM-UFSM e internacionais: Japão (Universidades de Takushoku e Rikkyo) e EUA(NASA). Linhas de Pesquisas: CIÊNCIAS ATMOSFÉRICAS: OZÔNIO x RADIAÇÃO, ENERGIAS RENOVÁVEIS. Pesquisa: a composição, a estrutura, os processos físico-químicos e dinâmicos, o potencial energético renovável e o transporte de energia, com medidas in situ e fenômenos: Atmosféricos, Biosféricos e Genéticos. O Programa de Monitoramento do Ozônio Atmosférico - PMOA, criado por Nelson Jorge Schuch em maio de 1992, executado em Convênio: CRS/CIE/INPE-MCT - LACESM/CT-UFSM, objetiva: a análise de sua concentração; o comportamento de sua "camada", a +/- 25 km no RS, suas correlações com: Radiação Ultravioleta (UV-A, UVB); gases traçadores (NO2 - SO2 -CO2); aerossóis - queimadas; dados físicos e meteorológicos de sondagens troposféricas e estratosféricas; precipitação de partículas na Anomalia Magnética do Atlântico Sul - AMAS. Pesquisa e monitoramento da Radiação Ultravioleta - UV: UV-A (400-320 nm), UV-B (320 e $280 \mathrm{~nm}$ ). Pesquisa da sensibilidade à Radiação UV: de seu Espectro de Ação; obtenção de Dose; do Índice Ultravioleta,I-UV; efeitos biológicos da Radiação UV-B em: nível celular, humanos, animais, vegetais, ecossistemas aquáticos. Pesquisa de Energias Renováveis com ênfase nas fontes solar e eólica. Vice-Líderes: Damaris K. Pinheiro, Marcelo B. da Rosa, Enio B. Pereira. 
Relatório Final de Atividades, 2008

\section{Recursos humanos}

Pesquisadores

Total: 17

André Passaglia Schuch

Augusta Maria Passaglia Schuch

Carlos Frederico Martins Menck

Damaris Kirsch Pinheiro

Enio Bueno Pereira

Ezequiel Echer

Fernanda de São Sabbas Tavares

Fernando Luís Guarnieri

Lucymara Fassarella Agnez Lima

Marcelo Barcellos da Rosa

Marcelo Pizzuti Pes

Nelson Jesus Ferreira

Nelson Jorge Schuch

Neusa Maria Paes Leme

Plínio Carlos Alvalá

Fernando Ramos Martins

\section{Estudantes}

Alexandre Ceretta Dalla Favera

Ana Marceli Soares

Caitano Luiz da Silva

Daniel Vinicius Fiorin

Germano Possani

$\underline{\text { Ricardo André Guarnieri }}$

Gustavo Pereira Guerra

Técnicos

Total: 4

Anderson Colvero - Ensino Profissional de nível técnico - Técnico em Eletrônica

Eduardo Ceretta Dalla Favera - Ensino Profissional de nível técnico - Técnico em Computação

Koiti Ozaki - Especialização - Analista de Sistemas

Vinicius Ceregati Costa - Graduação - IOutra Função

Linhas de pesquisa

Total: 2

- Ciências Atmosféricas: Ozônio x Radiação

- Energias Renováveis

Relações com o setor produtivo

Total: 0

Indicadores de recursos humanos do grupo

Integrantes do grupo

Total

Pesquisador (es)

Estudante(s)

Técnico(s) 


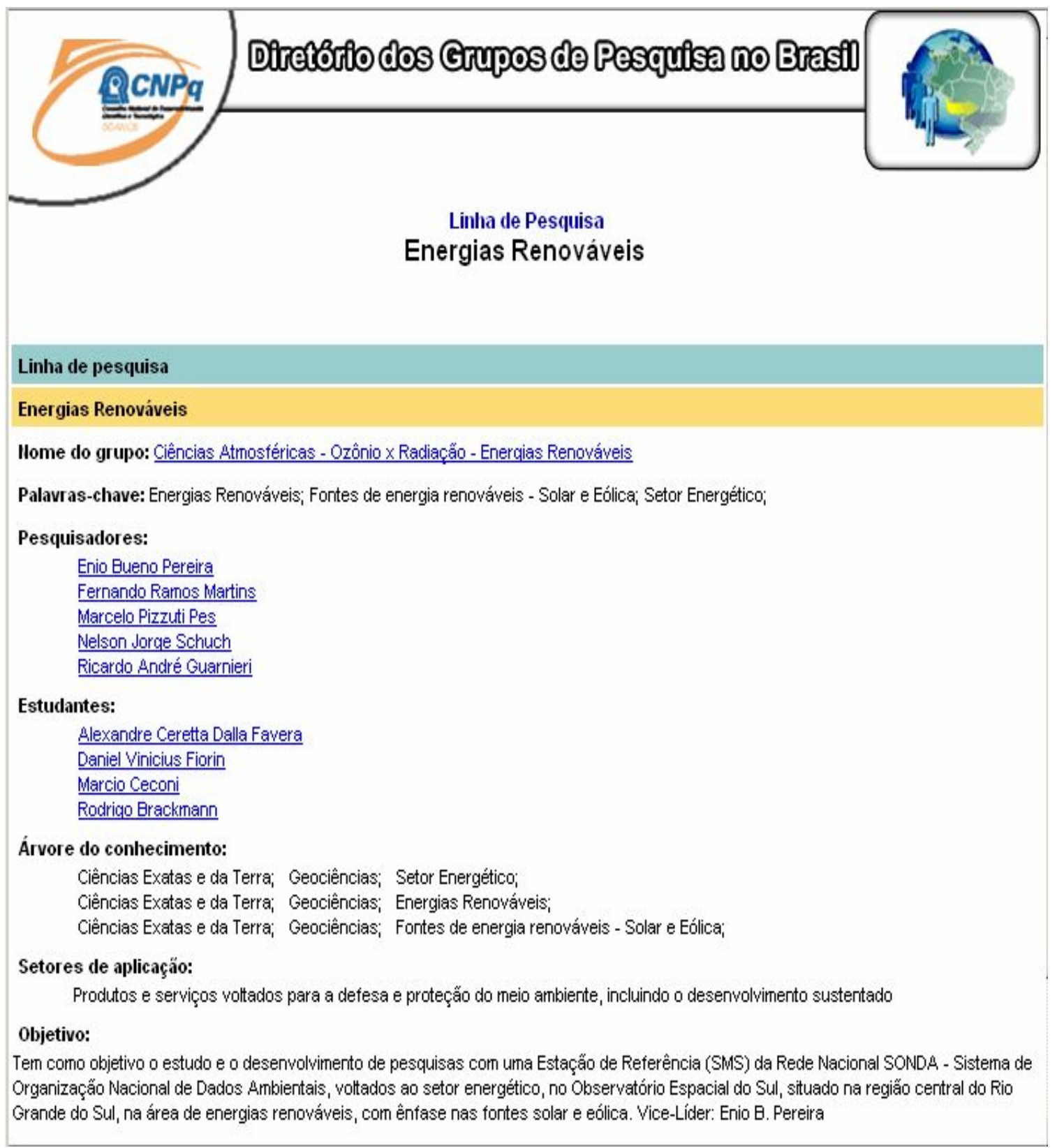




\section{AGRADECIMENTOS}

O Bolsista gostaria de agradecer à Coordenação do Programa Institucional de Bolsas de Iniciação Científica - PIBIC/INPE-CNPq/MCT, ao Conselho Nacional de Desenvolvimento Científico e Tecnológico do MCT, pela aprovação do Projeto de Pesquisa de Iniciação e ao INPE/MCT pelo apoio ao Projeto SONDA.

Da mesma forma, agradeço à FINEP - Financiadora de Estudos e Projetos, pelo financiamento do Projeto SONDA (Processo número 22.01.0569.00), à Petrobrás, por patrocinar o Projeto SONDA, ao CPTEC/INPE por disponibilizar os recursos necessários para o pleno desenvolvimento deste trabalho e a toda equipe nacional do Projeto SONDA.

Agradeço ao Dr. Fernando Ramos Martins, pesquisador do DMA/CPTEC/INPEMCT, por sempre estar disposto a esclarecer dúvidas e oferecer sugestões que enriquecessem o conteúdo deste trabalho.

Um obrigado especial ao Dr. Nelson Jorge Schuch, mentor e criador do Centro Regional Sul de Pesquisas Espaciais e do Laboratório de Recursos de Energias Renováveis, em Santa Maria, por acreditar na capacidade do Bolsista, orientar e auxiliálo no seu desenvolvimento pessoal e profissional, dedicando-lhe grande parte do seu tempo.

Outro obrigado muito especial aos colegas Daniel Vinícius Fiorin, Márcio Ceconi e Alexandre Ceretta Dalla Favera do Laboratório de Recursos de Energias Renováveis LRER/CRS/CIE/INPE-MCT pela amizade, companheirismo e pelo apoio incondicional no desenvolvimento deste Projeto de Pesquisa.

Agradeço aos meus amigos e à minha família, principalmente à minha mãe Teresinha Mueller Brackmann e ao meu pai Selmiro Brackmann que, apesar da distância física que nos separa, entre Santa Maria e Teutônia, RS, sempre acreditaram em mim, me incentivando e me ajudando a vencer todos os obstáculos e a seguir em frente. 


\section{RESUMO}

Durante o processo de queima de biomassa, emite-se para a atmosfera partículas de aerossóis, que possuem a propriedade de absorver e/ou refletir a radiação solar, modificando, dessa forma, o balanço radiativo terrestre. O presente Projeto de Pesquisa desenvolvido no Laboratório de Recursos de Energias Renováveis LRER/CRS/CIE/INPE - MCT objetiva investigar a relação existente entre a ocorrência de queimadas e a diminuição da radiação solar que atinge a superfície terrestre medida por sensores solarimétricos instalados nas estações do Projeto SONDA (Sistema de Organização Nacional de Dados Ambientais voltado para o Setor Energético). O estudo limita-se à análise de dias de céu claro a fim de se eliminar as incertezas associadas com a influência da nebulosidade sobre a irradiação solar na superfície. Para isto, a seleção dos dias de céu claro é realizada através da análise e qualificação de dados de irradiação solar global e difusa medidos respectivamente pelos sensores Piranômetro CM 21 (Kipp \& Zonen), Piranômetro CM 22 (Kipp \& Zonen). Dados de espessura ótica de aerossóis (AOT) foram disponibilizados pela NASA (http://aeronet.gsfc.nasa.gov) e dados de focos de queimadas estimados por satélites para todo o Território Brasileiro foram coletados pelo CPTEC/INPE-MCT (www.dpi.inpe.br/proarco/bdqueimadas). Nesta etapa do Projeto, os valores do índice de nebulosidade (Kt), parâmetro calculado através da razão entre a irradiância solar global que chega à superfície e a irradiância no topo da atmosfera (TDA), foram diagramados em função da AOT em diferentes comprimentos de onda, inicialmente para as cidades de Petrolina - BA, Cuiabá - MT e Campo Grande - MS. Verificou-se que, nos dois primeiros sítios, o fator Kt decresce exponencialmente com o aumento da AOT, enquanto que em Petrolina, o fator Kt não demonstrou boa correlação com as medidas de AOT. Permitindo concluir que Petrolina não sofre significativa influência de aerossóis, ao contrário do que ocorre nos outros dois sítios. $\mathrm{Na}$ continuidade do Projeto, pretende-se realizar novas análises utilizando dados da estação de Referência SONDA - SMS instalada no Observatório Espacial do Sul OES/CRS/CIE/INPE - MCT, em São Martinho da Serra - RS e de modelos empíricos que relacionem focos de queimadas, a espessura ótica de aerossóis e radiação solar. 


\section{SUMÁRIO}

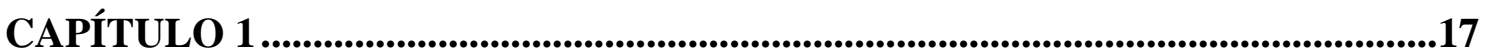

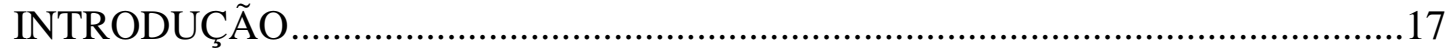

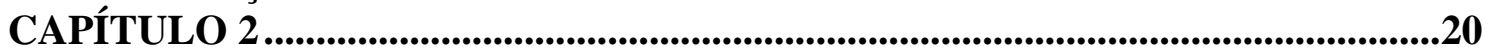

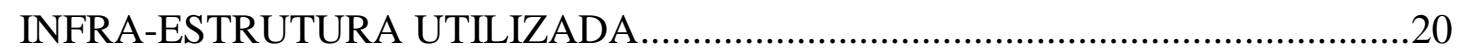

2.1 - O Projeto SONDA..........................................................................................20

2.2 - Estações Coletoras de Dados do Projeto SONDA ...........................................21

2.3 - Estação de Referência SONDA - SMS instalada no Observatório Espacial do Sul - OES/CRS/CIE/INPE - MCT ..................................................................23

2.4 - Laboratório de Recursos de Energias Renováveis LRER/CRS/CIE/INPE -MCT ....................................................................26

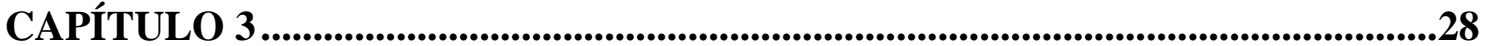

RADIAÇÃO SOLAR E A ATMOSFERA TERRESTRE ........................................28

3.1 - Descrição Quantitativa da Radiação.......................................................................28

3.2 - Radiação Solar e Radiação Terrestre ..............................................................29

3.3 - Interações da Radiação com a Atmosfera Terrestre ....................................30

3.4 - Modelos Computacionais para Estimativa da Radiação Solar Incidente 33

3.5 - Radiação Solar no Território Brasileiro ...........................................................34

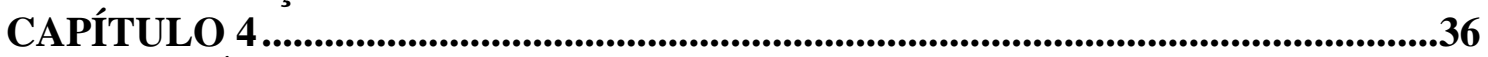

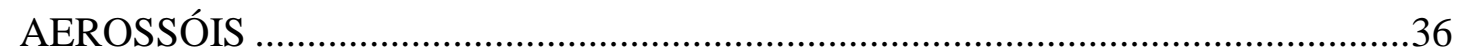

4.1 - Caracterização e Classificação dos Aerossóis ..............................................36

4.2 - Efeitos dos Aerossóis na Atmosfera .............................................................38

4.3 - Caracterização de Aerossóis pelo Sensor Modis........................................39

4.4 - Caracterização de Aerossóis pela Rede AERONET ...................................41

CAPÍTULO 5...........................................................................................................44

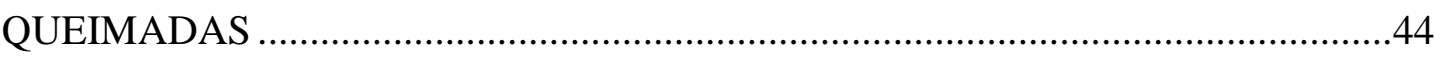

5.1 - Efeitos das Queimadas sobre a Radiação Solar e a Química da Atmosfera

5.2 - Efeito das Queimadas na Atmosfera Brasileira

5.3 - Identificação de Queimadas no Brasil através de sensoriamento remoto 47

5.4 - Monitoramento de Queimadas pelo CPTEC/INPE.....................................48

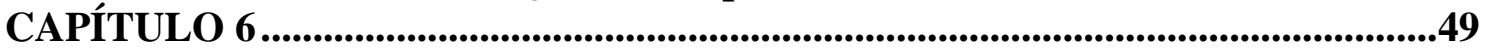

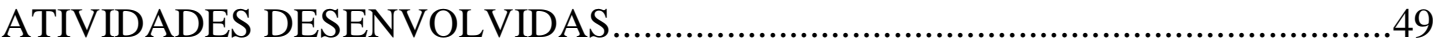

6.1 - Manutenção dos equipamentos da estação de referência SONDA - SMS

6.2 - Coleta, Redução e Análise dos Dados da estação de referência SONDA -

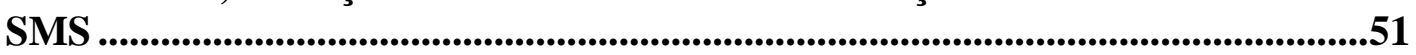

6.3 - Estimativas de Radiação Solar Global e da Radiação PAR a partir de dados de Iluminância obtidos no Observatório Espacial do Sul ..........................53

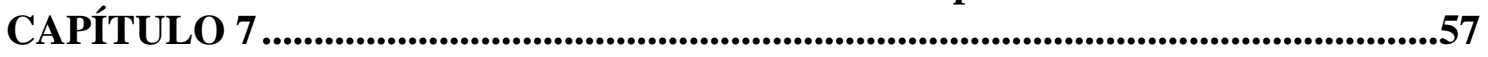

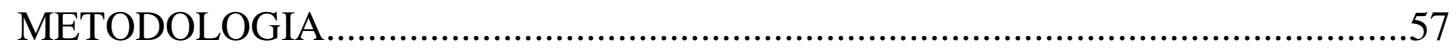

7.1 Obtenção de Medidas de Radiação Solar ............................................................57

7.2 - Seleção de Dias de Céu Claro ...................................................................58 
7.3 - Obtenção de Dados de Queimadas .60

7.4 - Obtenção de Dados de Espessura Óptica dos Aerossóis .............................62

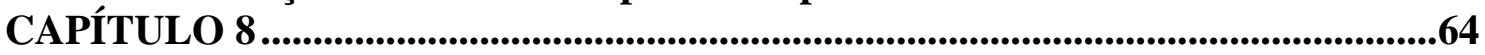

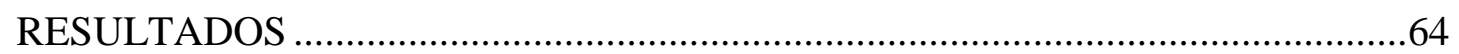

CONCLUSÃO

REFERÊNCIAS BIBLIOGRÁFICAS ......................................................................70

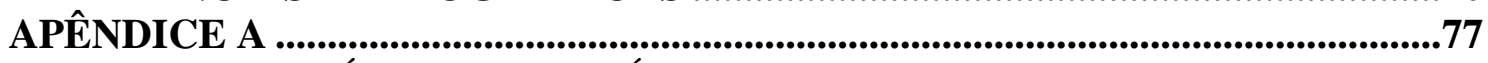

TRABALHOS TÉCNICO-CIENTÍFICOS APRESENTADOS EM EVENTOS.......77

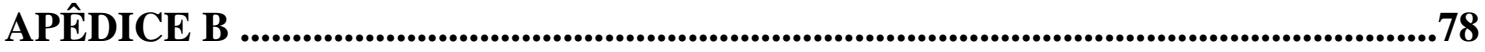

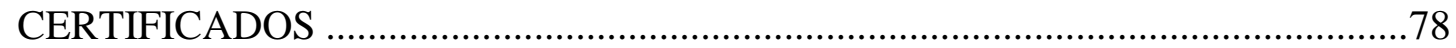




\section{LISTA DE FIGURAS}

Figura 1.1 - (a) Representação da matriz de oferta de energia primária brasileira; (b) Formas de energia utilizadas para a geração de eletricidade no Brasil. Fonte: Atlas Brasileiro de Energia Solar (2006). .18

Figura 2.1 - Estações do Projeto SONDA distribuídas ao longo do Território

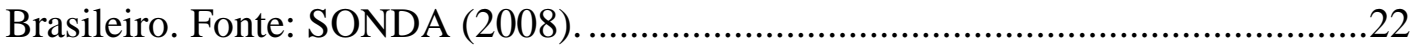

Figura 2.2 - Estação de referência SONDA - SMS instalada no Observatório Espacial do Sul - OES/CRS/CIE/INPE - MCT em São Martinho da Serra, RS....................23

Figura 2.3 - Torre Anemométrica instalada no Observatório Espacial do Sul OES/CRS/CIE/INPE - MCT. Em destaque o posicionamento dos três anemômetros instalados a 10,25 e 50 metros.

Figura 2.4 - Laboratório de Recursos de Energias Renováveis localizado no Centro Regional Sul de Pesquisas Espaciais - CRS/CIE/INPE - MCT.

Figura 3.1 - Trocas de energia entre o Sol e a Terra. Fonte: http://iara.meteo.furg.br/page/aulas/poligradf.pdf.................................................30

Figura 3.2 - Espectro solar no topo da atmosfera, comparado com o espectro de um corpo negro a $6000 \mathrm{~K}$ e com o espectro solar a nível do mar. Fonte: Modificado de Robinson (1966).

Figura 3.3 - (a) Curvas de corpo negro para a radiação solar $(6000 \mathrm{~K})$ e radiação terrestre $(255 \mathrm{~K})$. (b) Espectro de absorção para toda a extensão vertical da atmosfera. (c) Espectro de absorção para a atmosfera acima de $11 \mathrm{~km}$. (d) Espectros de absorção para vários gases atmosféricos entre o topo da atmosfera e a superfície da Terra. Fonte: Modificado de Peixoto e Oort (1992).

Figura 3.4 - Média anual do total diário de irradiação solar global incidente no território brasileiro. Fonte: Atlas Brasileiro de Energia Solar (2006).

Figura 4.1 - Profundidade Ótica dos Aerossóis em 550nm sobre a América do Sul obtida pelo sensor MODIS (a) a bordo do Satélite AQUA; (b) a bordo do Satélite TERRA.

Figura 4.2 - Estações AERONET espalhadas pelo globo terrestre. Fonte: AERONET (2008)

Figura 5.1 - Série temporal da profundidade ótica de aerossóis em 500 nm medidos em quatro sítios de pesquisa na Amazônia (Abracos Hill, Alta Floresta, Rio Branco e Cuiabá) com fotômetros solares da Rede AERONET no período de Fevereiro de 1999 a Novembro de 2002.

Figura 6.1 - Imageador Total Sky Imager TSI-440 (YES, Inc) instalado na estação SONDA - SMS no Observatório Espacial do Sul - OES/CRS/CIE/INPE - MCT em São Martinho da Serra, RS.

Figura 6.2 - Datalogger CR23X Micrologger junto ao computador SONDA no interior do Prédio 1 do Observatório Espacial do Sul - OES/CRS/CIE/INPE - MCT.........51

Figura 6.3 - Diagrama da configuração local dos equipamentos instalados na estação SONDA - SMS no Observatório Espacial do Sul - OES/CRS/CIE/INPE - MCT. Fonte: SONDA (2008). 
Figura 6.4 - (a) Relação entre as medidas de Irradiação Global e de Iluminância Natural coletadas no Observatório Espacial do Sul - OES/CRS/CIE/INPE-MCT; (b) Medidas instantâneas de Radiação PAR em função da Iluminância; (c) Relação entre as Integrais Diárias de Radiação Global e de Iluminância; (d) Integrais Diárias de Radiação PAR em função das Integrais Diárias de Iluminância.

Figura 7.1 - Equipamentos do Projeto SONDA utilizados para a realização de medidas de radiação solar (a) Piranômetro CM 21 (Kipp \& Zonen); (b) Piranômetro CM 22 (Kipp \& Zonen).

Figura 7.2 - Curva diária de radiação solar global obtida em 18/07/05 (dia de céu claro) na estação de referência SONDA de Petrolina - BA

Figura 7.3 - Curva diária de radiação solar global obtida no dia 12/05/07 na estação SONDA de Campo Grande - MS.

Figura 7.4 - Opções de satélites disponíveis para visualização dos focos de queimadas fornecidos pelo CPTEC/INPE - MCT. Fonte: DPI/PROARCO (2008).

Figura 7.5 - Tabela eletrônica contendo dados diários de focos de queimadas ocorridos no estado do Mato Grosso, disponibilizados pelo CPTEC/INPE - MCT.

Figura 7.6 - Gráfico de barras representando o número de focos de queimadas registrados semanalmente por todos os satélites disponíveis no estado da Bahia durante o ano de 2005. Fonte: DPI/PROARCO (2008)

Figura 7.7 - Produtos de Aerossóis disponibilizados pela rede AERONET para a cidade de Campo Grande - MS no período de Abril a Junho de 2007. Fonte: AERONET (2008).

Figura 8.1 - Índice de nebulosidade em função da espessura ótica de aerossóis para os comprimentos de onda de 500, 870 e $1020 \mathrm{~nm}$ em Campo Grande - MS.

Figura 8.2 - Relação entre KT e espessura ótica de aerossóis em Cuiabá - MT...........65

Figura 8.3 - $\mathrm{K}_{\mathrm{T}}$ em função de AOT para a cidade de Petrolina - BA. ..........................66

Figura 8.4 - Variação temporal do número de queimadas semanais registradas nos estados de Mato Grosso, Mato Grosso do Sul e Bahia de Janeiro de 2004 a Dezembro de 2007. 


\section{LISTA DE TABELAS}

Tabela 6.1 - Modelos empíricos desenvolvidos no LRER/CRS/CIE/INPE - MCT, suas correlações e desvios estatísticos.

Tabela 8.1: Informações relativas à seleção de dias de céu claro nas Estações SONDA 


\section{SIGLAS E ABREVIATURAS}

AERONET - AErosol RObotic NETwork

AOD - Aerosol Optical Depth

AOT - Aerosol Optical Thickness

AVHRR - Advanced Very High Resolution Radiometer

BSRN - Baseline Surface Radiation Network

CCD - Charge Coupled Device

CPTEC - Centro de Previsão de Tempo e Estudos Climáticos

CRS/CIE - Centro Regional Sul de Pesquisas Espaciais

DAS - Divisão de Satélites Ambientais

DMA - Divisão de Meio-Ambiente

DPI - Divisão de Processamento de Imagens

DU - Unidades Dobson

ETR - Equação de Transferência Radioativa

FINEP - Financiadora de Estudos e Projetos

GOES - Geostationary Operational Environmental Satellite

GSFC - Goddard Space Flight Center

IBAMA - Instituto Brasileiro do meio Ambiente e dos Recursos Naturais Renováveis

INPE - Instituto Nacional de Pesquisas Espaciais

IPCC - Intergovernmental Panel on Climate Change

LACESM - Laboratório de Ciências Espaciais de Santa Maria

LRER - Laboratório de Recursos de Energias Renováveis

MBE - Mean Bias Error

MCT - Ministério de Ciência e Tecnologia

MODIS - MODerate Resolution Imaging Spectroradiometer

NASA - National Aeronautics and Space Administration

NIP - Normal Incidence Pyrheliometer

NIR - Near Infra Red

NOAA - National Weather Service 
OES - Observatório Espacial do Sul

PAR - Photosynthetically Active Radiation

PC - Personal Computer

PIR - Precision Infrared Radiometer

PMOA - Programa de Monitoramento do Ozônio Atmosférico

PROARCO - Programa de Prevenção e Controle de Queimadas e Incêndios Florestais na Amazônia Legal

RMSE - Root Mean Square Error

SMS - São Martinho da Serra

SONDA - Sistema de Organização de Dados Ambientais

TDA - Topo Da Atmosfera

TSI - Total Sky Imager

USB - Universal Serial Bus

UFSM - Universidade Federal de Santa Maria

UV - Ultra Violeta

WMO - World Meteorological Organization 


\section{CAPÍTULO 1}

\section{INTRODUÇÃO}

Nos últimos anos, a demanda energética tem aumentado principalmente em países em desenvolvimento, como é o caso do Brasil, em função do crescimento das atividades econômicas e da melhoria da qualidade de vida. Além disso, o esgotamento dos recursos hídricos e a queima de combustíveis fósseis têm causado danos irreversíveis ao meio-ambiente comprometendo a qualidade de vida das gerações futuras. Desde o século passado, o petróleo tem sido a fonte de energia mais importante, porém, conforme revelam os estudos, este recurso está se esgotando. Dessa forma, torna-se necessário o desenvolvimento de formas alternativas de energia.

Entende-se por Energias Alternativas ou Renováveis quaisquer formas de energia cuja taxa de utilização é inferior a sua taxa de renovação, podendo-se citar a energia solar, eólica, biomassa, geotérmica e hidráulica.

No Brasil, a energia hidráulica ou hidroelétrica é a principal fonte de energia para a geração de eletricidade, mas, apesar de ser considerada uma fonte de energia limpa e renovável, sua utilização causa graves impactos ambientais, como o alagamento de grandes áreas. A Figura 1.1 apresenta a atual conjuntura energética do Brasil.

Neste contexto, os recursos energéticos solares e eólicos se apresentam como alternativas limpas, não danosas ao meio-ambiente e de caráter renovável. Como a maior parte do território brasileiro está localizado na região inter-tropical, nosso país apresenta grande potencial para aproveitar a energia solar durante o ano inteiro (Pereira et al., 2006).

No entanto, a atração de investimentos e a realização de ações efetivas ao desenvolvimento tecnológico e científico de novas fontes energéticas requerem a realização de estimativas da disponibilidade e distribuição dos seus recursos ao longo do território nacional, além do estabelecimento de um banco de dados acessível e confiável. 
Relatório Final de Atividades, 2008
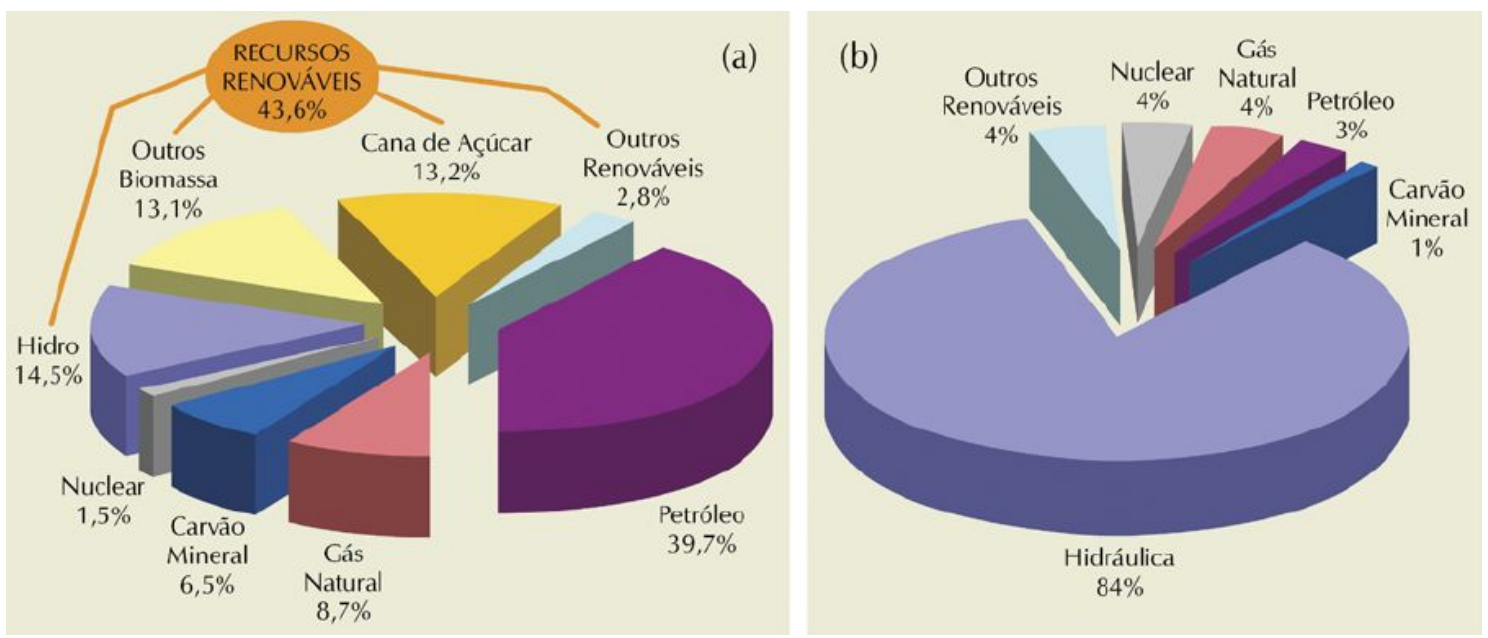

Figura 1.1 - (a) Representação da matriz de oferta de energia primária brasileira; (b) Formas de energia utilizadas para a geração de eletricidade no Brasil. Fonte: Atlas Brasileiro de Energia Solar (2006).

No Brasil, o CPTEC/INPE - MCT desenvolve o Projeto SONDA (Sistema de Organização Nacional de Dados Ambientais para o setor de energia) com o intuito de realizar medidas solarimétricas, eólicas e de outras variáveis meteorológicas necessárias ao estabelecimento do referido banco dados. Adicionalmente, realiza pesquisa científica para estudo da disponibilidade e previsão dos recursos energéticos solares utilizando modelos de Previsão Numérica do Tempo, e modelos de transferência radiativa específicos.

A parametrização atmosférica dos modelos computacionais abrange diversas variáveis climáticas, além da posição geográfica. Este procedimento, necessário a uma maior concordância entre os valores de irradiação solar estimados pelos modelos e por medidas de superfície, visa a minimização das incertezas introduzidas por diferentes aspectos atmosféricos.

As principais fontes de incertezas nos valores de irradiação solar na superfície estimados por modelos computacionais são resultados da variabilidade geográfica dos aerossóis na atmosfera causados por fenômenos naturais e por queimadas realizadas em florestas, juntamente com incertezas sobre a variabilidade da cobertura de nuvens (Pinker and Laszlo, 1989). Desta forma, informações sobre as propriedades ópticas e a distribuição geográfica dos aerossóis atmosféricos exercem grande influência na confiança das estimativas de irradiação solar (Box et al., 1996). 
Os aerossóis provenientes dos eventos de queima de biomassa têm exercido um importante papel em processos radioativos da atmosfera, podendo atenuar a radiação solar global incidente na superfície.

A inclusão da influência dos aerossóis nos modelos atmosféricos traz novos desafios para o desenvolvimento de novas parametrizações que representem apropriadamente os diversos processos através dos quais os aerossóis interagem com os outros elementos atmosféricos (Artaxo et al., 2006).

Inserido neste contexto, o presente Projeto de Iniciação Científica e Tecnológica tem por objetivo o estudo da relação existente entre a ocorrência de focos de queimadas e o déficit da radiação solar global incidente na superfície. Para tanto, foram coletados dados de radiação solar e de aerossóis para as estações SONDA de Cuiabá - MT, Campo Grande - MS e Petrolina - BA. Este trabalho contribui para o estudo da influência dos aerossóis sobre a radiação solar favorecendo o aperfeiçoamento dos modelos de transferência radiativa e maior precisão na avaliação da disponibilidade de energia solar. 


\section{CAPÍTULO 2}

\section{INFRA-ESTRUTURA UTILIZADA}

\section{1 - O Projeto SONDA}

O Instituto Nacional de Pesquisas Espaciais (INPE - MCT) coordena e executa, através do seu Centro de Previsão do Tempo e Estudos Climáticos (CPTEC/INPE MCT), o Projeto SONDA (Sistema de Organização Nacional de Dados Ambientais para o setor de Energia). O Dr. Enio Bueno Pereira é o Pesquisador Titular e Coordenador Nacional do Projeto. O SONDA é financiado pela FINEP - Financiadora de Estudos e Projetos, através do Fundo Setorial de Energia - CT - ENERG e pela PETROBRÁS Petróleo Brasileiro S/A.

O Projeto SONDA tem como objetivo geral prover dados de alta qualidade que contribuam no desenvolvimento de pesquisas e conhecimento científico sobre a disponibilidade de recursos energéticos renováveis com enfoque na energia solar e eólica no território brasileiro. A formação de um banco de dados de superfície necessária ao levantamento, avaliação e acompanhamento dos recursos de energia solar e eólica no Brasil, o estudo da variabilidade dos recursos destas fontes alternativas de energia em função da climatologia e de mudanças no meio-ambiente e a formação de recursos humanos são algumas das metas do Projeto. Em resumo, o projeto SONDA é de fundamental importância no estabelecimento de um planejamento energético, desenvolvimento de projetos com uso de fontes renováveis, e conseqüentemente para a atração de investimentos para o setor de energias renováveis.

A base de dados gerada pelo SONDA permite um aprimoramento do conhecimento em relação à distribuição e à variabilidade dos recursos de energia solar e eólica. $\mathrm{O}$ aprimoramento de modelos para estimativa e previsão de potencial energético é uma das aplicações principais da base de dados do SONDA.

Maiores informações sobre o projeto SONDA podem ser adquiridas no endereço eletrônico www.cptec.inpe.br/sonda. 
Relatório Final de Atividades, 2008

\section{2 - Estações Coletoras de Dados do Projeto SONDA}

O Projeto SONDA possui uma rede de estações coletoras de dados de superfície espalhadas pelo território nacional conforme mostra a Figura 2.1, totalizando 25 estações configuradas e instaladas, que dispõem de equipamentos de primeira linha para a aquisição dos dados, sendo que algumas ainda se encontram em fase de implantação.

As estações do Projeto SONDA são classificadas em quatro categorias (estações de referência, eólicas, solares básicas e solares avançadas) de acordo com a instrumentação instalada e o tipo de dados coletados.

A rede SONDA possui quatro estações de referência, que estão localizadas em Brasília - DF, Rolim de Moura - RO, São Martinho da Serra - RS no Observatório Espacial do Sul - OES/CRS/CIE/INPE - MCT, Petrolina - BA e Cachoeira Paulista SP, sendo que apenas esta última ainda não se encontra em operação. Estas estações são as mais completas do Projeto SONDA, pois possuem sensores solares, meteorológicos e eólicos que realizam as seguintes medidas:

- Medidas Solares - radiação global horizontal, radiação direta normal, radiação difusa horizontal, radiação de onda longa descendente, radiação fotossinteticamente ativa (PAR) e iluminância (Lux);

- Medidas Meteorológicas - temperatura, umidade relativa e pressão do ar atmosférico à superfície, e precipitação de chuva;

- Medidas Eólicas - velocidade e direção do vento nas alturas de 10, 25 e 50 metros a partir da superfície, e temperatura nas alturas de 25 e 50 metros. 


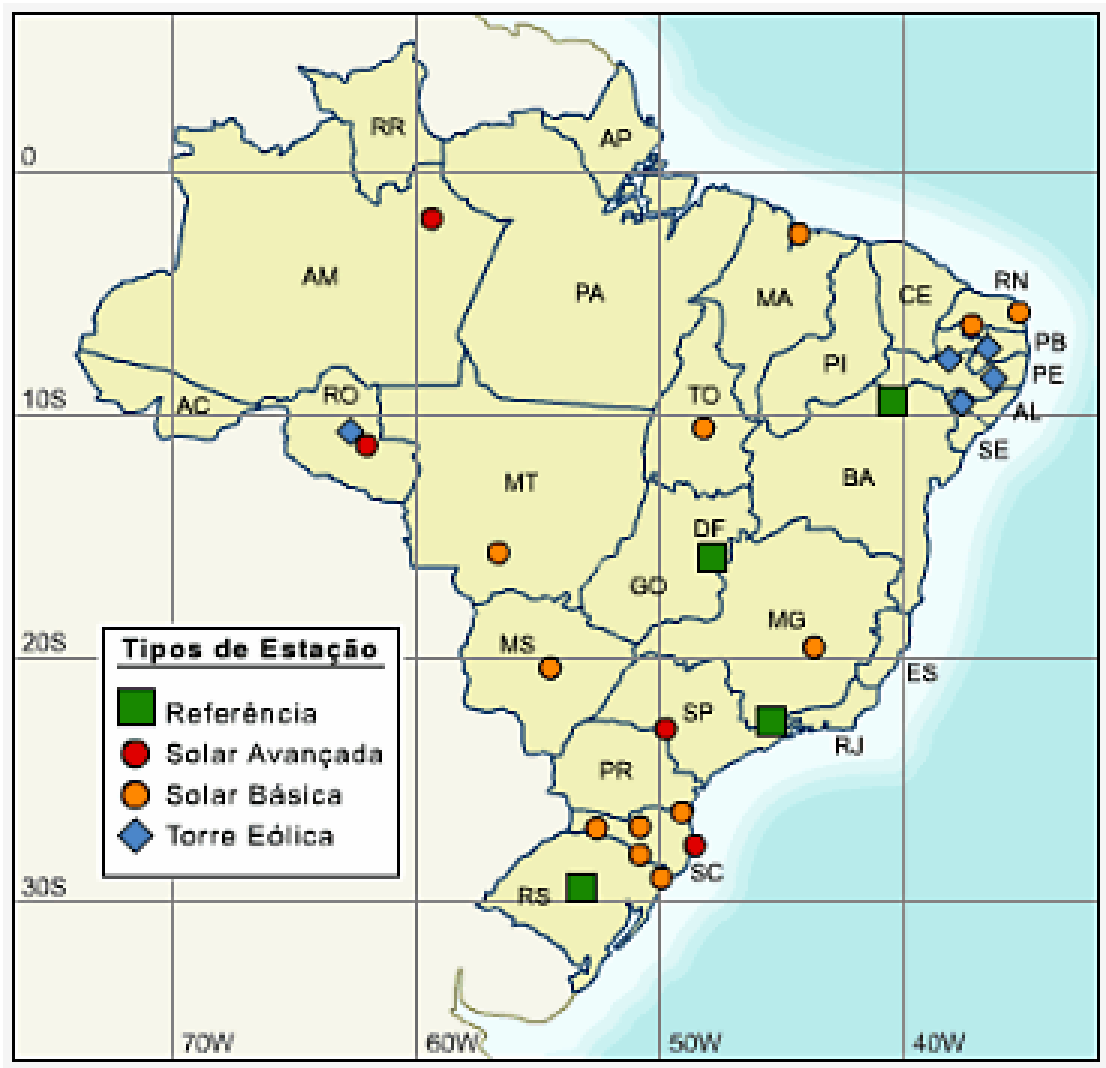

Figura 2.1 - Estações do Projeto SONDA distribuídas ao longo do Território Brasileiro. Fonte: SONDA (2008).

As estações solares possuem os mesmos sensores solares e meteorológicos utilizados pelas estações de referência, enquanto que as estações eólicas possuem torres anemométricas onde são instalados sensores que realizam medidas de velocidade e direção do vento nas alturas de 10,25 e 50 metros de altura, e de temperaturas nas alturas de 25 e 50 metros.

O processo de qualificação dos dados solarimétricos obtidos pelas estações SONDA baseia-se na estratégia de controle de qualidade adotada pela BSRN (Baseline Surface Radiation Network). O Projeto SONDA não altera sua base de dados original, mas sim executa um método de controle de qualidade que não corrige os dados, apenas sinaliza aqueles suspeitos de estarem incorretos, gerando um código de qualificação para cada dado coletado. O controle de qualidade aplicado aos dados meteorológicos e 
Relatório Final de Atividades, 2008

eólicos segue a mesma metodologia empregada para a qualificação dos dados solarimétricos (Martins et al., 2007).

\section{3 - Estação de Referência SONDA - SMS instalada no Observatório Espacial do Sul - OES/CRS/CIE/INPE - MCT}

A estação de referência SONDA - SMS (Latitude: 29²6'34"S, Longitude: 5349'23” O) está instalada no Observatório Espacial do Sul - OES/CRS/CIE/INPE MCT, localizado no município de São Martinho da Serra - RS, pertencente ao Centro Regional Sul de Pesquisas Espaciais - CRS/CIE/INPE - MCT, Santa Maria, RS.

A implantação da estação de referência SONDA - SMS no mês de julho de 2004 marcou o início do funcionamento da rede SONDA. A partir de então, muitas outras estações foram implantadas ou incorporadas à rede. A coleta de dados teve início no dia $1^{\circ}$ de Agosto de 2004 e continua sendo realizada de forma ininterrupta.

A estação é constituída por uma plataforma de três metros de altura aterrada ao lado do Prédio 1 do Observatório Espacial do Sul, onde estão instalados os sensores solarimétricos e alguns sensores meteorológicos do Projeto SONDA juntamente com os equipamentos do Programa de Monitoramento do Ozônio Atmosférico (PMOA), conforme apresentado na Figura 2.2.

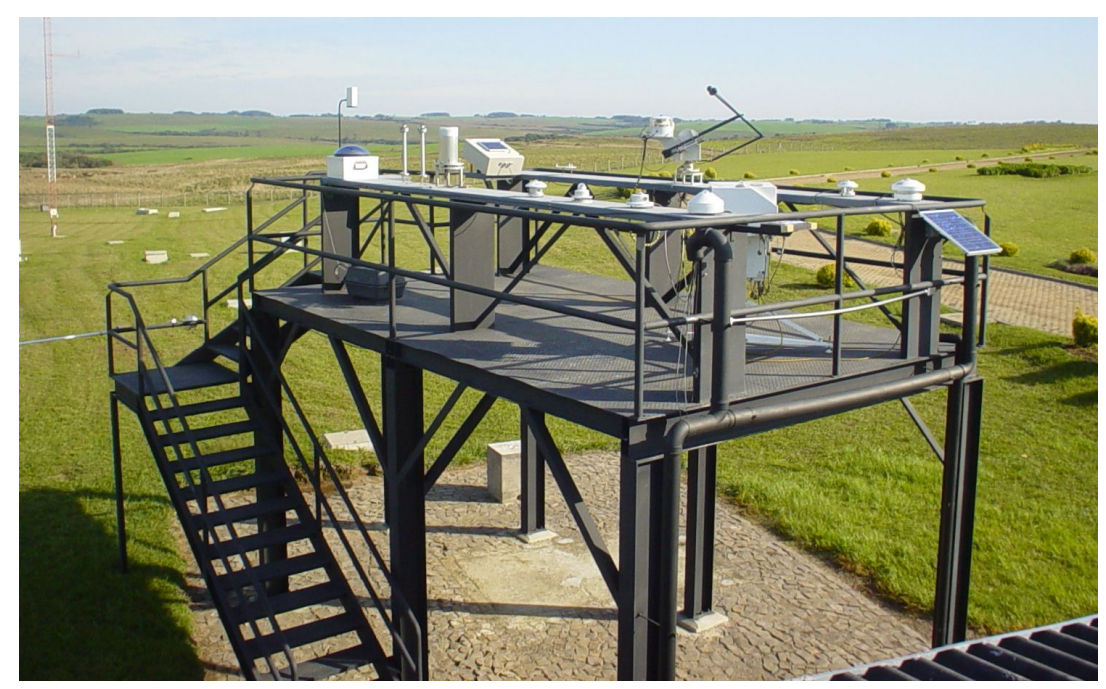

Figura 2.2 - Estação de referência SONDA - SMS instalada no Observatório Espacial do Sul - OES/CRS/CIE/INPE - MCT em São Martinho da Serra, RS. 
A estação ainda possui uma torre anemométrica de 52 metros de altura mostrada na Figura 2.3, onde estão instalados 3 anemômetros para monitorar a velocidade e direção do vento em alturas padrões de 10, 25 e 50 metros. Adicionalmente medidores de alta qualidade instalados na torre fornecem a temperatura do ar nas alturas de 1 e 50 metros.

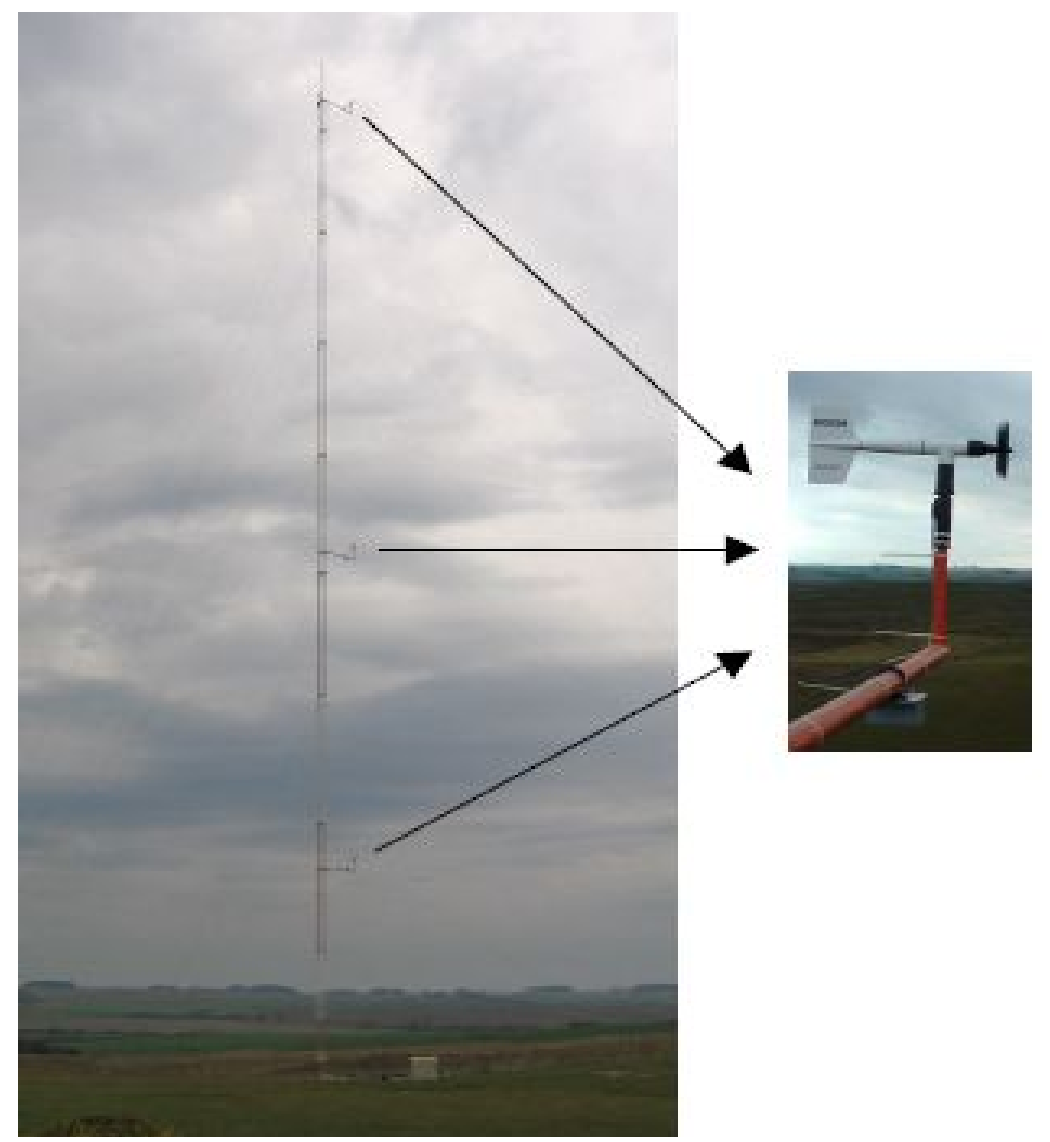

Figura 2.3 - Torre Anemométrica instalada no Observatório Espacial do Sul OES/CRS/CIE/INPE - MCT. Em destaque o posicionamento dos três anemômetros instalados a 10,25 e 50 metros.

Os sensores instalados na Estação de Referência SONDA - SMS são os seguintes:

- Piranômetro CM 21 (Kipp \& Zonen) - efetua medidas de radiação solar global na faixa de 300 a $2800 \mathrm{~nm}$;

- Piranômetro CM 22 (Kipp \& Zonen) - realiza medidas de radiação solar difusa na faixa de 200 a $3600 \mathrm{~nm}$. Possui ocultador do disco solar acoplado a um “tracker 2AP”; 
- Two Axis Positioner - 2AP (Kipp \& Zonen) - o "tracker" ou posicionador de dois eixos rastreia o caminho solar permitindo a realização das medidas de radiação solar difusa e direta por equipamentos acoplados a ele;

- Pireliômetro NIP (Eppley Laboratory, Inc) - trata-se de um Pireliômetro de Incidência Normal que efetua medidas de radiação solar direta em um plano normal à incidência de radiação, através do acompanhamento do sol ao ser acoplado ao "tracker 2AP”;

- Pirgeômetro PIR (Eppley Laboratory, Inc) - é um Radiômetro de Infravermelho de Precisão que efetua medidas de radiação de onda longa ou radiação terrestre na faixa de 3500 a $5000 \mathrm{~nm}$. Este sensor possui um domo de silicone para separação da radiação de onda longa e radiação de onda curta durante o dia;

- LUX Lite (Kipp \& Zonen) - efetua medidas de luz visível expressa em unidades de iluminância, através da simulação da resposta espectral do olho humano a radiação visível incidente;

- PAR Lite (Kipp \& Zonen) - efetua medidas da radiação PAR - Radiação Fotossinteticamente ativa durante o dia no intervalo de radiação solar visível de 400 a $700 \mathrm{~nm}$;

- Total Sky Imager TSI-440 (YES, Inc) - trata-se de um imageador do céu que possui uma câmera colorida CCD invertida apontada para o centro de um espelho convexo que reflete a imagem do céu diretamente para a sua lente. Imagens do céu são coletadas a cada 15 minutos durante o dia. As imagens são processadas por um programa que avalia a fração do céu coberta por nuvens;

- Anemômetro Modelo 05106 (R. M.Young Company) - efetua medidas da velocidade horizontal e da direção do vento de 0 a $60 \mathrm{~m} / \mathrm{s}$ resistindo a rajadas de até $100 \mathrm{~m} / \mathrm{s}$;

- Barômetro Vaisala PTB 101 - efetua medidas da pressão atmosférica na faixa de 600 a 1060 mbar através de um sensor capacitivo;

- Sensor de Temperatura do ar Model 41342 (R. M.Young Company) - efetua medidas da temperatura do ar através de um sensor de temperatura de platina; 
- Sensor de Temperatura do ar/Umidade do ar Model 41372 (R. M.Young Company) - efetua medidas de temperatura e umidade relativa do ar através de um sensor de umidade de alta precisão.

Os equipamentos da estação estão conectados a um datalogger, situado no interior do prédio 1 , que armazena os dados gerados pelos equipamentos com resolução de 1 e 10 minutos.

A instalação dos sensores e a organização dos dados seguem normas internacionais, tornando o Observatório Espacial do Sul qualificado a integrar a Rede de Estações de Superfície para Medição de Radiação - "Baseline Surface Radiation Network" - BSRN. A BSRN é um Projeto da Organização Meteorológica Mundial WMO, que tem como objetivo avaliar globalmente a interação da radiação solar com outras variáveis climáticas e a sua influência sobre mudanças percebidas no clima do planeta.

\section{4 - Laboratório de Recursos de Energias Renováveis - LRER/CRS/CIE/INPE - MCT}

O Laboratório de Recursos de Energias Renováveis (LRER), criado em 2003, está instalado no Centro Regional Sul de Pesquisas Espaciais - CRS/CIE/INPE - MCT, junto ao campus da Universidade Federal de Santa Maria - UFSM, na cidade de Santa Maria, RS.

No LRER são realizados estudos e pesquisas científicas referentes aos recursos de energias renováveis, com ênfase à energia solar e eólica. O Laboratório, apresentado na Figura 2.4, possui uma parceria com o Projeto SONDA. Esta parceria propicia a formação de recursos humanos e o desenvolvimento de pesquisas cujos resultados vêm sendo apresentados tanto em eventos científicos nacionais como internacionais.

Os alunos são responsáveis pela coleta dos dados e manutenção da estação de referência SONDA - SMS, localizada no Observatório Espacial do Sul, em São Martinho da Serra, RS. Os dados coletados já permitiram a obtenção do perfil preliminar dos potenciais eólico e solar da região central do Rio Grande do Sul. 


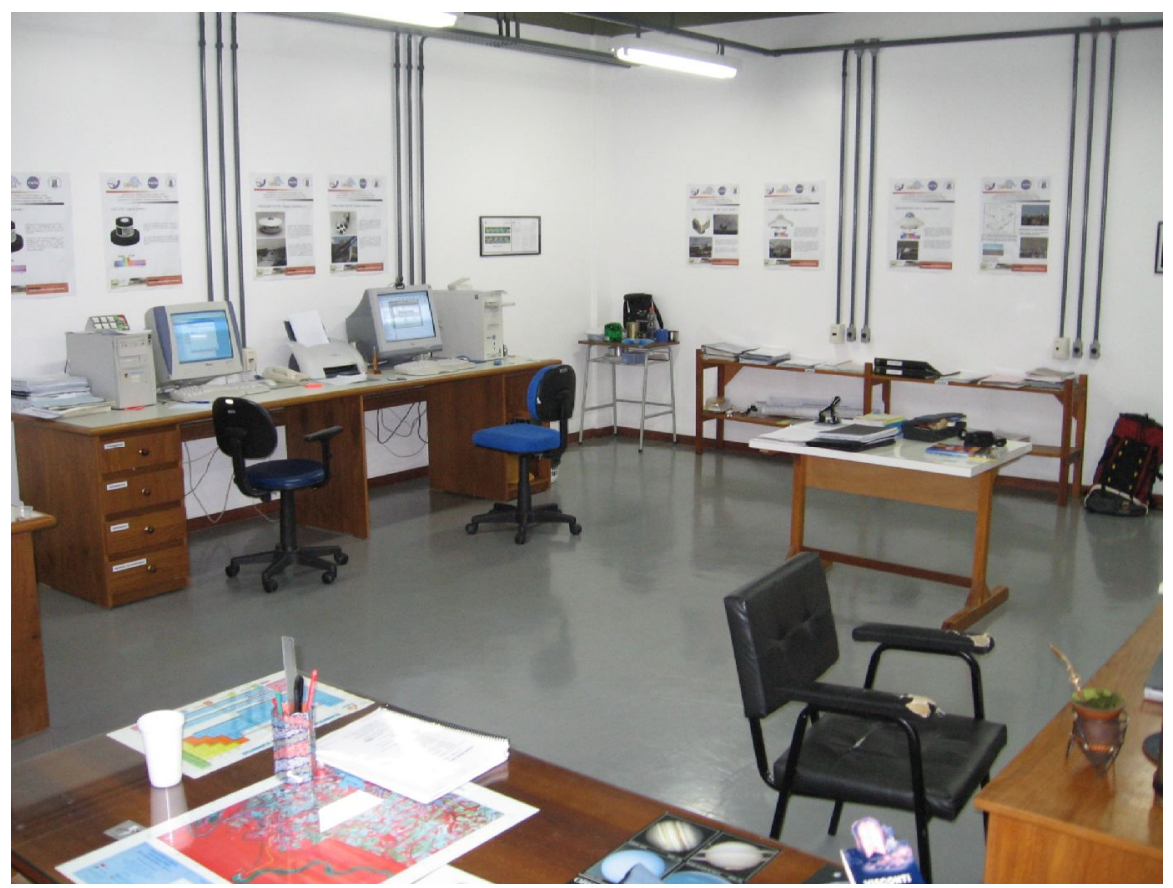

Figura 2.4 - Laboratório de Recursos de Energias Renováveis LRER/CRS/CIE/INPE MCT localizado no Prédio Sede do Centro Regional Sul de Pesquisas Espaciais CRS/CIE/INPE - MCT, em Santa Maria, RS. 
Relatório Final de Atividades, 2008

\section{CAPÍTULO 3}

\section{RADIAÇÃO SOLAR E A ATMOSFERA TERRESTRE}

\section{1 - Descrição Quantitativa da Radiação}

A transferência radiativa é o mecanismo pelo qual o sistema Terra-Atmosfera realiza praticamente toda a troca de energia com o resto do Universo (Wallace e Hobbs, 1977). O Sol pode ser considerado como a fonte de toda energia que entra no Planeta, e a radiação solar constitui a força motriz para os movimentos atmosféricos e para outros processos térmicos, dinâmicos e químicos que ocorrem na atmosfera e nas camadas superficiais da crosta terrestre (Brasseur e Solomon, 1986).

A radiação solar se propaga na forma de ondas eletromagnéticas, sendo que estas exibem uma faixa contínua de comprimentos de onda $(\lambda)$, sendo o espectro eletromagnético a totalidade de todos os possíveis comprimentos de onda (Wallace e Hobbs, 1977).

A taxa de transferência de energia por radiação eletromagnética ou intensidade de radiação é chamada comumente de fluxo radiante, sendo expresso em unidades de energia por unidade de tempo: joules por segundo $\left(J \cdot s^{-1}\right)$ ou watts (W). O Sol possui um fluxo radiante de aproximadamente $3,8 \times 10^{26} \mathrm{~W}$.

A densidade de fluxo radiante é o fluxo radiante que atravessa uma unidade de área, e é expressa em watts por metro quadrado $\left(W \cdot m^{-2}\right)$, sendo também denominada emitância ou irradiância (E) quando representa, respectivamente, o fluxo emergindo ou incidindo em uma área (Kidder e Vonder Haar, 1995).

A irradiância incidente sobre um elemento de área superficial pode consistir de contribuições oriundas de uma infinidade de diferentes direções, sendo necessário, às vezes, identificar a parte da irradiância que provém de direções dentro de um determinado arco infinitesimal de ângulo sólido d $\Omega$. Define-se, assim, a radiância (L), que é a irradiância por unidade de ângulo sólido, expressada em watts por metro quadrado por esterradiano $\left(W \cdot m^{-2} \cdot s r^{-1}\right)$ (Wallace e Hobbs, 1977). 
Relatório Final de Atividades, 2008

\section{2 - Radiação Solar e Radiação Terrestre}

O Sol emite um espectro contínuo, com uma distribuição espectral similar a da radiação de um de corpo negro a $6000 \mathrm{~K}$, seguindo aproximadamente a lei de Plank para a emissão de radiação (Coulson, 1975; Brasseur and Solomon, 1986). A radiação solar cobre todo o espectro eletromagnético, mas a porção mais significativa do espectro, associada com transferência de energia radiativa no sistema climático, é compreendida entre o ultravioleta e o infravermelho próximo (Peixoto e Oort, 1992).

A média anual da irradiância solar total, no topo da atmosfera (TOA), é conhecida como constante solar (S). O valor de S é de aproximadamente $1368 \mathrm{~W} \cdot \mathrm{m}^{-2}$. Apesar do nome "constante solar", este valor varia ao longo do ano, devido às variações de distância Terra-Sol entre afélio e periélio. A constante solar também varia ao longo do ciclo solar, que possui uma duração de aproximadamente 11 anos, alternando um período chamado de máximo solar, quando o Sol aumenta sua atividade magnética e atinge máximo número de manchas solares em sua superfície, e um período de menor atividade, chamado de mínimo solar.

Como as temperaturas da atmosfera e dos materiais da superfície terrestre são muito menores em relação à elevada temperatura do Sol, suas emissões de radiação ocorrem em comprimentos de onda maiores, entre 4 e $100 \mu \mathrm{m}$ (Coulson, 1975). O pico das emissões da superfície terrestre para a atmosfera ou da Terra como um todo para o espaço, ocorre entre 10 e $12 \mu \mathrm{m}$. Dessa forma, costuma-se dividir o espectro eletromagnético em aproximadamente $4 \mu \mathrm{m}$ (Coulson, 1975). A radiação menor que 4 $\mu \mathrm{m}$ é chamada radiação de onda curta e a radiação maior que $4 \mu \mathrm{m}$ é chamada radiação de onda longa. A radiação de onda longa é a emitida pela Terra para a atmosfera (Iqbal, 1983), embora se utilize também o termo radiação atmosférica.

Na Figura 3.1 são ilustradas as trocas de energia do Sol e da Terra com o Espaço. O Sol emite radiação de onda curta em todas as direções, sendo que uma parcela é transmitida na direção da Terra, onde é interceptada pela Atmosfera. Parte da radiação é retroespalhada ou refletida para o Espaço, e o restante da radiação de onda curta é absorvida pela Terra. A Terra irradia esta energia para o Espaço na forma de radiação de onda longa. 


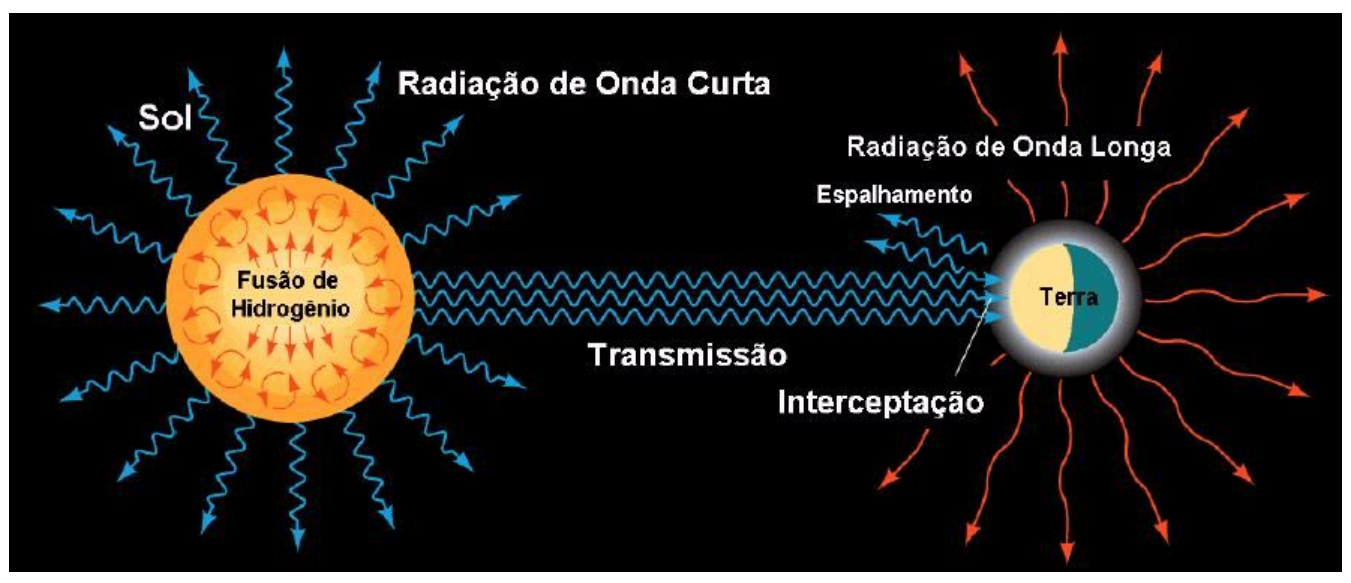

Figura 3.1 - Trocas de energia entre o Sol e a Terra. Fonte: http://iara.meteo.furg.br/page/aulas/poligradf.pdf.

\section{3 - Interações da Radiação com a Atmosfera Terrestre}

A radiação solar, após atingir o topo da atmosfera e penetrá-la, sofre processos de absorção e espalhamento (Liou, 1980). Mesmo que a Atmosfera seja muito transparente à radiação solar incidente, somente em torno de $25 \%$ penetra diretamente até a superfície da Terra sem nenhuma interferência da Atmosfera, constituindo a insolação direta. O restante é refletido de volta para o Espaço ou é absorvido ou ainda pode ser espalhado em volta até atingir a superfície da Terra ou retornar ao Espaço.

A Figura 3.2 mostra o espectro de radiação solar que atinge o TDA e o espectro de radiação solar que atinge a superfície da Terra, em termos de irradiância. A área entre as curvas representa a redução sofrida pela radiação solar incidente, durante sua passagem através da atmosfera. Essa redução é dividida em duas partes: a área não sombreada representa o espalhamento sofrido pela radiação e a área sombreada a absorção pelas moléculas do ar, primariamente por $\mathrm{H}_{2} \mathrm{O}, \mathrm{CO}_{2}, \mathrm{O}_{3}$ e $\mathrm{O}_{2}$ (Robinson, 1966; Wallace e Hobbs, 1977; Liou, 1980). Para comparação é apresentada uma curva de emissão de um corpo negro a $6000 \mathrm{~K}$ (linha tracejada). 


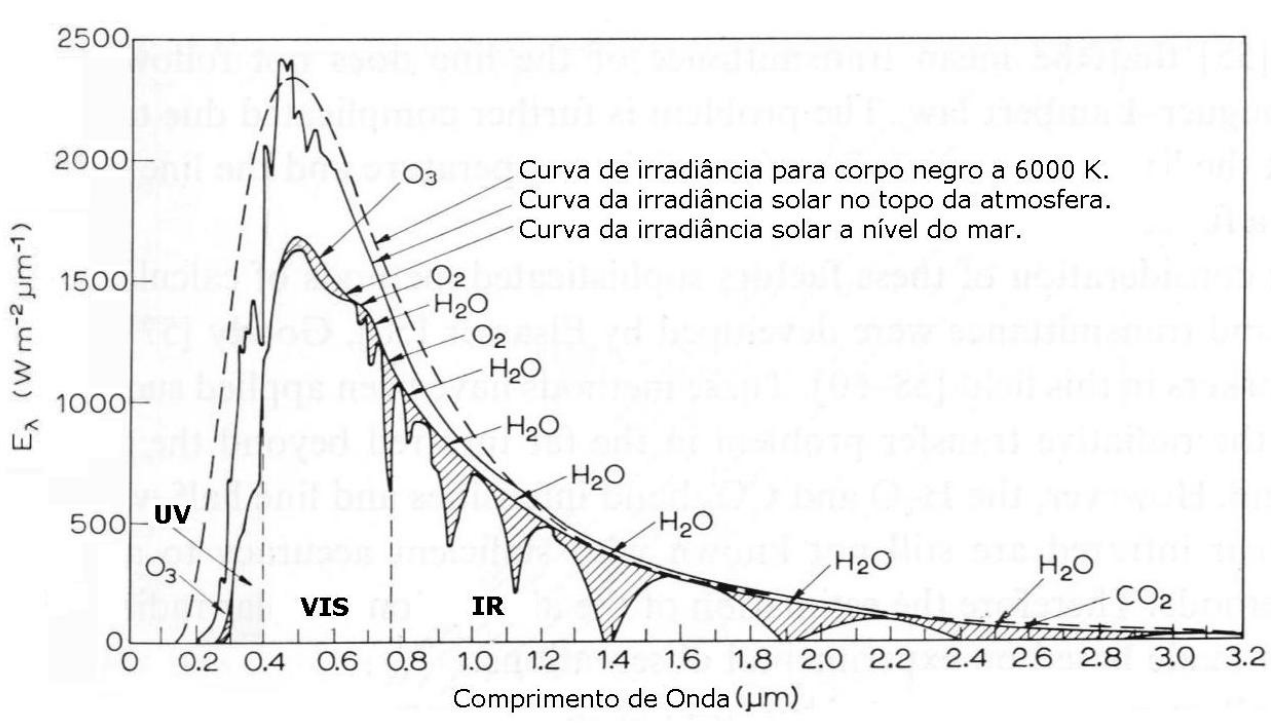

Figura 3.2 - Espectro solar no topo da atmosfera, comparado com o espectro de um corpo negro a $6000 \mathrm{~K}$ e com o espectro solar a nível do mar. Fonte: Modificado de Robinson (1966).

Devido à absorção ineficiente em caso de ausência de nuvens, a atmosfera é considerada praticamente transparente à radiação solar, especialmente nos comprimentos de onda do visível.

Dependendo do tipo de transição ou interação, a absorção da radiação pode ocorrer num continuo de comprimentos de onda, ou em comprimentos de onda discretos. Os gases atmosféricos absorvem diferentemente os comprimentos de onda da radiação solar e da radiação terrestre como se observa na Figura 3.3.

Através da análise da Figura 3.3, pode-se perceber que a Atmosfera é um absorvedor eficiente de radiação no intervalo de 1 a $30 \mu \mathrm{m}$. O vapor d'água e o dióxido de carbono são os principais gases absorvedores nesta faixa. $\mathrm{O}$ vapor d'água absorve aproximadamente 5 vezes mais radiação terrestre que todos os outros gases combinados e responde pelas temperaturas mais altas na baixa Troposfera, onde está mais concentrado. 

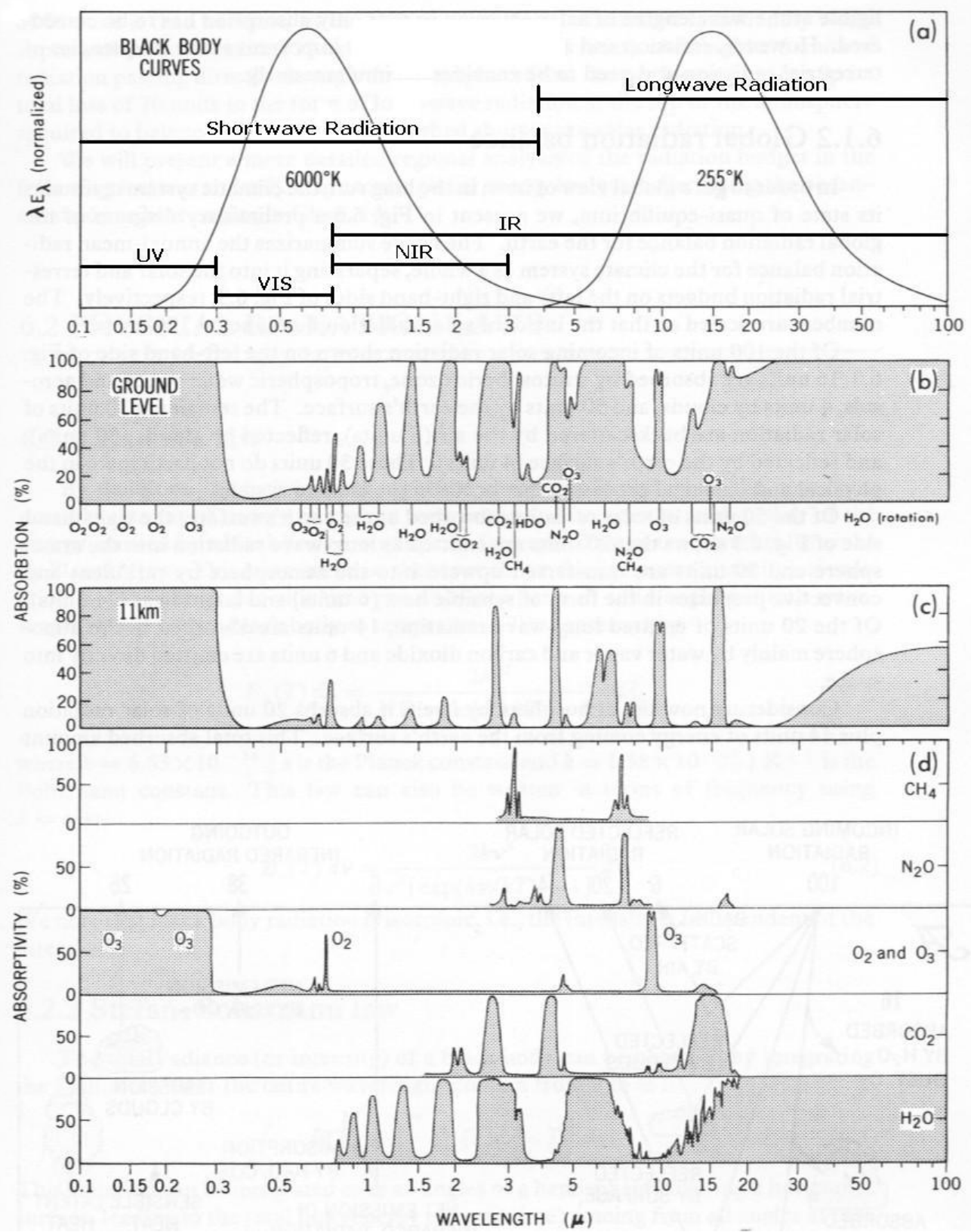

Figura 3.3 - (a) Curvas de corpo negro para a radiação solar $(6000 \mathrm{~K})$ e radiação terrestre $(255 \mathrm{~K})$. (b) Espectro de absorção para toda a extensão vertical da atmosfera. (c) Espectro de absorção para a atmosfera acima de $11 \mathrm{~km}$. (d) Espectros de absorção para vários gases atmosféricos entre o topo da atmosfera e a superfície da Terra. Fonte: Modificado de Peixoto e Oort (1992).

Espalhamento é um processo físico no qual uma partícula no caminho da onda eletromagnética continuamente remove energia da onda incidente e dispersa essa energia em todas as direções. Uma vez que parte da energia solar é espalhada para trás e para os lados, a quantidade de energia que atinge a superfície da Terra, após atravessar a 
Relatório Final de Atividades, 2008

atmosfera, é atenuada (Peixoto e Oort, 1992). Segundo Liou (1980), o espalhamento ocorre em todos os comprimentos de onda do espectro eletromagnético.

No regime Mie, a dispersão é menos seletiva ao comprimento de onda (van de Hulst, 1957) e ocorre predominância do pró-espalhamento sobre o retroespalhamento. Ocorre, neste regime, o espalhamento da luz do Sol por aerossóis, neblina, fumaça e poeira (Wallace e Hobbs, 1977; Kidder e Vonder Haar, 1995).

O espalhamento da radiação visível pelas gotículas de nuvens, gotas de chuva e partículas de gelo, é descrito pelos princípios da ótica geométrica. A ótica geométrica e o espalhamento Rayleigh são tomados como casos-limite da teoria de espalhamento Mie, considerada mais geral.

Após atravessar uma camada com agentes espalhadores, como é a atmosfera, a radiação de onda curta que atinge uma superfície pode ser subdividida entre uma componente proveniente da própria direção da fonte e uma componente que engloba a radiação vinda de todas as demais direções devido ao espalhamento. Podem-se definir, deste modo, as seguintes irradiâncias:

- Irradiância difusa: Consiste na irradiância descendente numa superfície horizontal, decorrente do espalhamento do feixe solar direto pelos constituintes atmosféricos (moléculas, material particulado, nuvens, etc.).

- Irradiância normal: Consiste na irradiância direta numa superfície normal à incidência do feixe direto, dada pela irradiância solar incidente no TDA (constante solar) que ainda resta no nível de observação, somados os efeitos de pró-espalhamento atmosférico.

- Irradiância direta: Consiste no produto entre a irradiância normal e o cosseno do ângulo zenital solar.

- Irradiância global: Consiste na irradiância descendente numa superfície horizontal, constituída pelo somatório das irradiâncias direta e difusa.

\section{4 - Modelos Computacionais para Estimativa da Radiação Solar Incidente}

A utilização de uma rede de radiômetros e de técnicas de interpolação das medidas de radiação obtidas permite o levantamento de diversas informações sobre a 
radiação solar incidente. No entanto, os dados levantados teriam sua confiabilidade dependente da quantidade de radiômetros e das distâncias entre eles (Pereira et al., 2006), em muitos casos inviabilizando tal metodologia. A adoção de modelos computacionais para obter estimativas da radiação solar por meio de relações empíricas ou pela solução da equação de transferência radiativa (ETR) constitui-se uma alternativa à metodologia anterior. Para mapear a disponibilidade de energia solar no território brasileiro, a adoção de modelos computacionais que utilizam dados de satélite parece ser a melhor alternativa (Martins, 2001).

Os modelos computacionais podem ser classificados em modelos estatísticos e modelos físicos. Os modelos estatísticos caracterizam-se por utilizar expressões empíricas para estimativa da radiação incidente em função de alguma propriedade do sistema Terra-atmosfera medida por satélite ou por instrumentos de superfície. Os modelos físicos caracterizam-se por utilizar métodos matemáticos que visam simular os processos físicos atmosféricos e solucionar a ETR.

Os modelos estatísticos apresentam validade restrita à região para qual as expressões empíricas foram desenvolvidas. Os modelos físicos, por modelarem os processos físicos que ocorrem na atmosfera, podem ser utilizados sem a necessidade de serem adaptados ao local de interesse. Apesar da generalidade espacial dos modelos físicos, estes necessitam de informações confiáveis sobre as condições atmosféricas, sendo que nem sempre tais informações são disponíveis ou apresentam a confiabilidade esperada. O modelo BRASIL-SR é um modelo físico desenvolvido e atualmente utilizado pela Divisão de Clima e Meio Ambiente do CPTEC/INPE para a obtenção de estimativas de radiação solar incidente na superfície que combina a utilização da aproximação de "Dois Fluxos" para solucionar a ETR ( Martins, 2001).

\section{5 - Radiação Solar no Território Brasileiro}

O Brasil, apesar de ser um país com dimensões continentais e apresentar diferentes características climáticas, possui uma boa uniformidade da média anual de irradiação global cujos valores são relativamente altos em todo país conforme pode ser 
visto na Figura 3.4. O valor máximo de irradiância global no Brasil é medido no norte da Bahia e o valor mínimo, no litoral norte de Santa Catarina.

Durante o verão, a Região Sul recebe maior incidência de radiação solar do que a Região Norte, já nos meses de inverno este quadro se inverte, sendo que na Região Sul são observados os menores valores de irradiação solar global, devido principalmente ao seu clima temperado. As Regiões Norte e Centro-Oeste recebem maior incidência de radiação solar durante as estações secas, particularmente entre os meses de julho e setembro. Já os maiores níveis de irradiação PAR (Radiação Fotossinteticamente Ativa) são observados durante a Primavera, sobre as regiões Nordeste e Centro-Oeste, e durante o Verão, na região Sul e Nordeste.

Na média anual, a Região Norte do país é a que apresenta maiores níveis de radiação difusa, principalmente sobre a foz do rio Amazonas. Sazonalmente, os maiores níveis de radiação difusa ocorrem durante o Verão sobre toda a região Amazônica e os menores índices ocorrem durante o Inverno sobre as regiões Sudeste e Sul (Pereira et al., 2006).

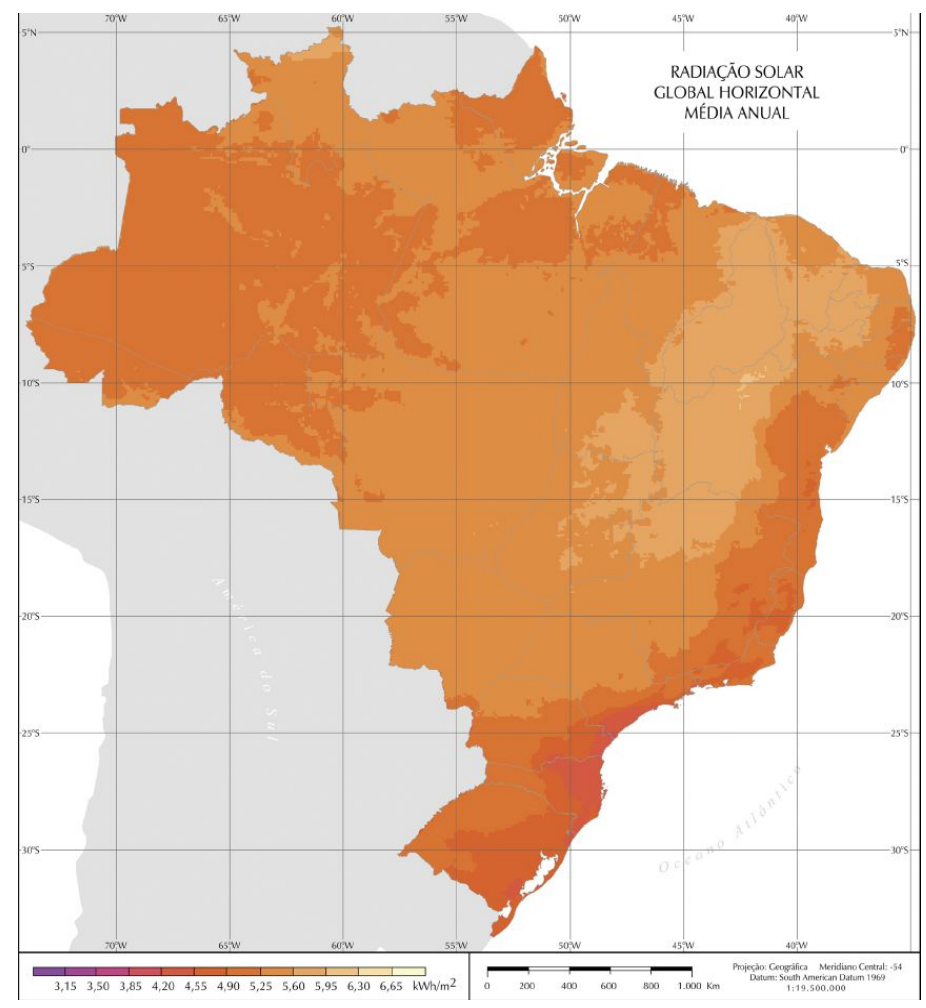

Figura 3.4 - Média anual do total diário de irradiação solar global incidente no território brasileiro. Fonte: Atlas Brasileiro de Energia Solar (2006). 


\section{CAPÍTULO 4}

\section{AEROSSÓIS}

\section{1 - Caracterização e Classificação dos Aerossóis}

Aerossol é o nome atribuído às partículas sólidas ou líquidas relativamente estáveis suspensas em um meio gasoso. Estas partículas podem ser classificadas de acordo com diversos critérios, tais como tamanho físico, origem, processos de formação, área de abrangência, entre outros. Em relação à origem, os aerossóis são denominados naturais, quando provenientes de processos naturais ou são ditos antropogênicos, quando produzidos pela ação direta das atividades humanas, como queima de biomassa e emissão de poluentes industriais e automotivos.

Junge (1963) concebeu uma classificação geográfica, dividindo os aerossóis em marinhos e continentais, e classificou-os por tamanhos em partículas de Aitken (0,001$0,1 \mu \mathrm{m})$, grosseiras $(0,1-1 \mu \mathrm{m})$ e gigantes $(>1 \mu \mathrm{m})$. Outra classificação dos aerossóis por tamanho divide-os em partículas finas $(<2 \mu \mathrm{m})$ e grossas $(>2 \mu \mathrm{m})$. As partículas finas são geralmente formadas por processos químicos, enquanto que as partículas grossas são geradas majoritariamente por processos mecânicos (Wallace e Hobbs, 1977, Correia, 1998).

Os aerossóis continentais são constituídos principalmente por poeiras minerais sopradas pelo vento, assim como partículas carbônicas e de enxofre produzidos por queimadas em florestas, uso da terra e atividades industriais.

Os aerossóis marinhos são, na sua maioria, partículas de sal do mar produzidas pela quebra das ondas e partículas de enxofre produzidas pela oxidação do dimetilsulfeto liberado pelo phytoplanton. Como a superfície terrestre é coberta por mais de $70 \%$ de águas salgadas, os mares e oceanos constituem-se em uma das maiores fontes naturais de aerossóis (Dubovik et al., 2002).

De acordo com os processos de formação, os aerossóis são classificados como primários ou secundários. As partículas primárias são emitidas por múltiplas fontes naturais ou antropogênicas, abrangendo os processos de combustão, as erupções 
vulcânicas, os fogos florestais, as emanações derivadas de certas atividades industriais, poeiras do solo, partículas de sal marinho e alguns materiais biológicos (ceras cuticulares, fragmentos foliares, matéria húmica e partículas microbianas) (Alves, 2005).

Os aerossóis no meio urbano são física e quimicamente diferentes dos aerossóis em áreas remotas, o que pode ser constatado pelas elevadas concentrações de enxofre e metais pesados presentes nas partículas urbanas (Latha and Badarinath, 2004). Alguns aerossóis constituídos por arsênio, cromo, cádmio, chumbo, cobre, zinco e compostos orgânicos são cancerígenos.

O impacto antropogênico na formação dos aerossóis através da queima de biomassa e combustíveis fósseis e por indústrias tem aumentado significativamente o número de partículas em suspensão na atmosfera, principalmente em áreas urbanas, como as grandes metrópoles (Raes et al., 2000).

Os aerossóis secundários são resultantes de mecanismos de nucleação e condensação de produtos gasosos. Os aerossóis de sulfato são formados pela oxidação do $\mathrm{H}_{2} \mathrm{~S}$ emitido por processos biológicos e vulcões a $\mathrm{SO}_{2}$ e $\mathrm{H}_{2} \mathrm{SO}_{4}$. Os aerossóis de nitrato derivam da oxidação e neutralização de compostos de $\mathrm{NO}_{\mathrm{x}}$ e $\mathrm{NH}_{3}$ naturalmente emitidos ou resultantes de atividades humanas. Os aerossóis orgânicos são formados por processos de condensação de compostos voláteis emitidos pelas plantas, transportes e indústrias (Alves, 2005).

À quantidade total de aerossóis presente na coluna atmosférica integrada é dado o nome de espessura ótica de aerossóis. As partículas finas exercem maior contribuição para o aumento da espessura ótica em comprimentos de onda visíveis do que no infravermelho próximo, enquanto partículas grossas exercem efeitos similares em ambos os comprimentos de onda (Schuster et al, 2006).

No Brasil ocorre uma grande variação sazonal da espessura ótica dos aerossóis, em virtude do aumento do número de queimadas nas estações secas, principalmente nos meses de agosto e setembro (Eck et al., 2003; Procópio et al., 2003; 2004). Os valores de espessura ótica medidos no Brasil estão entre os mais elevados de toda a rede de fotômetros solares da AERONET (AErosol RObotic NETwork), operada pela NASA (Holben et al., 1998; Procópio et al., 2003; 2004) 
Relatório Final de Atividades, 2008

\section{2 - Efeitos dos Aerossóis na Atmosfera}

Partículas de aerossóis em suspensão na atmosfera influenciam fortemente o balanço radiativo, a química da atmosfera, o clima, a visibilidade e a saúde das pessoas expostas às altas concentrações de partículas (Artaxo et al., 2006).

Os aerossóis podem influenciar o clima em escalas regionais e globais através de interações diretas, atuando como centros espalhadores ou absorvedores de luz solar (Jacobson, 2001), ou indiretamente atuando sobre a formação e o ciclo de vida de nuvens, e assim modificando ciclos hidrológicos (Kaufman, 1995). Cerca de 60 a 80\% das partículas naturais de aerossóis na Amazônia atuam como núcleos de condensação de nuvens. (Zhou et al., 2002, Rissler et al., 2004).

O chamado efeito direto dos aerossóis no clima consiste nos mecanismos que afetam diretamente o fluxo de radiação solar na superfície, podendo levar tanto ao seu aquecimento quanto ao seu resfriamento, dependendo das propriedades intrínsecas das partículas de aerossóis e da refletividade da superfície (Artaxo et al., 2006). A radiação solar ao atravessar a atmosfera sofre uma série de perturbações causadas por partículas de aerossóis e gases ao longo de seu caminho ótico, definindo seu espectro e sua intensidade no nível do solo (Procópio et al., 2003, 2004).

A quantidade de radiação solar removida pelos aerossóis é geralmente referida como a diferença entre as radiações efetivas que atingem a superfície com e sem a camada de aerossóis. (Martins et al., 2005). O IPCC (Intergovernmental Panel on Climate Change) estima que o efeito direto global dos aerossóis no balanço radiativo situa-se entre 0,2 a $1,5 \mathrm{~W} / \mathrm{m}^{2}$ (i.e. favorecendo o resfriamento).

Somente nesta última década tem-se assumido a relevância da inclusão dos efeitos dos aerossóis em modelos numéricos atmosféricos para previsão do tempo, clima e qualidade do ar. A inclusão dos aerossóis nos modelos atmosféricos traz novos desafios para o desenvolvimento de novas parametrizações que representem apropriadamente os diversos processos através dos quais os aerossóis interagem com os outros elementos atmosféricos (Artaxo et al., 2006).

As partículas de aerossol na troposfera apresentam vida média curta (da ordem de dias a semanas) e, portanto sua distribuição espacial é altamente não homogênea e é 
correlacionada com suas fontes de emissão (Jonas et al., 1995, Holben et al., 1996). Este é um dos fatores que contribuem para dificultar a quantificação do efeito das partículas de aerossol no balanço radiativo.

Algumas propriedades dos aerossóis necessárias para a determinação de seus efeitos no clima são: distribuição do tamanho e forma das partículas, composição e dependência espectral das propriedades óticas. As propriedades de espalhamento e absorção de radiação dependem também da morfologia da partícula e do tipo de mistura entre os materiais absorvedores (black carbon) e os não absorvedores de radiação (sulfatos, compostos orgânicos) (Toon, 1995, Martins et al., 1998).

As partículas finas de aerossóis exercem uma grande influência na atenuação da irradiação solar em comprimentos de onda mais curtos (Reid et al., 1998). Elas são especialmente seletivas ao espalhamento, sendo responsável por $82 \%$ do espalhamento na atmosfera (Molnàr and Mészáros, 2001).

Por outro lado, uma alta percentagem de partículas grossas absorve menos irradiação em menores comprimentos de onda, absorvendo mais em comprimentos de onda maiores (Badarinath et al, 2006). A atenuação da irradiação na atmosfera decresce continuamente com o comprimento de onda (Iqbal, 1983), desta forma, no espectro do infravermelho próximo (NIR) as diferenças nos valores de irradiância devido às diferenças das concentrações de aerossóis passam a ser pequenos.

Uma alta carga de aerossóis pode, de maneira benéfica, reduzir em até 50\% o fluxo de radiação ultravioleta na superfície (Liu et al., 1991; Kylling et al., 1998). Em uma escala regional, mesmo um decréscimo de 50 DU na quantidade de ozônio em combinação com um aumento na carga de aerossóis pode conduzir a uma diminuição da radiação UV na superfície (Balis et al., 2002; Papayannis et al., 1998).

\section{3 - Caracterização de Aerossóis pelo Sensor Modis}

O sensor MODIS (MODerate Resolution Imaging Spectroradiometer) é um radiômetro espectral passivo, que foi desenvolvido especificamente para obter observações globais de aerossóis com resolução moderada. 
É um instrumento de pesquisa multidisciplinar que possui como objetivo fornecer contribuições ao conhecimento científico do sistema terrestre, envolvendo: superfície terrestre (alterações de uso de solo, temperatura de superfície, cobertura de neve, propriedades de vegetações), oceano (temperatura da superfície do mar, clorofila) e atmosfera (aerossóis, propriedades de nuvens, vapor de água, perfil de temperatura) (Remer et al., 2005).

Lançado a bordo dos satélites TERRA e AQUA da NASA em dezembro de 1999 e maio de 2002 respectivamente, o MODIS possui 36 canais abrangendo a faixa espectral de 0,41 a $15 \mu \mathrm{m}$ e é o único sensor capaz de determinar a espessura ótica de aerossóis e os parâmetros que caracterizam o tamanho das partículas com grande precisão (Tanré et al. 1996; Tanré et al. 1997).

Este sensor fornece uma cobertura global diária da carga de aerossóis presente na atmosfera possuindo para tanto uma largura de cobertura de observação de $2330 \mathrm{~km}$, o que é suficiente para realizar uma cobertura global completa de 1 a 2 dias (Artaxo et al., 2006).

A detecção de aerossóis com o MODIS é baseada nas radiâncias obtidas pelo sensor, em regiões das imagens não cobertas por nuvem, após a realização de uma calibração radiométrica e de geolocalização, também utilizando dados auxiliares para determinar as condições meteorológicas de cada elemento da imagem a ser processada (Artaxo et al., 2006).

Há dois algoritmos independentes para obtenção das propriedades de aerossóis sobre continentes e sobre oceanos, mas que se baseiam na mesma estratégia de uso de tabelas pré-computadas de cálculos de transferência radiativa na atmosfera. Sob essa estratégia, várias condições de observação do sensor MODIS e de iluminação da atmosfera são computadas para diferentes níveis de concentração de aerossóis e refletâncias de superfície. As radiâncias espectrais medidas pelo sensor no topo da atmosfera e as estimativas de refletância da superfície são comparadas com os valores pré-calculados até que a melhor solução seja encontrada com ajustes de mínimos quadrados (Correia et al., 2006).

As medidas dos satélites TERRA e AQUA são periodicamente transmitidas para estações de recepção em terra e recebidas pelo sistema do INPE em Cuiabá assim como 
Relatório Final de Atividades, 2008

pela NASA Goddard Space Flight Center (GSFC) e posteriormente disponibilizadas na internet através do site http://paraguay.cptec.inpe.br:8080/produto/aerossois/\# (Artaxo et al., 2006).

Os dados obtidos a partir dos sensores MODIS são validados através da comparação com resultados obtidos a partir de diversas metodologias. Atualmente utilizam-se os produtos obtidos da AERONET (Aerosol Robotic Network), uma rede de radiômetros automáticos concebida e mantida pelo GSFC (http://aeronet.gsfc.nasa.gov) para monitorar as propriedades óticas do aerossol em várias regiões do mundo (Holben et al., 1998).

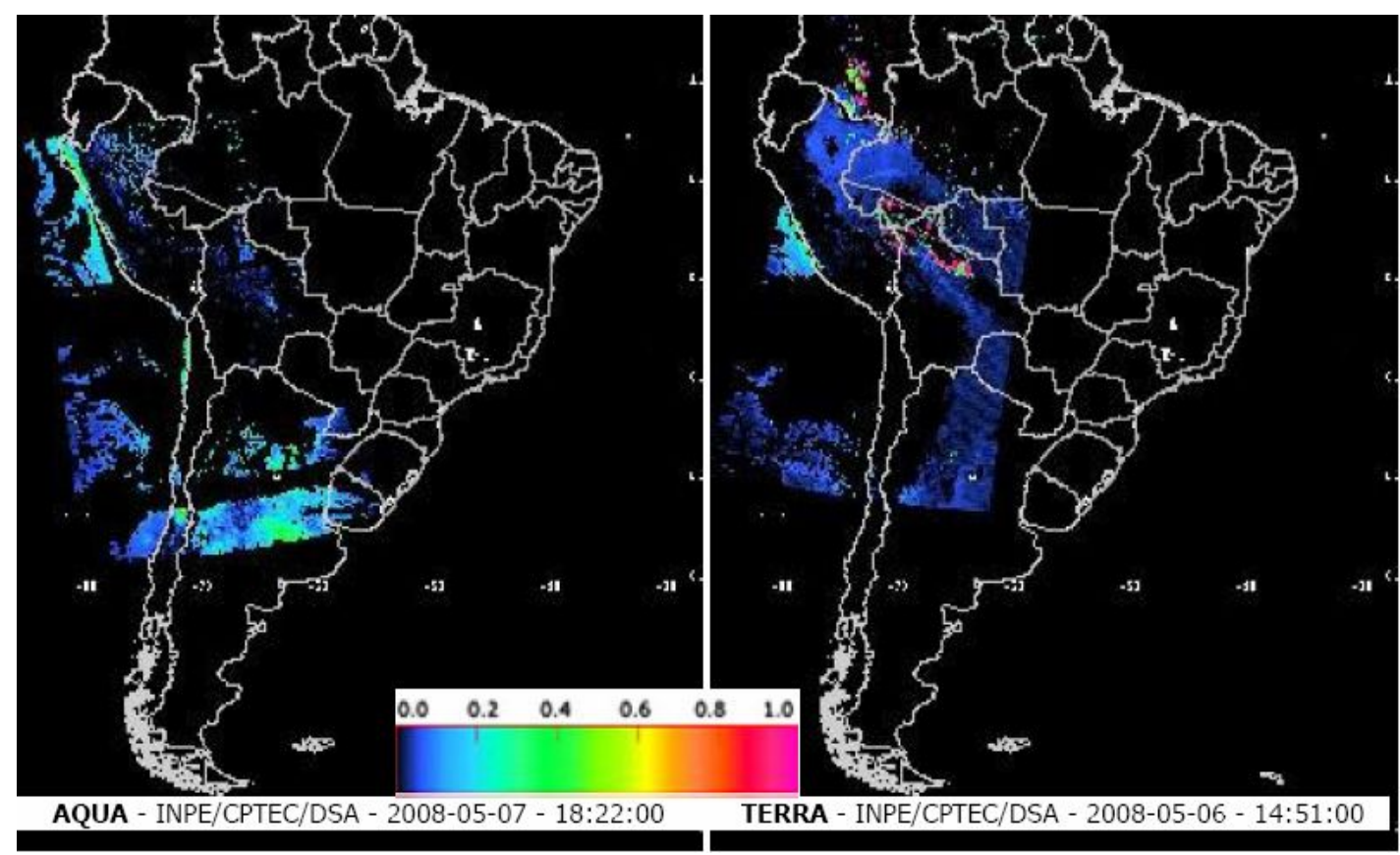

Figura 4.1 - Profundidade Ótica dos Aerossóis em 550nm sobre a América do Sul obtida pelo sensor MODIS (a) a bordo do Satélite AQUA; (b) a bordo do Satélite TERRA.

\section{4 - Caracterização de Aerossóis pela Rede AERONET}

A NASA Goddard Space Flight Center em colaboração com outras instituições internacionais implantou uma rede de radiômetros solares e terrestres em todo globo, a AERONET (Aerosol Robot Network) cujas Estações são apresentadas na Figura 4.2. O 
objetivo dessa rede é monitorar e caracterizar as propriedades ópticas das partículas de aerossóis provenientes de diferentes fontes (Holben et al., 1998).

No total são 132 radiômetros espalhados por todo o globo terrestre (sobre continente e oceano, neste caso, em pequenas ilhas ou na costa) que realizam medições da atenuação da radiação solar direta em até oito comprimentos de onda para obter a profundidade óptica dos aerossóis.

As medições são realizadas ao longo de todo dia, em intervalos de aproximadamente quinze minutos e são pontuais, ou seja, específicas de uma localidade, visto que o instrumento é mantido fixo. Os radiômetros da AERONET realizam também medidas de irradiância difusa em quatro comprimentos de onda (1020, 870, 670, 440 nm), a cada hora. Estas medidas são utilizadas para obtenção de propriedades ópticas das partículas na coluna (Artaxo et al., 2006).

Os produtos da AERONET estão disponíveis em diferentes níveis de confiança. Os produtos de nível 1.0 são obtidos quase em tempo real (apenas um dia após as medições) sem processamento prévio quanto a erros espúrios como contaminação por nuvens. Os produtos de nível 1.5 são analisados a partir de um algoritmo automático que elimina eventuais resultados contaminados por nuvens (Smirnov et al., 2000). Os produtos de nível 2.0 são certificados quanto a eventuais variações de calibração dos instrumentos e, dependendo da localidade, são disponíveis apenas vários meses após a realização das medições.

Os dados coletados pela referida rede são disponibilizados pela rede mundial de informações internet, para acesso em tempo real (Artaxo, 1994; Gerab, 1996; Holben et al., 1998). Os valores de espessura ótica de aerossóis (AOT) disponíveis, após serem convertidos em valores de profundidade óptica, relacionam-se com a presença de material particulado na atmosfera distribuído ao longo de toda a coluna de ar existente sobre o fotômetro solar.

Os dados obtidos com os fotômetros são coletados, apenas, no período diurno e processados para que os registros feitos na presença de nuvens sejam extraídos (Gerab, 1996). Maiores informações sobre a Rede AERONET podem ser encontradas no endereço eletrônico http://aeronet.gsfc.nasa.gov junto à NASA. 


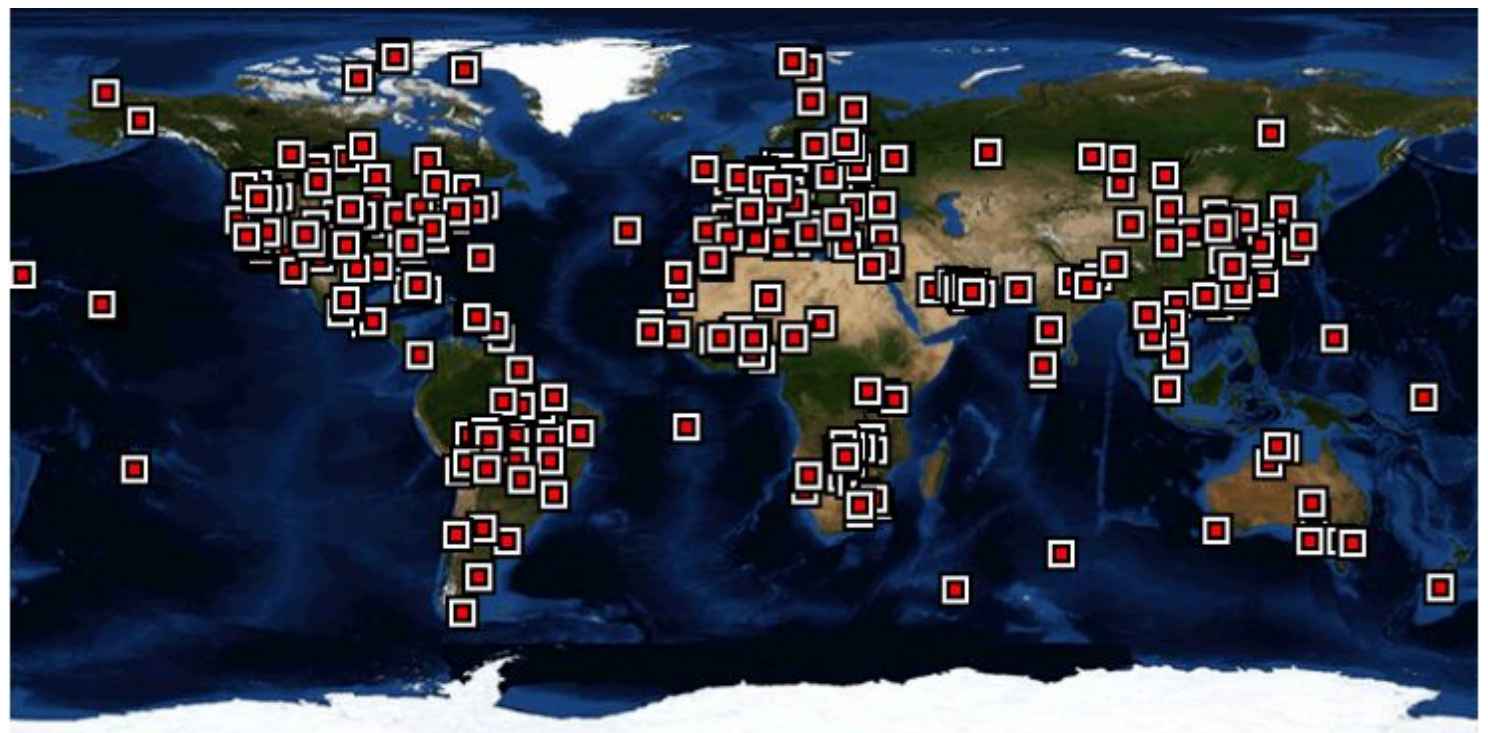

Figura 4.2 - Estações AERONET espalhadas pelo globo terrestre. Fonte: AERONET (2008). 


\section{CAPÍtULO 5}

\section{QUEIMADAS}

\section{1 - Efeitos das Queimadas sobre a Radiação Solar e a Química da Atmosfera}

Como decorrência das emissões de queimadas, as concentrações atmosféricas de partículas de aerossóis e gases traço aumentam por fatores de 2 a 8 em grandes áreas, o que altera o balanço de radiação, com a absorção de até $70 \%$ da radiação fotossinteticamente ativa. Esta redução no fluxo radiativo afeta a taxa fotossintética, a temperatura na superfície e os fluxos de calor latente e sensível (Artaxo et al., 2006). Whitlock and Tarpley (1996) obtiveram superestimativas de até $120 \mathrm{~W} / \mathrm{m}^{2}$ nas medidas de irradiância solar na superfície em função da presença de produtos de combustão na atmosfera (incluindo aerossóis) emitidos por eventos de queimadas próximos a sítios de coleta de dados na África.

O black carbon (carbono negro) é uma terminologia que se utiliza para referenciar partículas altamente absorvedoras de radiação solar na região do visível, que são emitidas por processos de combustão incompleta, como por exemplo, durante a queima de biomassa. Os aerossóis gerados pelas queimadas absorvem melhor a radiação em comparação aos aerossóis naturais em função da presença, em grande quantidade, de carbono negro.

No Brasil, o carbono negro representa cerca de 4 a $8 \%$ da quantidade total de aerossóis (Pereira et al., 1996, Reid et al., 1998), apresentando uma larga variabilidade de composições nos aerossóis, mesmo em eventos isolados. Esta variabilidade depende do tipo de vegetação, fase de queima, umidade, entre outros fatores.

As queimadas constituem também uma das mais significativas fontes globais de vários gases do "efeito estufa" como $\mathrm{CO}_{2}$ (dióxido de carbono), $\mathrm{CH}_{4}$ (metano) e $\mathrm{N}_{2} \mathrm{O}$ (óxido nitroso) (Andreae e Crutzen, 1997, Liousse et al., 2004). Adicionalmente contribuem com significativas emissões de $\mathrm{CO}, \mathrm{NO}_{2}$ (dióxido de nitrogênio), HCNM (Hidrocarbonetos não metano), cloreto e brometo de metila, compostos orgânicos voláteis (VOCs) e dezenas de outros gases (Andreae et al., 2002). 
As emissões de precursores de $\mathrm{O}_{3}$ (ozônio), gás formado através de reações fotoquímicas a partir de emissões de queimadas, são de particular importância para as características químicas e radiativas da atmosfera. As emissões de gases precursores da formação de ozônio pelas queimadas fazem com que as concentrações deste importante gás atinjam níveis que podem ser danosos à floresta não queimada, uma vez que o ozônio é fitotóxico, danificando a superfície foliar mesmo de florestas situadas a milhares de quilômetros das áreas queimadas (Artaxo et al., 2006).

\section{2 - Efeito das Queimadas na Atmosfera Brasileira}

A maior fonte de aerossóis para a atmosfera na América do Sul são as emissões por queimadas de florestas e cerrados, que ocorrem principalmente na estação seca na região amazônica modificando, dessa forma, a química da atmosfera e gerando importantes implicações em nível local, regional e global (Artaxo et al., 2002). É nesta época que a série temporal da profundidade ótica dos aerossóis medidos na Amazônia apresenta picos acentuados conforme ilustra a Figura 5.1.

Esta alta concentração de partículas faz com que haja um déficit significativo de radiação superficial com picos instantâneos de até $-300 \mathrm{~W} / \mathrm{m}^{2}$ (Procópio et al., 2003; 2004). A redução no fluxo de radiação fotossintética (radiação PAR) pode ser da ordem de $70 \%$, afetando fortemente a produtividade primária da floresta Amazônica (Eck et al., 2003, Procópio et al., 2003, 2004). Esta espessa coluna de aerossóis também aumenta a fração de radiação difusa na atmosfera, que por seu lado aumenta a penetração de radiação dentro do dossel da floresta. A vegetação utiliza de modo mais eficiente a radiação difusa para a realização da fotossíntese, fato que ameniza em parte os efeitos da redução do fluxo direto de radiação (Artaxo et al., 2006). 


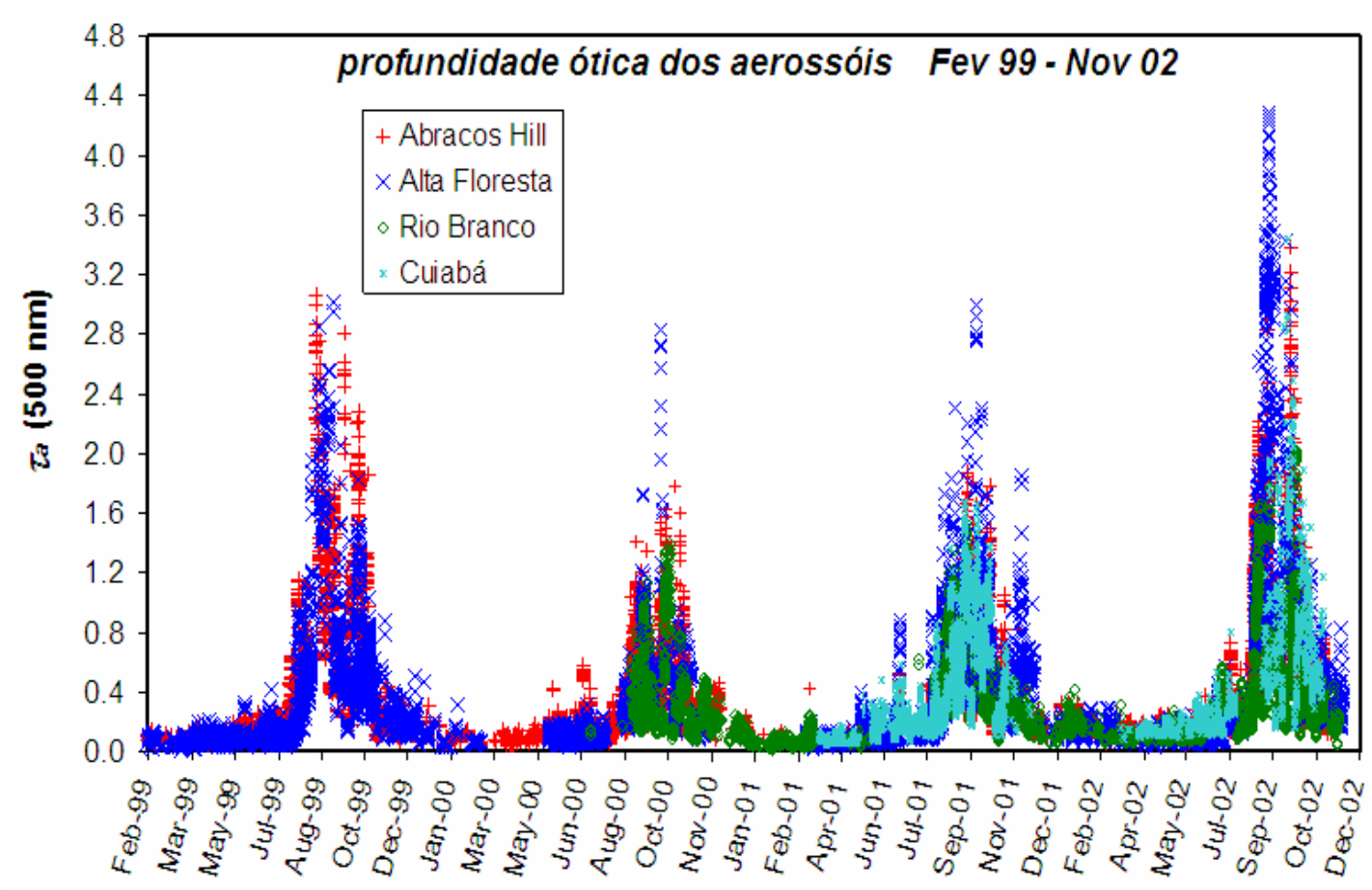

Figura 5.1 - Série temporal da profundidade ótica de aerossóis em 500 nm medidos em quatro sítios de pesquisa na Amazônia (Abracos Hill, Alta Floresta, Rio Branco e Cuiabá) com fotômetros solares da Rede AERONET no período de Fevereiro de 1999 a Novembro de 2002.

Christopher et al. (1996), Anderson et al. (1996) and Eck et al. (1998) encontraram um efeito de resfriamento efetivo na atmosfera causado por camadas de aerossóis sobre as regiões Amazônica e Cerrado no Brasil.

A coleta de partículas de aerossóis por aviões durante o projeto Smoke, Clouds and Radiation-Brazil (SCAR-B), realizada na região amazônica em agosto e setembro de 1995, permitiu a detecção de cinco componentes principais de aerossóis: uma parcela principal (54\%) de componentes derivados de queima de biomassa; uma parcela de aerossóis provenientes de poeira do solo (15\%); componentes biogênicos naturais $(18,7 \%)$; um segundo tipo de poeira do solo enriquecida em Si, Ti e Fe (5,7\%); um componente de aerossol de $\mathrm{NaCl}$ (5,9\% da massa de aerossóis com $\mathrm{Na}, \mathrm{Cl}, \mathrm{Br}$ e iodo). Com relação ao tamanho das partículas, as mais finas representavam $78 \%$ da massa total de aerossóis e as maiores 22\% (Artaxo et al., 1998). 
O transporte à longa distância de gases traço e partículas de aerossóis segue o mesmo padrão de circulação atmosférica, fazendo com que as emissões da floresta amazônica saiam do continente Sul Americano por duas vias principais: o oceano Pacífico tropical e o oceano Atlântico Sul (Freitas et al., 1997; 2000).

As altas temperaturas envolvidas na fase de chamas da combustão e a ocorrência de circulações associadas às nuvens devidas, por exemplo, à entrada de frentes frias provenientes da região sul do Brasil, favorecem o movimento convectivo ascendente e podem ser responsáveis pela elevação destes poluentes até altas camadas da atmosfera, de onde podem ser transportados para regiões distantes das fontes emissoras, o que resulta em uma distribuição espacial de fumaça sobre uma extensa área, ao redor de 4-5 milhões de $\mathrm{km}^{2}$, em muito superior à área onde estão concentradas as queimadas (Freitas, Longo, Silva Dias, Silva Dias et al., 2005).

\section{3 - Identificação de Queimadas no Brasil através de sensoriamento remoto}

O sensoriamento remoto é uma ferramenta importante na ajuda do entendimento da dinâmica do desflorestamento e do uso da terra, assim como seus impactos ecológicos e sociais, pois esta tecnologia permite obter dados de áreas muito extensas em intervalos de tempo regulares.

Desse modo, podem ser disponibilizadas informações espaciais e temporais sobre a ocorrência de queimadas, além de quantificações da área afetada pelo fogo, fornecendo uma importante contribuição para o estudo de incêndios no meio ambiente e seus efeitos ecológicos, climáticos e na química da atmosfera (França e Ferreira, 2005).

Satélites como o GOES (Geostationary Operational Environmental Satellite), que possuem órbita geoestacionária, podem ser usados para a detecção e o acompanhamento de incêndios em grandes áreas da superfície da Terra. Os seus sensores operam em cinco canais espectrais: um no visível $(0,55$ a $0,75 \mu \mathrm{m})$, três na região do infravermelho $(3,8$ a 4,0 $\mu \mathrm{m}, 10,2$ a 11,2 $\mu \mathrm{m}, 11,5$ a 12,5 $\mu \mathrm{m})$ e um na região do vapor d'água $(6,5-7,0$ $\mu \mathrm{m})$.

Os satélites da série NOAA (National Oceanic Atmospheric Administration) carregam o sensor AVHRR, muito utilizado para estudos de vegetação e incêndio. Este 
sensor possui cinco canais, distribuídos da seguinte forma: canal 1 no visível $(0,6 \mu \mathrm{m})$, canal 2 no infravermelho próximo $(0,9 \mu \mathrm{m})$, canal 3 na faixa em torno de 3,7 $\mu \mathrm{m}$ e os canais 4 e 5 no infravermelho termal $(10,8 \mu \mathrm{m}$ e $12 \mu \mathrm{m}$, respectivamente).

A largura de imageamento do sensor AVHRR é de aproximadamente $2700 \mathrm{~km}$, o que possibilita uma cobertura espacial de praticamente todo o território brasileiro em apenas uma imagem. O AVHRR possui também alta freqüência temporal com pelo menos uma imagem no período vespertino e outra de madrugada. Os dados deste sensor se constituem como uma importante série histórica para os estudos sobre as queimadas, pois têm sido coletados pela NOAA desde 1978.

Os produtos de aerossóis do MODIS monitoram globalmente a espessura ótica de aerossóis sobre oceanos e continentes. Estes produtos são utilizados para estudar a climatologia dos aerossóis (incluindo os provenientes de eventos de queimadas), suas fontes e sumidouros. Este sensor possui uma série de características melhoradas em relação aos sistemas do NOAA/AVHRR e do GOES, como por exemplo, uma melhor resolução espectral e radiométrica (Justice et al., 2002).

\section{4 - Monitoramento de Queimadas pelo CPTEC/INPE}

O monitoramento de queimadas no Brasil é realizado pelo CPTEC/INPE - MCT, que vem desenvolvendo e aprimorando desde a década de 1980 o sistema operacional de detecção de queimadas. A partir de 1998, o trabalho passou a ser feito conjuntamente com o IBAMA/PROARCO, dando ênfase particular à Amazônia. Os dados são obtidos nas imagens termais dos satélites meteorológicos NOAA quatro vezes ao dia, GOES oito vezes ao dia, e TERRA e AQUA duas vezes por dia, e são posteriormente integrados a dois sistemas geográficos de informações (SpringWeb-Queimadas e TerraLib-Queimadas) que podem ser utilizados pela Internet. As informações são disponibilizadas aos usuários cerca de 20 minutos após as passagens dos satélites no enderece eletrônico http://paraguay.cptec.inpe.br/produto/queimadas/\#. Os dados são atualizados a cada três horas, todos os dias do ano. Todo país e grande parte da América do Sul são cobertos pelas imagens, pois se utilizam recepções das estações do INPE em Cachoeira Paulista, SP e de Cuiabá, MT. 


\section{CAPÍTULO 6}

\section{ATIVIDADES DESENVOLVIDAS}

\section{1 - Manutenção dos equipamentos da estação de referência SONDA - SMS}

A manutenção dos equipamentos instalados na estação de referência SONDA SMS é de fundamental importância para a conservação física dos sensores e conseqüentemente para a obtenção de dados confiáveis. Essa manutenção é realizada pelos alunos do Laboratório de Recursos de Energias Renováveis LRER/CRS/CIE/INPE - MCT através de visitas periódicas ao Observatório Espacial do Sul - OES/CRS/CIE/INPE - MCT.

As principais atividades realizadas durante estas visitas contemplam a coleta de dados de cobertura de nuvens, troca das sílicas gel dos equipamentos, limpeza dos domos dos sensores, limpeza e polimento do imageador e a verificação do nível do "tracker".

Os medidores de radiação precisam operar com níveis mínimos de umidade em suas proximidades para que seus componentes eletrônicos não sejam danificados. Por este motivo, os equipamentos são providos de dessecadores ou então admitem a introdução no seu interior de pequenos pacotes contendo sílica gel, uma substância que retém a umidade do ar. A sílica gel, que inicialmente se encontra na cor azul, torna-se rosada quando saturada de água, voltando à sua cor original através de aquecimento. Uma das tarefas do bolsista consistiu em trocar a sílica saturada dos equipamentos, secá-la a uma temperatura de aproximadamente $105^{\circ} \mathrm{C}$ em uma estufa apropriada para ser posteriormente reutilizada.

A limpeza dos domos de quartzo dos sensores e da câmera CCD do imageador de nuvens é importante, pois a sujeira sobre os domos pode absorver parte da radiação solar incidente, resultando em um déficit da irradiância medida pelos equipamentos. Uma flâmula umedecida com álcool isopropílico é utilizada para a remoção das sujidades. 
A calota espelhada do imageador é limpa com o uso de flâmulas e líquido para limpeza de vidros e polida com cera automotiva. Esse procedimento visa remover a sujeira presente em sua superfície, para que esta não seja confundida com nuvens no instante em que o imageador, visualizado na Figura 6.1, determina a cobertura de nuvens do céu.

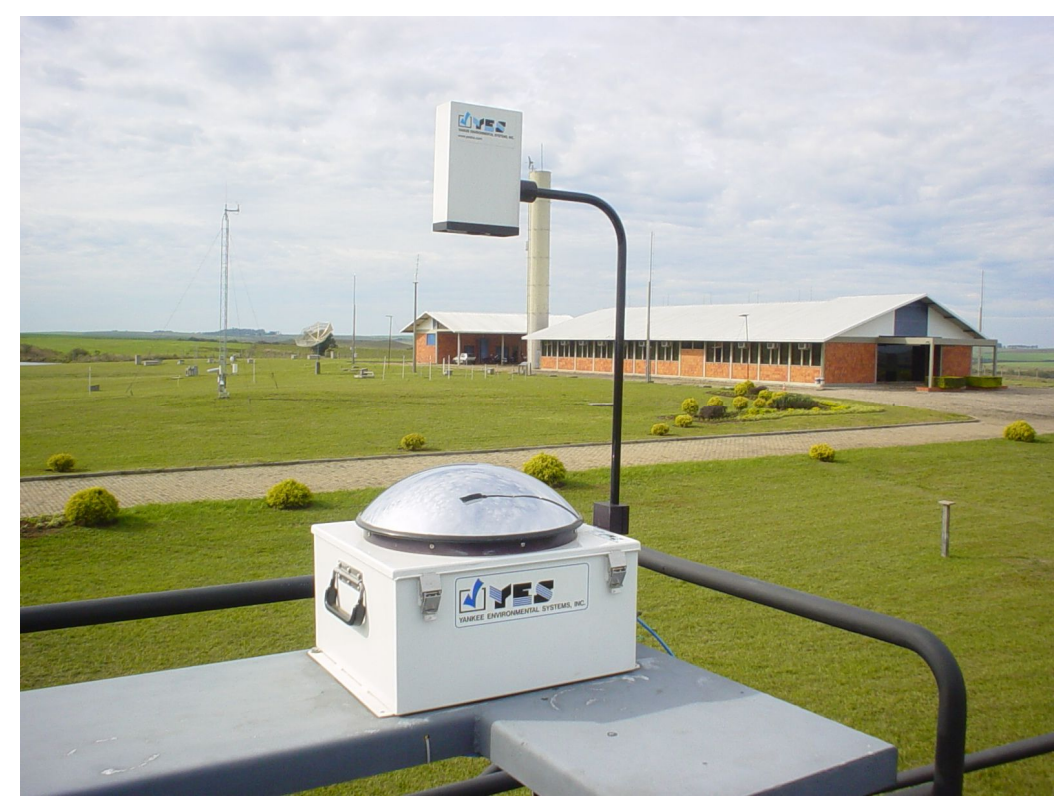

Figura 6.1 - Imageador Total Sky Imager TSI-440 (YES, Inc) instalado na estação SONDA - SMS no Observatório Espacial do Sul - OES/CRS/CIE/INPE - MCT em São Martinho da Serra, RS.

O Piranômetro CM 22 (Kipp \& Zonen), o Pirgeômetro PIR (Eppley Laboratory, Inc) e o Pireliômetro NIP (Eppley Laboratory, Inc) estão acoplados ao Two Axis Positioner (Kipp \& Zonen) - 2 AP (“Tracker"), que é um rastreador de corpos celestes. O Tracker é responsável pelo posicionamento do Pireliômetro na direção direta do Sol e pelo sombreamento dos domos do Piranômetro CM 22 e do Pirgeômetro PIR através dos ocultadores de disco solar, que são esferas que não permitem que a radiação solar direta alcance os domos dos equipamentos. Dessa forma, é necessária a verificação do nível do Tracker, ou seja, o seu alinhamento com o Sol, o que é feito através da observação visual da incidência de radiação solar sobre uma marca do equipamento. 
Relatório Final de Atividades, 2008

\section{2 - Coleta, Redução e Análise dos Dados da estação de referência SONDA - SMS}

Os equipamentos da estação SONDA - SMS estão conectados a um Datalogger CR23X Micrologger (Campbell Sci.), que armazena os dados solares, meteorológicos e eólicos coletados pelos respectivos sensores. O Datalogger, apresentado na Figura 6.2, está localizado no interior do prédio 1 do OES/CRS/CIE/INPE - MCT. Um diagrama com a configuração local dos equipamentos da Estação é apresentado na Figura 6.3.

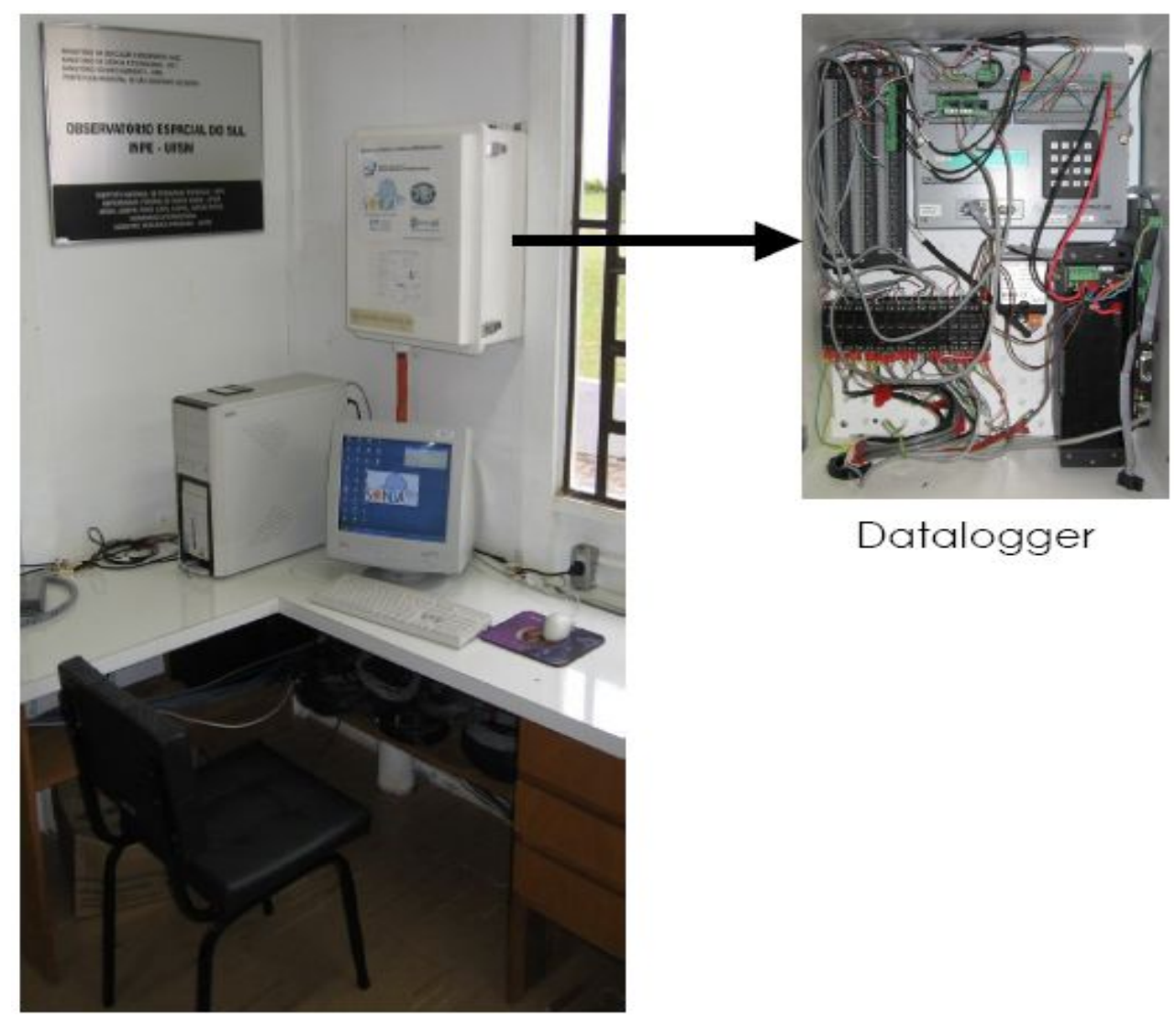

Figura 6.2 - Datalogger CR23X Micrologger junto ao computador SONDA no interior do Prédio 1 do Observatório Espacial do Sul - OES/CRS/CIE/INPE - MCT. 
Relatório Final de Atividades, 2008

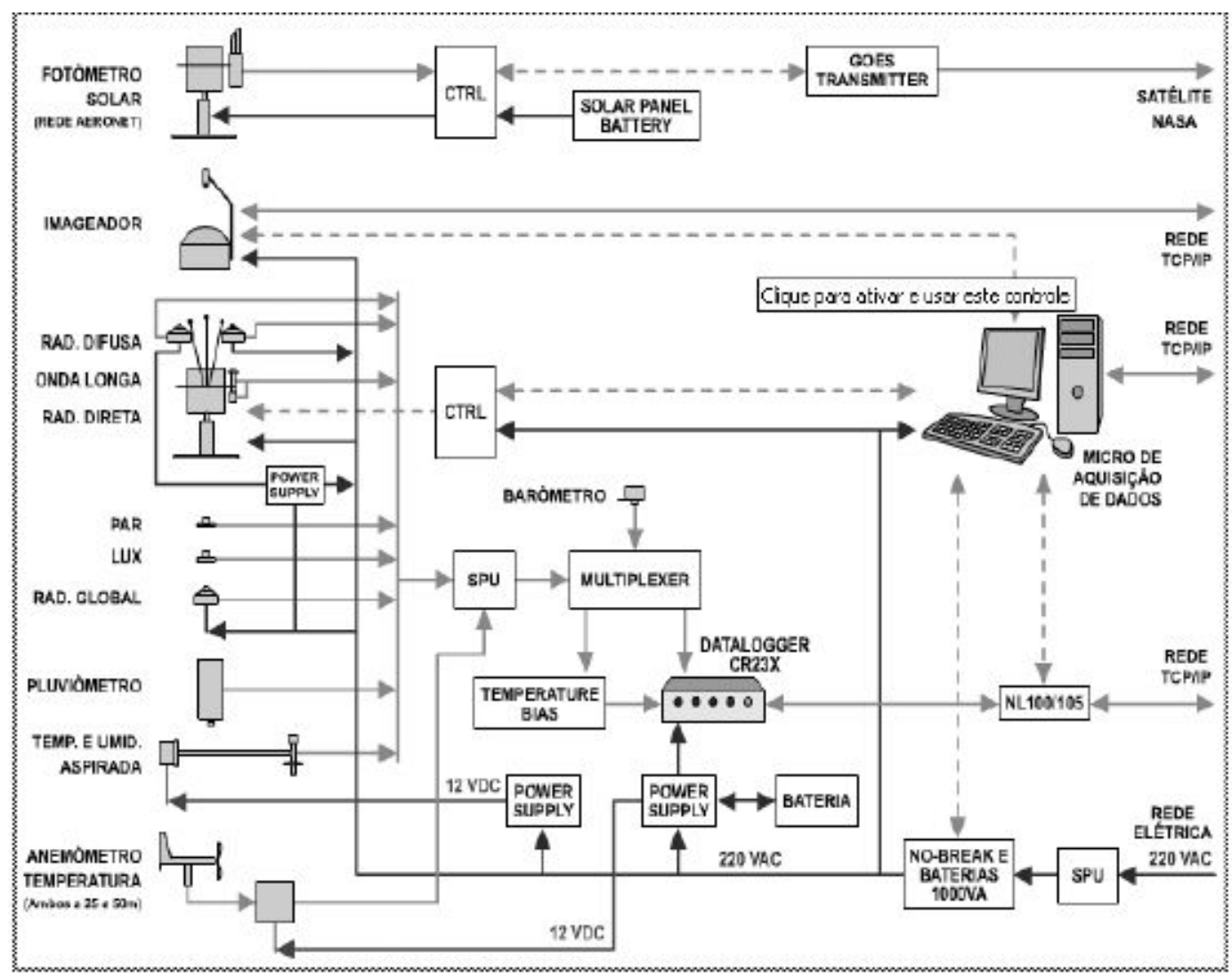

Figura 6.3 - Diagrama da configuração local dos equipamentos instalados na estação SONDA - SMS no Observatório Espacial do Sul - OES/CRS/CIE/INPE - MCT. Fonte: SONDA (2008).

Os sensores solarimétricos da estação SONDA - SMS realizam uma medida a cada segundo. Estes dados são armazenados pelo Datalogger, que fornece, como dados de saída, os valores médio, máximo, mínimo e o desvio padrão das medidas em cada minuto (1440 medidas diárias) ou a cada 10 minutos no caso das medidas eólicas.

Os dados do Datalogger são repassados a cada hora ao microcomputador PC SONDA, que também se encontra no interior do Prédio 1 do OES. Estes dados são acessados pela internet através do software LoggerNet, copiados e salvos nos computadores do Laboratório de Recursos de Energias Renováveis no Centro Regional Sul de Pesquisas Espaciais CRS/CIE/INPE - MCT em Santa Maria, RS.

Os dados do Imageador de nuvens Total Sky Imager TSI-440 (YES, Inc), no entanto, representam um volume muito grande, e por esta razão, são armazenados no microcomputador PC SONDA e copiados em dispositivos USB de memória Flash ou 
em CDs nas ocasiões de visita ao OES/CRS/CIE/INPE - MCT, sendo posteriormente salvos no microcomputador do LRER/ CRS/CIE/INPE - MCT.

Os dados do Imageador e dos demais sensores constituem o banco de dados brutos. Estes dados são separados em planilhas eletrônicas de acordo com a classificação em dados solarimétricos, eólicos e meteorológicos e passam a ser chamados de dados semi-tratados. Por fim os valores médios das medidas de cada minuto são separados em planilhas diárias para cada equipamento, que por sua vez são agrupadas em meses e anos, constituindo os dados reduzidos.

Os dados solarimétricos são plotados temporalmente ao longo do dia em softwares gráficos e, através da integração da área sob a curva obtida, são determinados os valores das integrais diárias das medidas (quantidade total de energia incidente durante o período de um dia). Já os dados eólicos recebem tratamento estatístico característico após serem reduzidos.

\section{3 - Estimativas de Radiação Solar Global e da Radiação PAR a partir de dados de Iluminância obtidos no Observatório Espacial do Sul}

O bolsista realizou, simultaneamente às atividades do Projeto de Pesquisa, o desenvolvimento de modelos empíricos que permitem estimar medidas de Radiação Solar Global e Radiação Fotossinteticamente Ativa (PAR) a partir de dados de Iluminância Natural.

Os dados de irradiação PAR, iluminância natural e irradiação solar global foram coletados na estação de referência SONDA - SMS, no Observatório Espacial do Sul OES/CRS/CIE/INPE-MCT no período de Janeiro de 2006 a Dezembro de 2007.

A coleta de dados de iluminância foi realiza através da utilização de um luxímetro LUX LITE (Kipp \& Zonen). Os dados de irradiância solar global e irradiância PAR foram obtidos respectivamente pelos equipamentos Piranômetro CM 21 (Kipp \& Zonen) e um sensor de irradiação Fotossinteticamente Ativa PAR LITE (Kipp \& Zonen).

Os dados instantâneos foram plotados temporalmente ao longo do dia e, através da integração da área sob a curva obtida, foram determinados os valores das integrais diárias (quantidade total de energia incidente durante o período de um dia) de irradiação 
solar global, irradiação PAR e iluminância, expressas respectivamente em $\mathrm{J} / \mathrm{m}^{2}$, $\mu \mathrm{mol} / \mathrm{m}^{2}$ e klux.

As medidas de irradiação solar global (I) e irradiação PAR ( $\mathrm{I}_{\mathrm{PAR}}$ ) coletadas no período de Janeiro de 2006 a Maio de 2007 foram plotadas em função dos dados de iluminância natural ( $\mathrm{I}_{\mathrm{IL}}$ ) e, através de análises de regressão linear, estabeleceram-se os modelos GI e PI para respectivas estimativas destas variáveis a partir de dados de iluminância.

Utilizando-se a mesma metodologia, porém empregando-se os valores das integrais diárias, foram desenvolvidos os modelos IGI e IPI, que possibilitam calcular, respectivamente, as integrais diárias de irradiação solar global $(\mathrm{H})$ e irradiação PAR $\left(\mathrm{H}_{\mathrm{PAR}}\right)$ a partir do conhecimento dos valores das integrais diárias de Iluminância $\left(\mathrm{H}_{\mathrm{IL}}\right)$.

O restante dos dados foi utilizado na etapa de validação dos modelos através do cálculo dos desvios estatísticos MBE (mean bias error) e RMSE (root mean square error).

A Figura 6.4 mostra os gráficos obtidos relacionando-se as medidas instantâneas de irradiação solar global e de irradiação PAR aos dados de iluminância natural. A Figura também ilustra os valores das integrais diárias de irradiação global e PAR em função das integrais diárias de iluminância natural. 
Relatório Final de Atividades, 2008
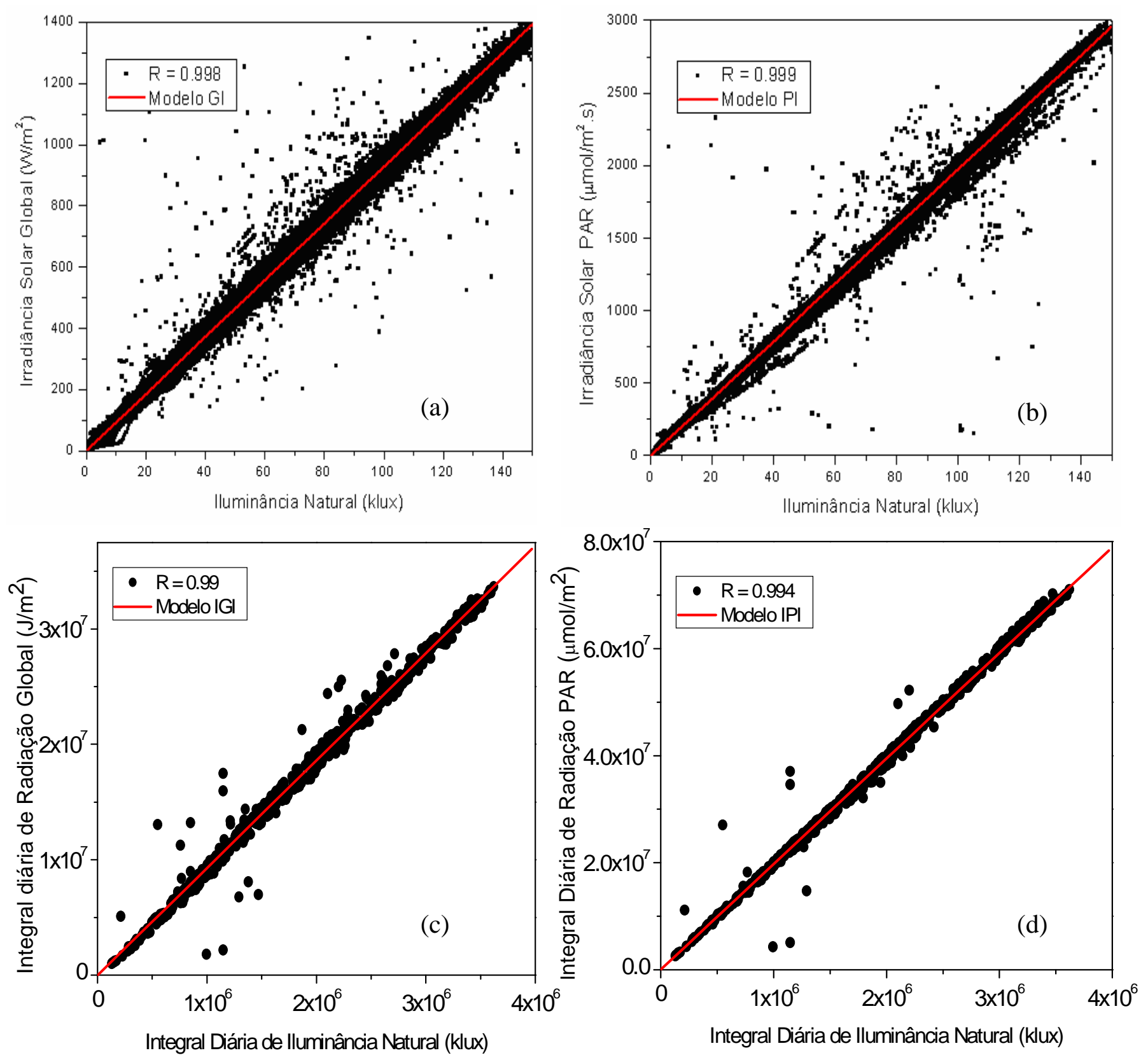

Figura 6.4 - (a) Relação entre as medidas de Irradiação Global e de Iluminância Natural coletadas no Observatório Espacial do Sul - OES/CRS/CIE/INPE-MCT; (b) Medidas instantâneas de Radiação PAR em função da Iluminância; (c) Relação entre as Integrais Diárias de Radiação Global e de Iluminância; (d) Integrais Diárias de Radiação PAR em função das Integrais Diárias de Iluminância. 
As equações que definem os modelos criados e as correlações entre as variáveis são apresentadas na Tabela 6.1 juntamente com os respectivos desvios estatísticos MBE e RMSE calculados.

Tabela 6.1 - Modelos empíricos desenvolvidos no LRER/CRS/CIE/INPE - MCT, suas correlações e desvios estatísticos.

Modelo

PI

IPI

GI

IGI

\section{Equação}

$$
\mathrm{I}_{\mathrm{PAR}}=19,733 * \mathrm{I}_{\mathrm{IL}}-0,713
$$$$
\mathrm{H}_{\mathrm{PAR}}=19,724 * \mathrm{H}_{\mathrm{IL}}+23074,533
$$$$
\mathrm{I}=9,295 * \mathrm{I}_{\mathrm{IL}}+0,26
$$$$
\mathrm{H}=9,302 * \mathrm{H}_{\mathrm{IL}}-12806,76
$$

\begin{tabular}{ccc} 
& \multicolumn{2}{c}{ Desvios estatísticos } \\
R & MBE (\%) & $\begin{array}{c}\text { RMSE } \\
(\%)\end{array}$ \\
0,999 & 1.52 & 3.13 \\
0,994 & 1.64 & 2.19 \\
0,998 & $-0,6$ & 4.83 \\
0,99 & $-0,19$ & 2.92
\end{tabular}

No desenvolvimento de novos trabalhos, será verificada a adequação destes modelos a medidas realizadas em outros sítios de coleta de dados e a série de dados será expandida a fim de aumentar a confiabilidade dos modelos. 


\section{CAPÍTULO 7}

\section{METODOLOGIA}

\subsection{Obtenção de Medidas de Radiação Solar}

Os dados de radiação solar utilizados neste Projeto de Pesquisa foram coletados nas estações SONDA de Petrolina - BA (Lat.: 09 04' 08" S Lon.: 40 19' 11" O), Campo Grande - MS (Lat.: 20²6' 18" S Lon.: 54 32' 17" O) e Cuiabá - MT (Lat.: $15^{\circ}$ 33' 19" S Lon.: 56 04' 12" O) através do site do SONDA. Dados de radiação também foram adquiridos junto à AERONET através do endereço eletrônico http://solradnet.gsfc.nasa.gov/ para a cidade de Cuiabá a fim de expandir o período de dados utilizados.

As estações SONDA são dotadas de Piranômetros CM 21 (Kipp \& Zonen), que realizam medidas de irradiância solar global na faixa espectral de 0,3 a 2,8 $\mu \mathrm{m}$ e Piranômetros CM 22 (Kipp \& Zonen) para a realização de medidas de irradiância solar difusa na faixa de 0,2 a 3,6 $\mu \mathrm{m}$ apresentados na Figura 7.1. A rede AERONET possui os mesmos sensores para a realização de medidas de radiação solar global e difusa.
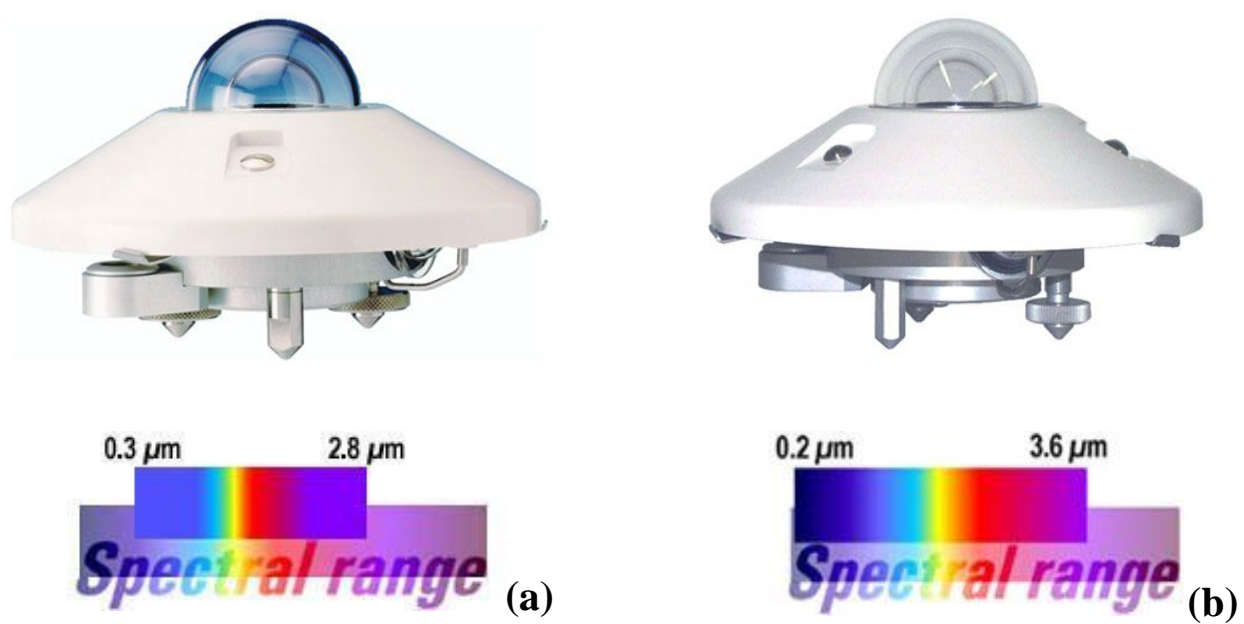

Figura 7.1 - Equipamentos do Projeto SONDA utilizados para a realização de medidas de radiação solar (a) Piranômetro CM 21 (Kipp \& Zonen); (b) Piranômetro CM 22 (Kipp \& Zonen). 
Relatório Final de Atividades, 2008

\section{2 - Seleção de Dias de Céu Claro}

O presente estudo limita-se à análise de dias de céu claro visando eliminar as incertezas provenientes da influência da nebulosidade sobre a radiação solar. A seleção dos dias de céu claro é realizada através da análise e qualificação dos dados de radiação solar global e difusa.

As medidas de irradiância solar global e difusa obtidas respectivamente pelos equipamentos Piranômetro CM 21 (Kipp \& Zonen) e Piranômetro CM 22 (Kipp \& Zonen) instalados nas estações SONDA foram plotadas temporalmente ao longo de cada dia, obtendo-se as curvas diárias de radiação solar global e difusa.

Um dia de céu claro é caracterizado por uma curva suave de traço contínuo, com simetria perfeita e com pico máximo próximo ao meio-dia do horário solar local conforme ilustra a Figura 7.2. Os dias cujas curvas diárias de irradiância solar global e/ou difusa apresentam variações abruptas, como ilustrado na Figura 7.3, são excluídos da análise. Os dados de radiação obtidos pela rede AERONET também passaram por essa seleção, porém foram analisadas apenas as curvas diárias de radiação solar global, pois não se dispunha de dados de irradiância difusa provenientes desta fonte.

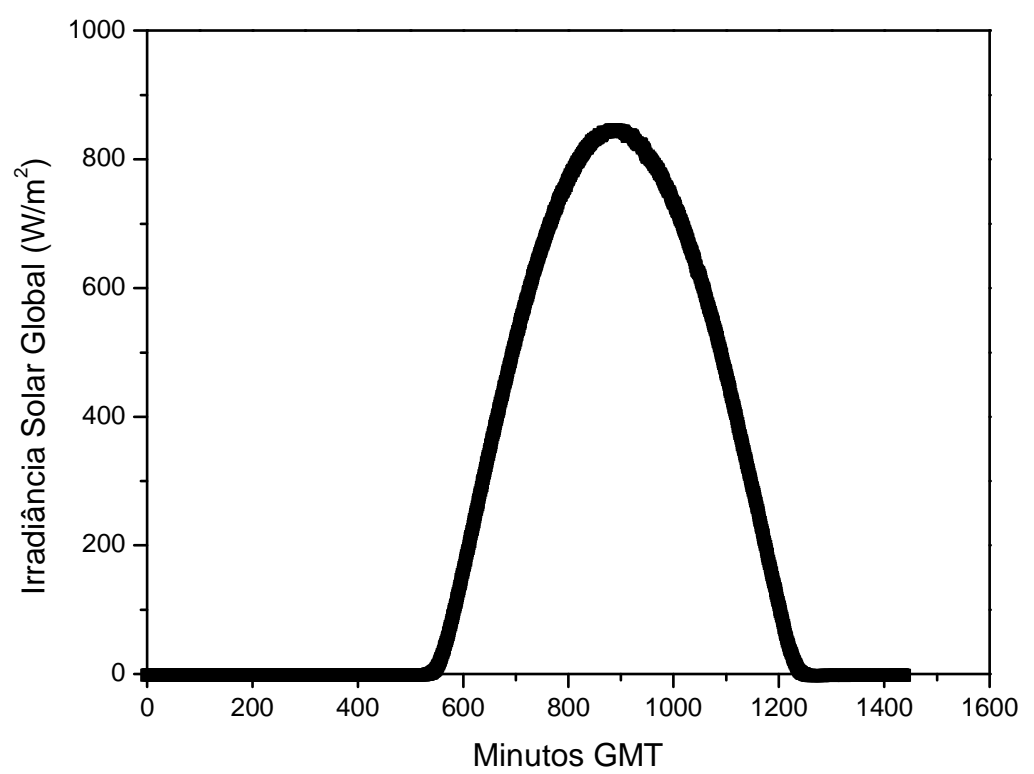

Figura 7.2 - Curva diária de radiação solar global obtida em 18/07/05 (dia de céu claro) na estação de referência SONDA de Petrolina - BA. 


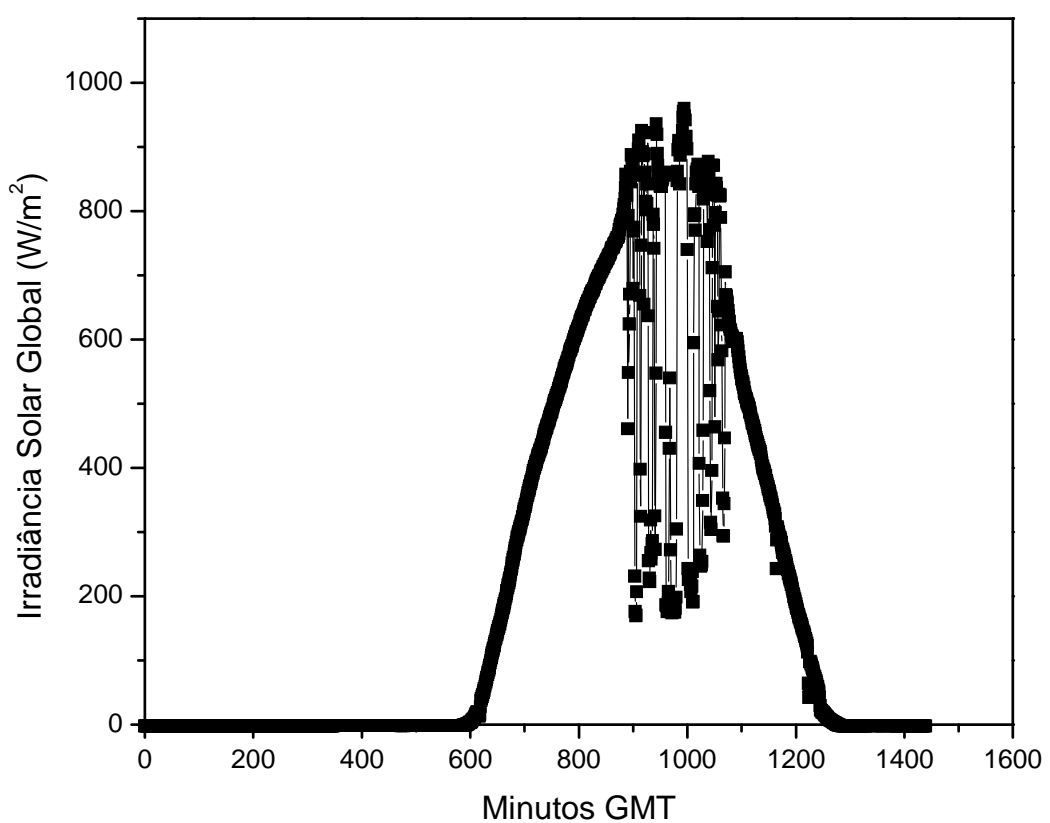

Figura 7.3 - Curva diária de radiação solar global obtida no dia 12/05/07 na estação SONDA de Campo Grande - MS.

Os dias pré-selecionados tiveram seus índices de nebulosidade $\left(\mathrm{K}_{\mathrm{T}}\right)$ e parâmetro de radiação difusa $\left(K_{d}\right)$ calculados de acordo com Iqbal (1983):

$$
\begin{gathered}
K_{T}=\frac{H}{H_{0}} \\
K_{d}=\frac{H_{d}}{H_{0}}
\end{gathered}
$$

onde $\mathrm{H}$ é a integral diária de radiação solar global, $\mathrm{H}_{\mathrm{d}}$ é a integral diária de radiação solar difusa, e $\mathrm{H}_{0}$ é a integral diária de radiação incidente no topo da atmosfera (TDA), sendo que $\mathrm{H}_{0}$ é obtido a partir da seguinte equação também de acordo com Iqbal (1983):

$$
H_{0}=\frac{I_{s c}}{\pi}\left(\frac{d_{m}}{d}\right)^{2}\left[h_{0} \operatorname{sen}(\varphi) \operatorname{sen}(\delta)+\cos (\varphi) \cos (\delta) \operatorname{sen}\left(h_{0}\right)\right]
$$

onde $I_{s c}$ é a constante solar, convencionada em $1368 \mathrm{Wm}^{-2},\left(d_{m} / d\right)^{2}$ é o fator de correção de excentricidade, $d_{m}$ é a distância média entre o Sol e a Terra, $d$ é distância entre o Sol e a Terra para um dia específico, $\varphi$ representa a latitude do sítio observado, $\delta$ é a declinação solar e $h_{0}$ é o ângulo horário. 
O índice de nebulosidade $\left(\mathrm{K}_{\mathrm{T}}\right)$ é definido como a razão entre a irradiância solar global que atinge a superfície e a irradiância solar incidente no topo da atmosfera. Valores de $\mathrm{K}_{\mathrm{T}}$ relativamente inferiores aos dos demais dias pré-selecionados aliados a valores de $K_{d}$ relativamente superiores aos demais indicam a ocorrência de uma cobertura de nuvens constante, originando curvas de radiação com comportamento semelhante ao das curvas características de um dia de céu claro. Neste caso, este dia deve ser excluído do grupo de dias pré-selecionados como dias de céu claro.

\section{3 - Obtenção de Dados de Queimadas}

Os dados de queimadas foram fornecidos pelo CPTEC/INPE - MCT através do site http://www.dpi.inpe.br/proarco/bdqueimadas/.

Foram coletados dados diários e semanais de focos de queimadas registrados por todos os satélites disponíveis (Figura 7.4) nos estados de Mato Grosso, Mato Grosso do Sul e Bahia durante o período de Janeiro de 2004 a Dezembro de 2007.

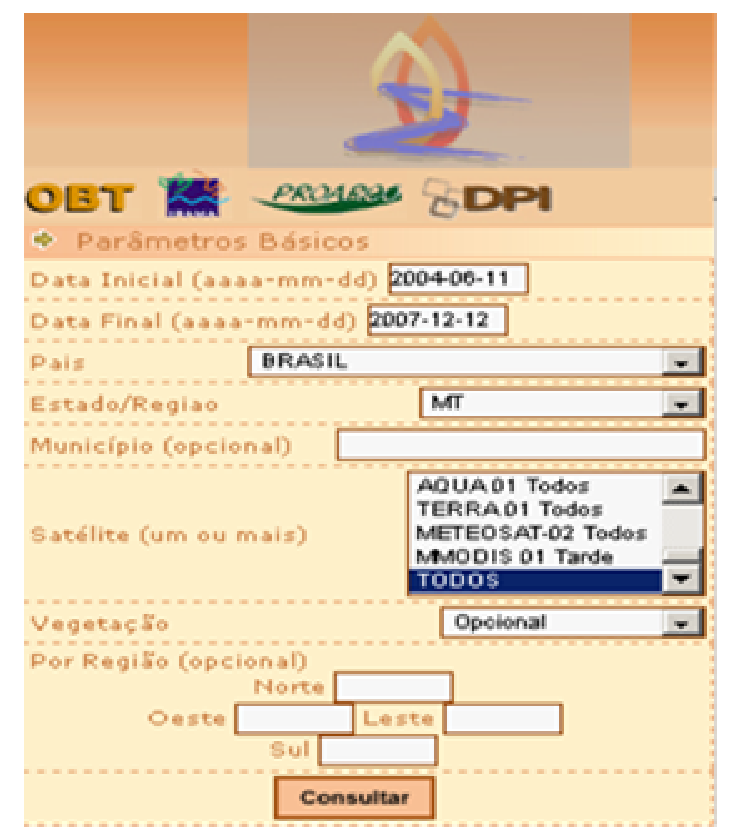

Figura 7.4 - Opções de satélites disponíveis para visualização dos focos de queimadas fornecidos pelo CPTEC/INPE - MCT. Fonte: DPI/PROARCO (2008). 
As medidas diárias foram obtidas em tabelas eletrônicas (Figura 7.5), contendo os seguintes dados: Número, Latitude, Longitude, Latitude GMS, Longitude GMS, Data, Hora, Satélite, Município, Estado, País, Vegetação, Suscetibilidade, Precipitação, Número de Dias Sem Chuva, Risco e Persistência. As medidas semanais foram obtidas na forma de gráficos de barras como ilustra a Figura 7.6.

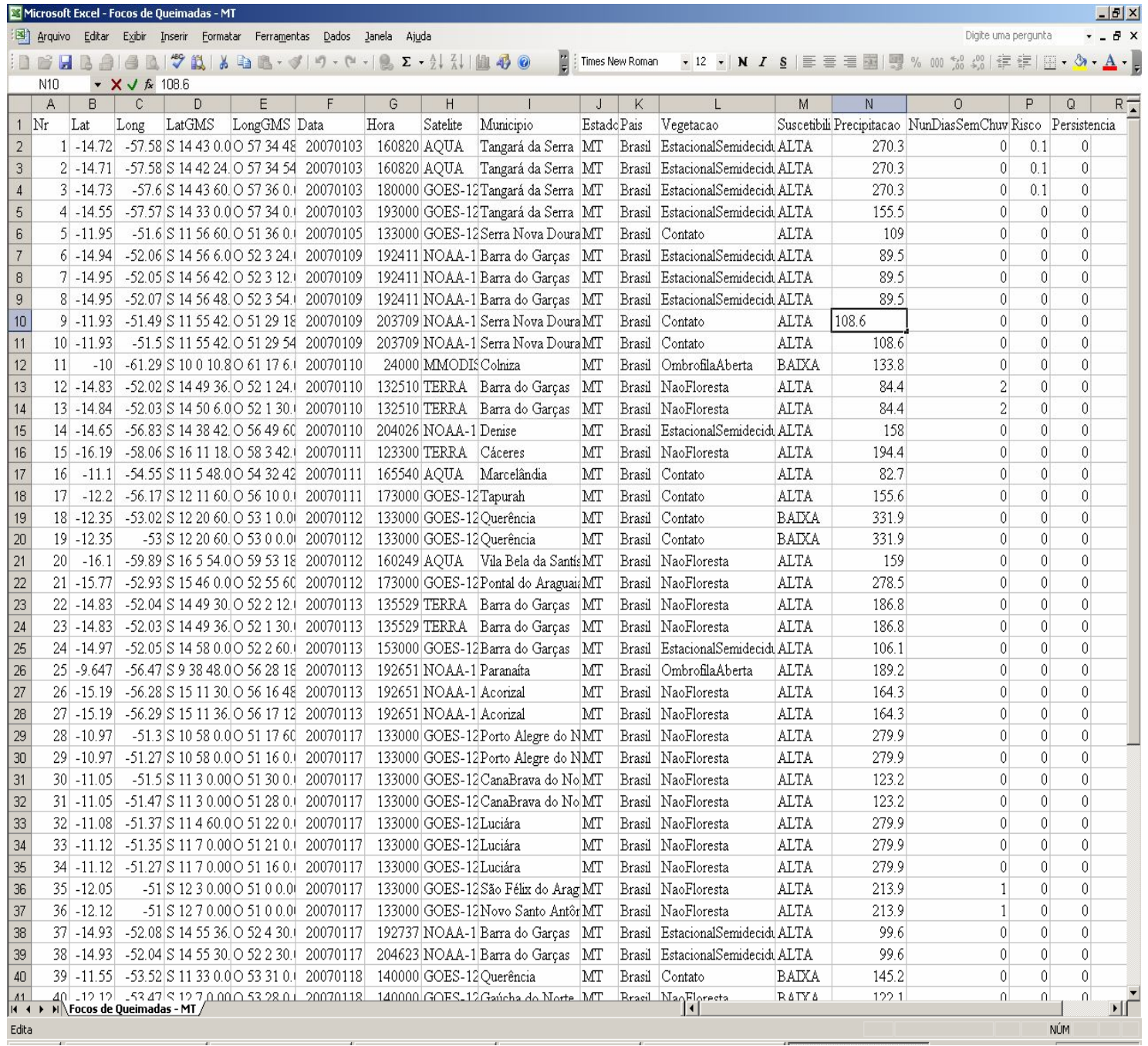

Figura 7.5 - Tabela eletrônica contendo dados diários de focos de queimadas ocorridos no estado do Mato Grosso, disponibilizados pelo CPTEC/INPE - MCT. 


\begin{tabular}{|c|c|c|}
\hline \multicolumn{3}{|c|}{ - HISTOGRAMA DOS FOCOS DE QUEIMA - } \\
\hline \multicolumn{3}{|c|}{ Disthibuição dos 62656 focos de $2005-01-01$ a $2005-12-31$ no BA } \\
\hline \multirow{47}{*}{$\begin{array}{c}\mathrm{S} \\
\mathrm{e} \\
\mathrm{m} \\
\mathbf{a} \\
\mathrm{n} \\
\mathrm{a} \\
\mathrm{s}\end{array}$} & $1 / \mathrm{J}$ an/2005 & (46) \\
\hline & $2 / \mathrm{J}$ an/2005 & $(470)$ \\
\hline & $9 / \mathrm{J}$ and 2005 & $(1044)$ \\
\hline & $16 / \mathrm{J}$ an $/ 2005$ & $(248)$ \\
\hline & $23 / \mathrm{J}$ an $/ 2005$ & (BSa) \\
\hline & $30 / \operatorname{Jan} / 2005$ & $(2512)$ \\
\hline & $6 / \mathrm{Fev} / 2005$ & (IGS) \\
\hline & $19 / \mathrm{Fev} / 2005$ & $(2)$ \\
\hline & $20 / \mathrm{Fev} / 2005$ & (3s) \\
\hline & $27 / \mathrm{Fev} / 2005$ & $(29)$ \\
\hline & $6 / \mathrm{TMar} / 2005$ & $(378)$ \\
\hline & $13 / \mathrm{M}$ ar/ 2005 & $(6)$ \\
\hline & 20/Mar/2005 & (136) \\
\hline & $27 / \mathrm{Mar} / 2005$ & $(36)$ \\
\hline & $3 / \mathrm{Abr} / 2005$ & $(164)$ \\
\hline & $10 / \mathrm{Abr} / 2005$ & $(230)$ \\
\hline & $17 / \mathrm{Abr} / 200 \mathrm{~S}$ & (2s) \\
\hline & $24 / \mathrm{Ab} / 2005$ & (x) \\
\hline & 1/M ai/2005 & (25) \\
\hline & $8 / \mathrm{M}$ ai/2005 & $(F D)$ \\
\hline & $15 / \mathrm{M}$ aid 2005 & $(25)$ \\
\hline & 28/Mai/200s & (96) \\
\hline & 30/M ai/2005 & $(a)$ \\
\hline & $9 / \mathrm{Jun} / 2005$ & $(84)$ \\
\hline & $13 / \mathrm{Jun} / 200 \mathrm{~s}$ & (223) \\
\hline & $25 / \mathrm{Jun} / 2005$ & $(225)$ \\
\hline & $27 / \mathrm{Jun} / 2005$ & $(224)$ \\
\hline & $5 / \mathrm{Ju} / 2005$ & $(20)$ \\
\hline & $11 / \mathrm{Ju} / 2005$ & $(213)$ \\
\hline & $17 / \mathrm{J} u 1 / 2005$ & $(25)$ \\
\hline & 24/Ju1/2005 & $(312)$ \\
\hline & $1 / \mathrm{Ag} / 2005$ & $(2 I I)$ \\
\hline & $10 / \mathrm{Ag} / 2005$ & $(214)$ \\
\hline & $14 / \mathrm{Ag} / 2005$ & (613) \\
\hline & $21 / \mathrm{Ag}$ g/2005 & (633) \\
\hline & 28/Ago/2005 & (1679) \\
\hline & $4 /$ Set/2005 & (1629) \\
\hline & $11 /$ Set/2005 & (2779) \\
\hline & $18 /$ Set/2005 & $a_{(3842)}$ \\
\hline & $25 /$ Set/2005 & (1992) \\
\hline & $2 / 0 u t / 2005$ & $(50 s 9)$ \\
\hline & $9 / 0 u t / 2005$ & $(B I D)$ \\
\hline & $16 / 0 u t / 2005$ & $(8 I B)$ \\
\hline & $23 / 0 u t / 2005$ & $(7980)$ \\
\hline & $30 / 0 u t / 2005$ & $(237)$ \\
\hline & $6 / \mathrm{Nov} / 2005$ & (7382) \\
\hline & $13 / \mathrm{Nov} / 2005$ & (366) \\
\hline
\end{tabular}

Figura 7.6 - Gráfico de barras representando o número de focos de queimadas registrados semanalmente por todos os satélites disponíveis no estado da Bahia durante o ano de 2005. Fonte: DPI/PROARCO (2008).

\section{4 - Obtenção de Dados de Espessura Óptica dos Aerossóis}

Os dados de espessura óptica de aerossóis utilizados neste Projeto de Pesquisa referentes às Estações SONDA de Cuiabá - MT, Campo Grande - MS e Petrolina - BA foram fornecidos pela AERONET, através do endereço eletrônico http://aeronet.gsfc.nasa.gov. 
Os produtos de aerossóis da AERONET abrangem medidas instantâneas, médias diárias e médias mensais de espessura ótica de aerossóis e são disponibilizados em três diferentes níveis de confiança: 1.0, 1.5 e 2.0 conforme detalhado no Capítulo 4.3 e mostrado na Figura 7.7. Os dados coletados contemplam a média diária da espessura ótica de aerossóis com nível de confiança 1.0.

Com o apoio da Divisão Ambiental de Satélites - DAS/CPTEC/INPE - MCT e do Serviço de Atendimento ao Usuário do CPTEC/INPE - MCT, também foram obtidos dados de aerossóis para toda a América Latina através do sensor MODIS a bordo dos satélites AQUA e TERRA, disponibilizados através do endereço eletrônico http://paraguay.cptec.inpe.br:8080/produto/aerossois/\#.

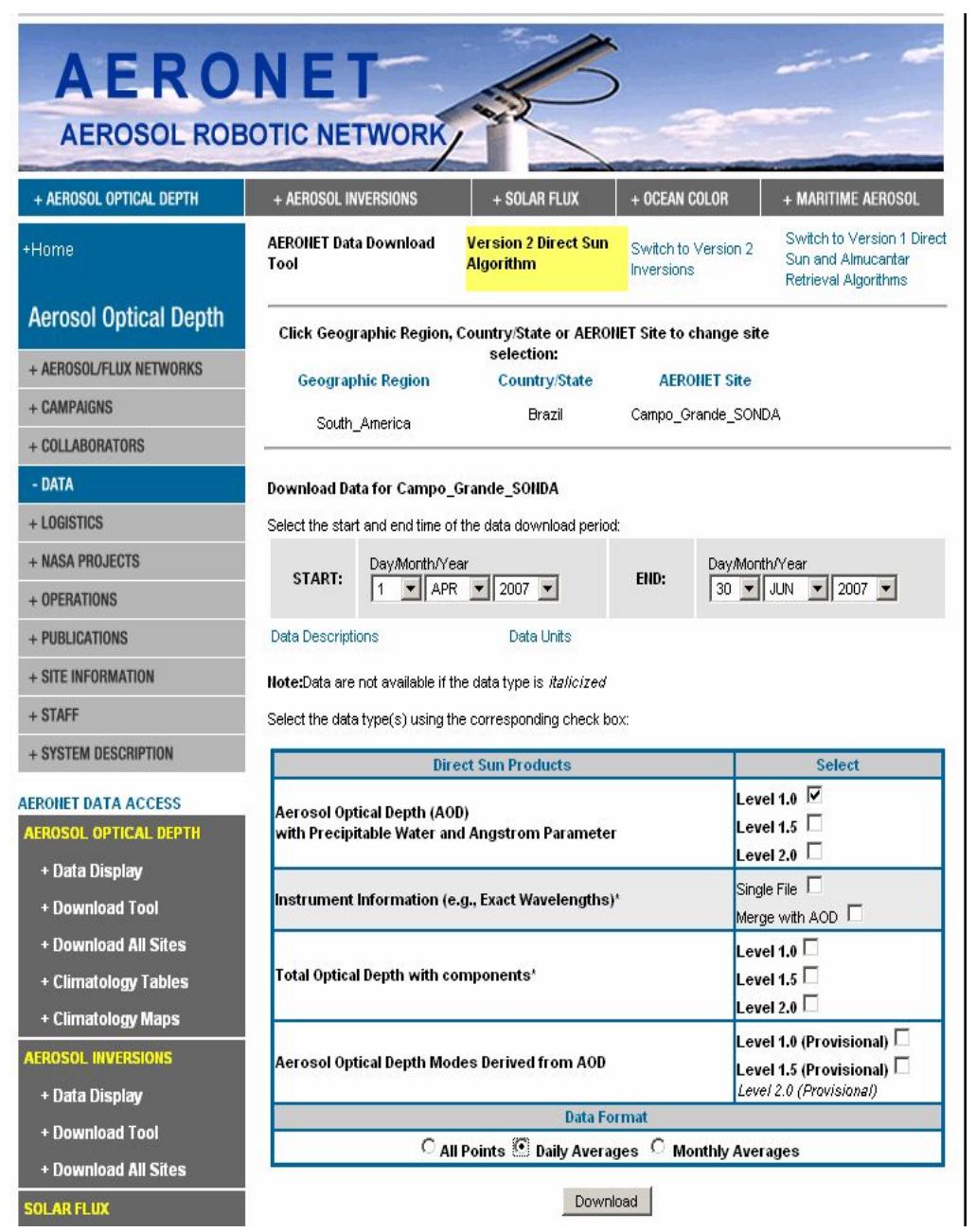

Figura 7.7 - Produtos de Aerossóis disponibilizados pela rede AERONET para a cidade de Campo Grande - MS no período de Abril a Junho de 2007. Fonte: AERONET (2008). 


\section{CAPÍTULO 8}

\section{RESULTADOS}

Os períodos de dados de radiação solar global e difusa coletados nas Estações SONDA de Campo Grande - MS, Cuiabá - MT e Petrolina - BA, apresentados na Figura 8.1, foram utilizados na seleção de dias de céu claro, conforme a metodologia descrita no Capítulo 7.2. O número de dias de céu claro obtidos para cada uma das estações também é mostrado na Tabela abaixo.

Tabela 8.1: Informações relativas à seleção de dias de céu claro nas Estações SONDA

\begin{tabular}{|c|c|c|}
\hline Estação SONDA & Período de dados analisados & $\begin{array}{c}\text { Número de dias } \\
\text { de céu claro }\end{array}$ \\
\hline Campo Grande - MS & Abril a Junho de 2007 & 13 \\
\hline Cuiabá - MT & Janeiro de 2001 a Dezembro de 2007 & 84 \\
\hline Petrolina - BA & $\begin{array}{c}\text { Julho a Dezembro de 2004; Janeiro a Maio } \\
\text { de 2005; Maio a Dezembro de 2007 }\end{array}$ & 36 \\
\hline
\end{tabular}

Os dias selecionados tiveram seus respectivos índices de nebulosidade $\left(\mathrm{K}_{\mathrm{T}}\right)$ calculados. Os valores diários de $\mathrm{K}_{\mathrm{T}}$ foram diagramados em função das médias diárias de espessura ótica de aerossóis nos comprimentos de onda de 500, 870 e $1020 \mathrm{~nm}$ coletadas para as diferentes estações, conforme ilustram os gráficos a seguir. 
Relatório Final de Atividades, 2008

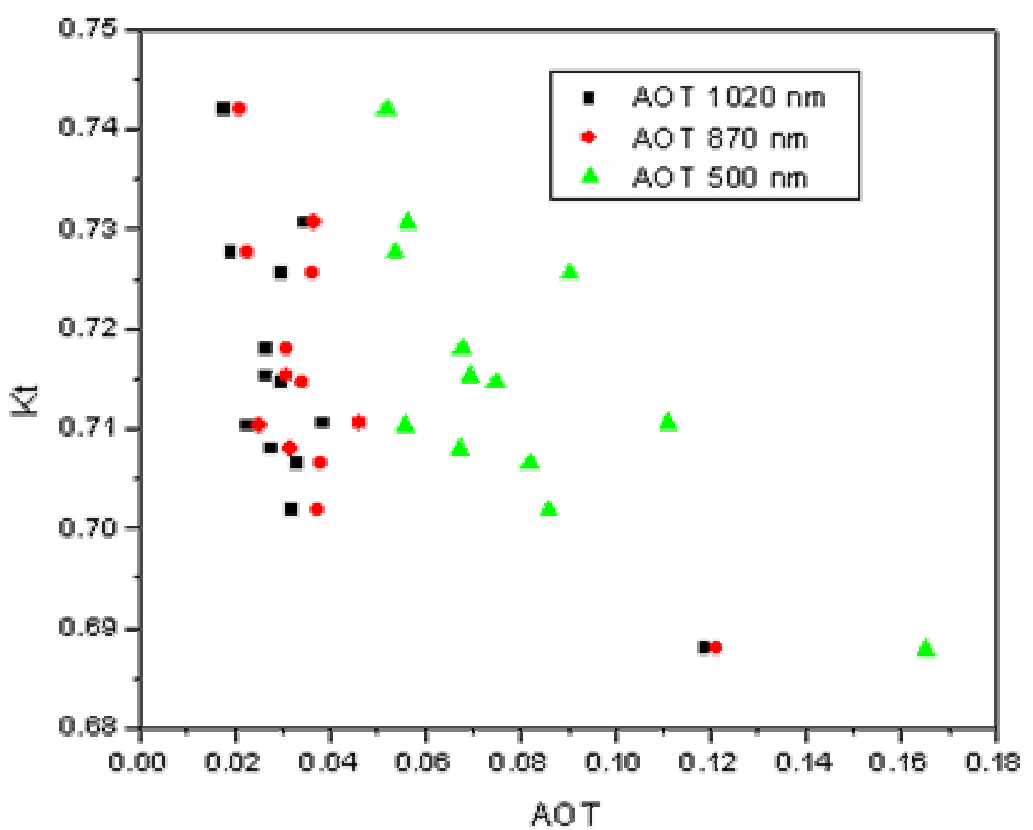

Figura 8.1 - Índice de nebulosidade em função da espessura ótica de aerossóis para os comprimentos de onda de 500, 870 e 1020 nm em Campo Grande - MS.

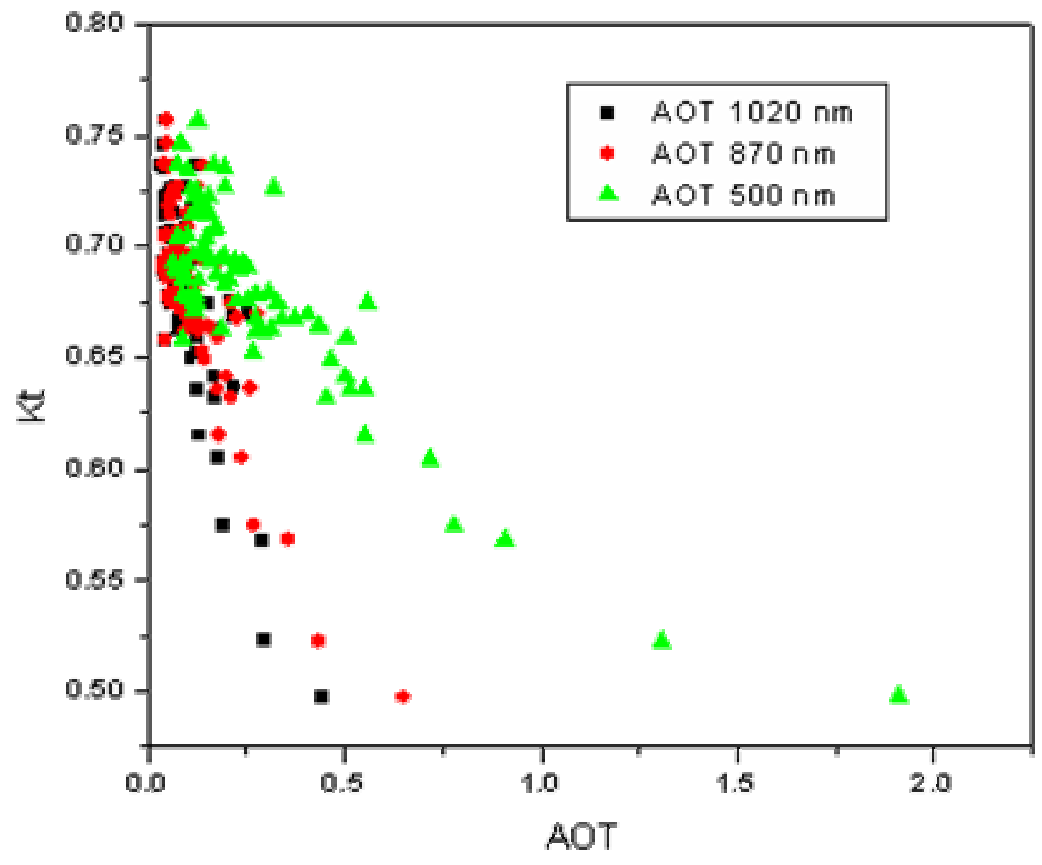

Figura 8.2 - Relação entre KT e espessura ótica de aerossóis em Cuiabá - MT. 


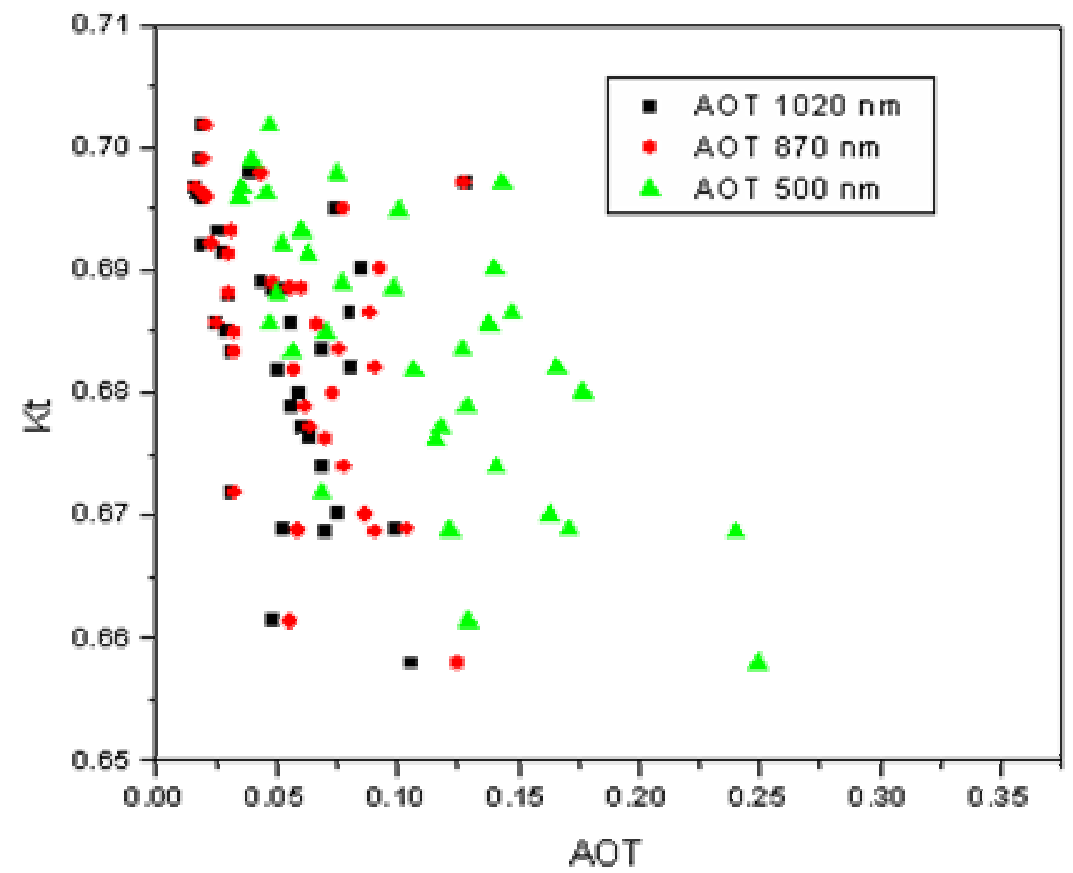

Figura 8.3 - $\mathrm{K}_{\mathrm{T}}$ em função de AOT para a cidade de Petrolina - BA.

Através da análise dos gráficos obtidos, pode-se comprovar que, com o aumento da espessura ótica dos aerossóis, ocorre uma diminuição nos valores de $\mathrm{K}_{\mathrm{T}}$, ou seja, quanto mais espessa for a coluna atmosférica em termos de aerossóis, menor será a relação entre a quantidade de radiação solar incidente na superfície e a radiação no topo da atmosfera. Este resultado é válido para todas as estações estudadas, adicionalmente percebe-se que, nas estações de Cuiabá e Campo Grande, o valor de $\mathrm{K}_{\mathrm{T}}$ decai exponencialmente com o aumento da espessura ótica de aerossóis.

Os dados referentes ao número de focos de queimadas semanais disponibilizados pelo DPI/PROARCO e registrados por todos os satélites disponíveis nos estados de Mato Grosso, Mato Grosso do Sul e Bahia durante o período de Janeiro de 2004 a Dezembro de 2007 foram plotados temporalmente ao longo dos anos com o intuito de se observar a variação temporal dos eventos de queima de biomassa nestes estados, obtendo-se, dessa forma o gráfico da Figura 8.4. 


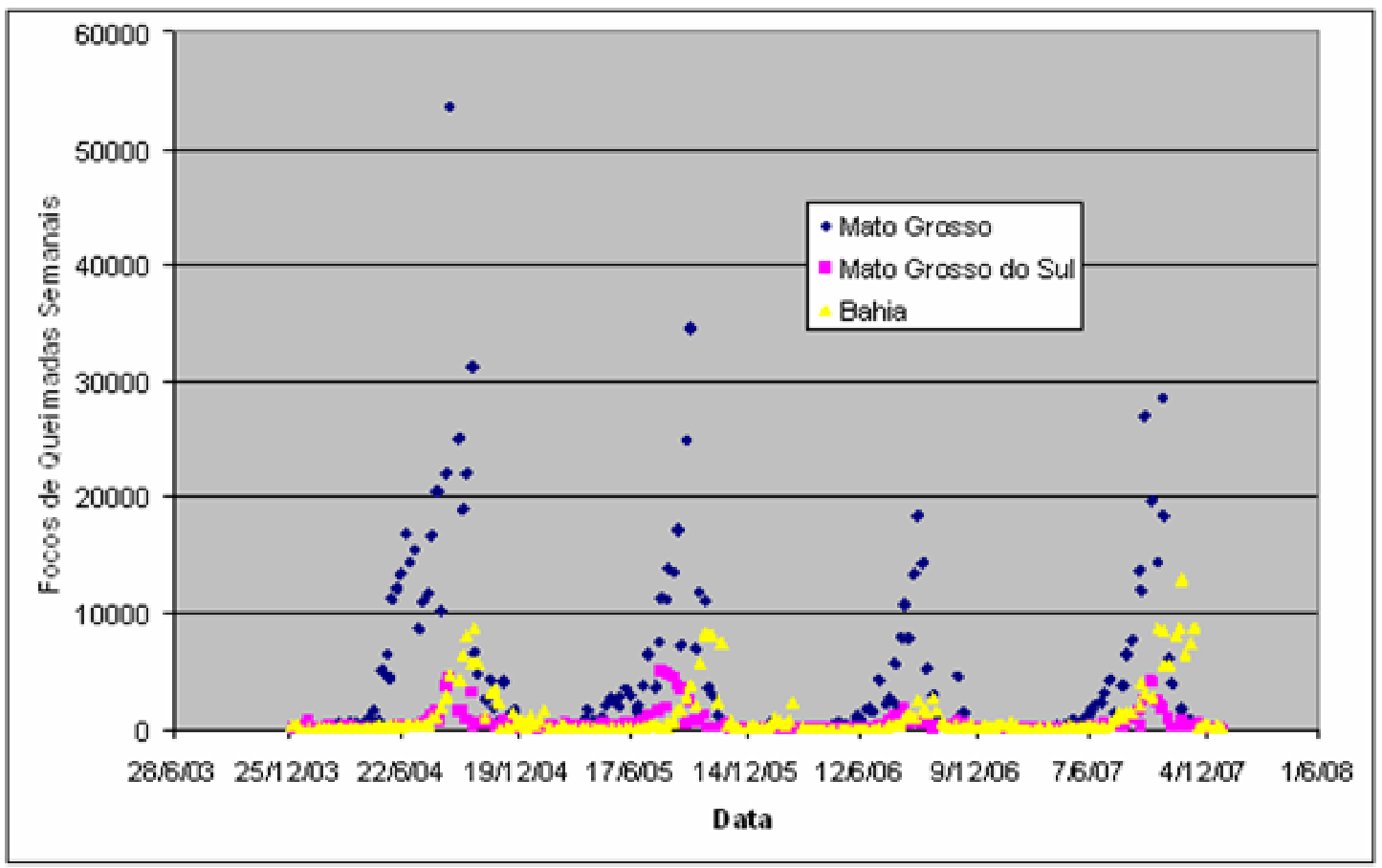

Figura 8.4 - Variação temporal do número de queimadas semanais registradas nos estados de Mato Grosso, Mato Grosso do Sul e Bahia de Janeiro de 2004 a Dezembro de 2007.

Pode-se perceber claramente pelo gráfico que, dentre os três estados analisados, Mato Grosso é, sem dúvida, o que registra o maior número semanal de queimadas, sendo que em 2004 este número chegou próximo aos 60000. Também se observa que realmente é nas estações secas, principalmente nos meses de agosto e setembro, que as queimadas ocorrem mais freqüentemente. 


\section{CONCLUSÃO}

Durante o período de atividades deste Projeto de Iniciação Científica, o bolsista realizou uma ampla revisão bibliográfica referente ao tema do projeto com o intuito de desenvolver os tópicos descritos anteriormente.

A análise de dados de radiação solar medidos nas estações SONDA de Cuiabá MT, Campo Grande - MS e Petrolina - BA, a seleção de dias de céu claro e a aquisição de dados de aerossóis permitiram concluir que um aumento na espessura ótica dos aerossóis atmosféricos (AOT) resulta em uma diminuição exponencial do índice de nebulosidade $\left(\mathrm{K}_{\mathrm{T}}\right)$.

Esse decaimento exponencial de $\mathrm{K}_{\mathrm{T}}$ foi determinado através da análise do gráfico que relaciona esta variável a AOT para as estações de Cuiabá e Campo Grande. $\mathrm{Na}$ estação de referência SONDA de Petrolina, esta relação exponencial não foi observada devido principalmente ao curto período de dados disponível e ao fato de que Petrolina não sofre diretamente os efeitos das queimadas ocorrentes no norte do Brasil.

A variação temporal do número de focos de queimadas registrados no período de Janeiro de 2004 a Dezembro de 2007 nos estados de Mato grosso, Mato Grosso do Sul e Bahia permitiu concluir que dentre os três estados analisados, Mato Grosso é o que apresenta o maior número de queimadas. Também se pôde perceber que, independentemente do estado, os picos de queimadas ocorrem nas estações secas, principalmente em agosto e setembro.

Adicionalmente o bolsista desenvolveu modelos empíricos que permitem estimar medidas instantâneas e os valores das integrais diárias de Radiação Solar Global e de Radiação Fotossinteticamente Ativa (PAR) em função de dados de Iluminância Natural coletados na estação de referência SONDA - SMS, localizada no observatório Espacial do Sul - OES/CRS/CIE/INPE - MCT. Os modelos desenvolvidos apresentaram altíssimas correlações e baixos desvios estatísticos.

$\mathrm{Na}$ continuidade de suas atividades como aluno de Iniciação Científica, o bolsista visa desenvolver novos modelos empíricos que permitam determinar medidas de Radiação Solar Global e Radiação PAR a partir de dados de Iluminância Natural a 
nível nacional, utilizando, para este propósito, dados de várias estações SONDA espalhadas pelo Brasil. 
Relatório Final de Atividades, 2008

\section{REFERÊNCIAS BIBLIOGRÁFICAS}

AERONET, Aerosol Robotic Network. National Aeronautics and Space Administration. Goddard Space Flight Center. Disponível em: 〈http://aeronet.gsfc.nasa.gov/〉. Acessado em 01 de janeiro de 2008.

Alves, C. Aerossóis Atmosféricos: Perspectiva Histórica, Fontes, Processos Químicos de Formação e Composição Orgânica. Química Nova, v. 28, n. 5, p. 859-870, 2005.

Anderson, B.E., Grant, W.B., Gregory, G.L., Browell, E.V., Collins Jr., J.E., Sachse, W.G., Bagwell, D.R., Hudgins, C.H., Blake, D.R., Blake, N.J., 1996. Aerosols from burning over the tropical South Atlantic region: distributions and impacts. J. Geophys. Res.101(D19) (24), 117-137.

Andreae, M.O.; Almeida, S. S. DE; Artaxo, P.; Brandão, C.; Carswell, F. E.; Ciccioli, P.; Culf, A.; Esteves, J. L.; Gash, J.; Grace, J.; Kabat, P.; Lelieveld, J.; Malhi, Y.; Manzi, A. O.; Meixner, F. X.; Nobre, A.; Nobre, C.; Ruivo, M. A. DE L.; Silva-Dias, M. A. F.; Stefani, P.; Valentini, R.; Jouanne, J. Von; Waterloo, M. Biogeochemical cycling of carbon, water, energy, trace gases and aerosols in Amazonia: The LBAEUSTACH experiments. Journal of Geophysical Research, v.107, n.D20, p.8.066 8.091, 2002. doi:10.1029/2001JD000524.

Andreae, M. O.; Crutzen, P. J. Atmospheric aerosols: biogeochemical sources and role in atmospheric chemistry. Science, v. 276, p.1.052-1.058, 1997.

Artaxo, P.; Fernandes, E. T.; Martins, J. V.; Yamasoe, M.A.; Hobbs, P.V.; Maenhaut, W.; Longo, K. M. \& Castanho, A. Large-scale aerosol source apportionment in Amazonia. Journal of Geophysical Research- D: Atmospheres, v. 103, n.24, p. 31837-31847, Dec. 1998.

Artaxo, P.; Gerab, F.; Yamasoe, M. A.; Martins, J. V. Fine mode aerosol composition at three long-term atmospheric monitoring sites in the Amazon Basin. Journal of Geophysical Research, v. 99, n. D11, p. 22857-22868, nov. 1994.

Artaxo, P.; Martins, J. V.; Yamasoe, M. A.; Procópio, A. S.; Pauliquevis, T. M.; Andreae, M. O.; Guyon, P.; Gatti, L. V.; Cordova, A. M. Physical and chemical properties of aerosols in the wet and dry season in Rondônia, Amazonia. Journal of

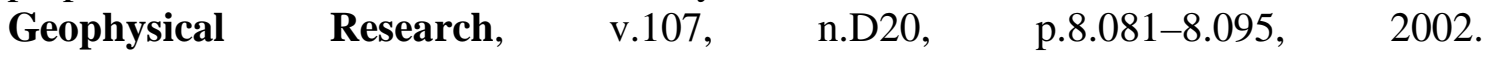
doi:10.1029/2001JD000666.

Artaxo,P., Oliveira, P. H.,Lara,L.H., Pauliquevis,T.M., Rizzo, L.V., Junior, c.P., Paixão, M.A., Longo K.M., Freitas, s. e Correia, A.L. 2006. Efeitos climáticos de partículas de aerossóis biogênicos e emitidos em queimadas na Amazônia. Revista Brasileira de Meteorologia, v.21, n.3a, 168-22, 2006. 
B.A., Haites, E., Harris, N. e Maskell, K. Cambridge University Press, EUA, pp. 127$162,1995$.

Badarinath, K.V.S., Kharol, S.K., Kaskaoutis, D.G., Kambezidis, H.D., 2006. Influence of atmospheric aerosols on solar spectral irradiance in an urban area. Journal of Atmospheric and Solar-Terrestrial Physics 69 (2007) 589-599.

Balis, D.S., Zerefos, C.S., Kourtidis, K., Bais, A.F., Hofzumahaus, A., Kraus, A., Schmitt, R., Blumthaler, M., Gobbi, G.P., 2002. Measurements and modeling of photolysis rates during the PAUR II campaign. Journal of Geophysical Research 107. Box, M.A., Beck, S., Trautmann, T., 1996. Computational techniques to incorporate aerosol variability in climate models. J. Geophys. Res. 101 (D14), 19293-19297.

Brasseur, G. and Solomon, S. Aeronomy of the Middle Atmosphere, D. Reidel Publishing Company, Dordrecht, Holland, 452p. 1986.

Christopher, S.A., Kliche, D.V., Chou, J., Welch, R.M., 1996. First estimates of the radiative forcing of aerosols generated from biomass burning using satellite data. $\mathbf{J}$. Geophys. Res. 101, 21256-21273.

Correia, A.L. Aerossóis atmosféricos na Antártica: sazonalidade, composição elementar e relação com El Niño. São Paulo. Dissertação (Mestrado) - Instituto de Física, Universidade de São Paulo, 1998.

Correia, A.L.; Castanho, A.D.A.; Martins, J.V.; Longo, K.; Yamasoe, M.; Artaxo, P. Inferência de Aerossóis. In: Rudorff, B.F.T.; Shimabukuro, Y.E.; Ceballos, J.C. (Org.). O sensor MODIS e suas aplicações ambientais no Brasil. São José dos Campos, Bookimage, ISBN 85-8739329-4, p.297-314, 2006.

Coulson, K. L. Solar and Terrestrial Radiation: Methods and Measurements, New York, Academic Press, 1975, 322 p.

DPI/PROARCO, Divisão de Processamento de Imagens. Banco de Dados de Queimadas, Disponível em: < http://www.dpi.inpe.br/proarco/bdqueimadas/>. Acessado em 08 de abril de 2008.

DSA/CPTEC, Centro de Previsão de Tempo e Estudos Climáticos. Divisão de Satélites Ambientais. Disponível em: 〈http://www.cptec.inpe.br/queimadas/>. Acessado em 09 de maio de 2008.

Dubovik, O., Holben, B.N., Eck, T.F., Smirnov, A., Kaufman, Y.J., King, M.D., Tanre, D., Slutsker, I., 2002. Variability of absorption and optical properties of key aerosol types observed in worldwide locations. Journal of Atmospheric Science 59, 590-608.

Eck, T. F.; Holben, B. N.; Reid, J. S.; O’neill, N. T.; Schafer, J.; Dubovik, O.; Smirnov, A.; Yamasoe, M.A.; Artaxo, P. High aerosol optical depth biomass burning events: a 
comparison of optical properties for different source regions. Geophysical Research Letters, v.30, n.20, p.2.035-2.048, 2004. doi: 10.1029/2003GL017861.

Eck, T.F., Holben, B.N., Slutsker, I., Setzer, A., 1998. Measurements of irradiance attenuation and estimation of aerosol single scattering albedo for biomass burning aerosols in Amazonia. J. Geophys. Res. 103 (D24), 31865-31878.

França, D.A., Ferreira, N.J. Considerações sobre o uso de satélites na detecção e avaliação de queimadas. Anais XII Simpósio Brasileiro de Sensoriamento Remoto, Goiânia, Brasil, 16-21 abril 2005, INPE, p. 3017-3023.

Freitas, S.R.; Longo, K. M.; Silva Dias, M.; Artaxo, P. Numerical modelling of air mass trajectories from the biomass burning areas of the Amazon basin. Annais da Academia Brasileira de Ciências, v.68, p.193-206, 1997.

Freitas, S. R.; Silva Dias, M. A. F.; Silva Dias, P. L.; Longo, K. M.; Artaxo, P.; Andreae, M. O.; Fischer, H. A convective kinematic trajectory technique for low resolution atmospheric models. Journal of Geophysical Research, v.105, n.D19, p.24.375-24.386, 2000.

Freitas, Saulo R., Longo, Karla M., Dias, M. A. F. Silva et al. Emissões de queimadas em ecossistemas da América do Sul. Estud. av., 2005, vol.19, no.53, p.167-185. ISSN 0103-4014.

Gerab, F. Técnicas analíticas nucleares aplicadas à média em larga escala de aerossóis atmosféricos na região amazônica. São Paulo. 203p. (USP/IF/SBI-03). Tese (Doutorado em Física Nuclear) - Universidade de São Paulo, 1996.

Holben, B.N.; Eck, T. F.; Slutsker, I.; Tanre, D.; Buis, J. P.; Setzer, A.; Vermote, E.; Reagan, J. A.; Kaufman, Y. J.; Nakajima, T.; Lavenu, F.; Jankowiak, I.; Smirnov, A. AERONET-A Federated Instrument Network and Data Archive for Aerosol Characterization. Remote Sensing of the Environment, v.66, p.1-16, 1998.

Holben, B.N., Setzer, A., Eck, T.F., Pereira, A. e Slutsker, I. Effect of dry-season biomass burning on Amazon basin aerosol concentrations and optical properties, 19921994. Journal of Geophysical Research 101 D14, 19465-19481, 1996.

IPCC2001 - Intergovernamental Panel on Climate Change. A plan for a Research Program on Aerossol Radiative forcing and climate change. National Academy Press, Washington, D.C., 2001.

Iqbal, M. An Introduction to Solar Radiation, Toronto, Academic Press Canada, 390p., 1983.

Jacobson, M. Z. Strong Radiative Heating due to the Mixing State of Black Carbon in Atmospheric Aerosols. Nature, v.409, p.695697, 2001. 
Jonas, P.R., Charlson, R.J. e Rodhe, H., Aerosols. Em: Climate Change 1994 Radiative Forcing of Climate Change and An Evaluation of the IPCC IS92 Emission Scenarios. Editores: Houghton, J.T., Meira Filho, L.G., Bruce, J., Lee, H., Callander.

Junge, C. E.; Air Chemistry and Radioactivity, Academic Press: London, 1963.

Justice, C.O.; Giglio, B.; Korontzi, S.; Owens, J.; Morisette, J.T.; Roy, D.P.; Descloitres, J.; Alleaume, S.; Petitcolin, F.; Kaufman, Y. 2002. The MODIS fire products. Remote Sensing of Environment, 83: 244-262.

Kaufman, Y. J. Remote sensing of direct and indirect aerosol forcing. In: Aerosol forcing of climate. Ed. por R. J. Charlson e J. Heintzenberg, John Wiley \& Sons, 1995.

Kidder, S. Q.; Vonder Haar, T. H. Satellite Meteorology: an introduction, San Diego, Academic Press, 466p. 1995.

Kylling, A., Bais, A.F., Blumthaler, M., Schrede, R.J., Zerefos, C.S., Kosmidis, E., 1998. Aerosols on solar UV irradiances during the photochemical activity and solar ultraviolet radiation campaign. Journal of Geophysical Research 103, 26051-26060.

Latha, M.K., Badarinath, K.V.S., 2004. Characterization of aerosols and its radiative impacts over urban and rural environments-a case study from Hyderabad and Srisailam. Environmental Pollution 132, 463-468.

Liou, K. N. An Introduction to Atmospheric Radiation, New York, Academic Press Inc., 392p., 1980.

Liousse, C.; Cachier, H.; Grégoire, J.M.; Penner, J.; Lavoué, D.; Hobbs, P.; Scholes, M.; Barbosa, P.; Andreae M. O.; Artaxo, P. Deriving global quantitative estimates for spatial and temporal distributions of biomass burning emissions. In: Granier, C.; Artaxo, P.; Reeves, C. (eds). Emissions of trace gases and aerosols into the atmosphere, London, Kluwer Academic Publishers, 2004, ISBN: 1-4020-2166-6.

Liu, D.C., McKeen, S.A., Madronich, S., 1991. Effect of anthropogenic aerosols on biologically active ultraviolet radiation. Geophysical Research Letters 8, 2265-2268.

Martins, F.R., Bueno, E.B., 2005. Parameterization of aerosols from burning biomass in the Brazil-SR radiative transfer model. Solar Energy 80, 231-239.

Martins, F.R., 2001. Influência do processo de determinação da cobertura de nuvens e dos aerossóis de queimada no modelo físico de radiação BRASIL-SR. PhD thesis. Brazilian Institute for Space Research. São José dos Campos, Brazil.

Martins, J.V., Artaxo, P., Liousse, C., Reid, J.S., Hobbs, P.V., Kaufman, Y. Effects of black carbon content, particle size, and mixing on light absorption by aerosol from 
biomass burning in Brazil. Journal of Geophysical Research 103 D4, 32041-32050, 1998.

Martins, F. R., Guarnieri, R. A., Pereira, E. B., Mantelli, S., Chagas, R. C., Thomaz, C., Andrade, E. Projeto SONDA - Rede Nacional de Estações para a coleta de dados meteorológicos aplicados ao setor de energia. In: I Congresso Brasileiro de Energia Solar, 2007, Fortaleza. Anais do I Congresso Brasileiro de Energia Solar. Fortaleza: Associação Brasileira de Energia Solar, 2007.

Molnár, A., Mészá ros, E., 2001. On the relation between the size and chemical composition of aerosol particles and their optical properties. Atmospheric Environment 35, 5053-5058.

Papayannis, A., Balis, D., Bais, A., Van Der Berch, H., Calpini, B., Durieux, E., Fiorani, L., Jaquet, L., Ziomas, I., Zerefos, C.S., 1998. Role of urban and suburban aerosol on solar UV radiation over Athens, Greece. Atmospheric Environment 32, 2193-2201.

Peixoto J. P.; Oort, A. H. Physics of Climate, American Institute of Physics, AIP Press, 520p., 1992.

Pereira, E.B., Setzer, A.W., Gerab, F., Artaxo, P.E., Pereira, M.C., Monroe, G., 1996. Airborne measurements of burning of biomass aerosols in Brazil related to "TRACEA'” experiment. J. Geophys. Res. 101 (D19), 23983-23999.

Pereira, E. B., Martins, F.R., Abreu S. L., Rüther, R. Atlas Brasileiro de Energia Solar, São José dos Campos, Programa das Nações Unidas para o Meio Ambiente, 2006. (disponível em www.cptec.inpe.br/sonda).

Pinker, R.T., Laszlo, I., 1989. Derivation of surface solar radiation on a continental scale with the ISCCP B3 data. IRS_88 Current Problems, 272-274.

Procopio, A. S.; Remer, L. A.; Artaxo, P.; Kaufman, Y. J.; Holben, B. N. Modeled spectral optical properties for smoke aerosols in Amazonia. Geophysical Research Letters, v.30, n.24, p.2.265-2.270, 2003. doi: 10.1029/2003GL018063.

Procopio, A. S.; Artaxo, P.; Kaufman, Y. J.; Remer, L. A.; Schafer, J. S.; Holben, B. N. Multiyear analysis of Amazonian biomass burning smoke radiative forcing of climate. Geophysical Research Letters, 31, L03108-L03112, 2004. doi:10.1029/2003GL018646.

Raes, F., Dingenen, R. V., Vignati, E., Wilson, J., Putaud, J. P., Seinfeld, J. H., Adams, P. (2000). Formation and cycling of aerosols in the global troposphere. Atmospheric Environment 34, 4215 - 4240. 
Reid, J.S., Hobbs, P.V., Ferek, R.J., Blake, D.R., Martins, J.V., Dunlap, M.R., Liousse, C., 1998. Physical, chemical and optical properties of regional hazes dominated by smoke in Brazil. J. Geophys. Res. 103 (D24), 32059-32080.

Remer, L.A.; Kaufman, Y.J.; Tanré, D.; Matoo, S.; Chu, D.A.; Martins, J.V.; Li, R.-R.; Ichoku, C.; Levy, R.C.; Kleidman, R.G.; Eck, T.F.; Vermote, E.; Holben, B.N. The MODIS aerosol algorithm, products, and validation. Journal of the Atmospheric Sciences, v.62, (CLAMS Special Section), p.947-973, 2005.

Rissler, J.; Swietlicki, E.; Zhou, J.; Gatti, L. V.; Roberts, G.; Andreae, M. O.; Artaxo, P. Physical properties of the sub-micrometer aerosol over the Amazon rain forest during the wet-to-dry season transition - Comparison of modeled and measured CCN concentrations. Atmospheric Chemistry and Physics, v.4, p.2.119-2.143, 2004.

Robinson, N. (Ed.) Solar Radiation, Amsterdam, Elsevier Publishing Company, 347p., 1966.

Schuster, G.L., Dubovik, O., Holben, B.N., 2006. Ångström exponent and bimodal aerosol size distributions. Journal of Geophysical Research 111, D07207.

Smirnov, A., Holben, B.N., Eck, T.F., Dubovik, O., Slutsker, I. Cloudscreening and quality control algorithms for the AERONET database. Remote Sensing of the Environment, v.73, p.337349, 2000.

SONDA, Sistema Nacional de Organização Nacional de Dados Ambientais. Estações do Projeto SONDA. Disponível em: 〈http://www.cptec.inpe.br/sonda/>. Acessado em 10 de maio de 2008.

Tanré, D., M. Herman, and Y. J. Kaufman, 1996: Information on aerosol size distribution contained in solar reflected spectral radiances. J. Geophys. Res., 101, 19 043-19060.

Tanré, Y. J. Kaufman, M. Herman, and S. Mattoo, 1997: Remote sensing of aerosol properties over oceans using the MODIS/EOS spectral radiances. J. Geophys. Res., 102, $16971-16988$.

Toon, O.B. Modeling the relationships between aerosol properties and the direct and indirect effects of aerosols on climate. Em: Aerosol Forcing of Climate. Editores: R.J. Charlson e J. Heintzenberg. John Wiley \& Sons, Chichester, pp. 198-213, 1995.

Van de Hulst, H. C. Light Scattering by Small Particles, New York, Wiley, 470p., 1957.

Wallace, J. M.; Hobbs, P. V. Atmospheric Science: an introductory survey, San Diego, Academic Press, 467p. 1977. 
Whitlock, C.H., Tarpley, D. 1996. Satellite-Based solar radiation data archives and new data. In: Proceedings of the workshop: Satellites for Solar Energy Resource Information, Washington, DC, April 10-11.

Zhou, J.; Swietlicki, E.; Hansson, H. C.; Artaxo, P. Sub-micrometer aerosol particle size distribution and hygroscopic growth measured in the Amazon rain forest during the wet season, Journal of Geophysical Research, v.107, n.D20, p.8.055-8.065, 2002. doi:10.1029/2000JD000203.

http://iara.meteo.furg.br/page/aulas/poligradf.pdf. 


\section{APÊNDICE A}

\section{TRABALHOS TÉCNICO-CIENTÍFICOS APRESENTADOS EM EVENTOS}

Neste Apêndice estão enumerados os trabalhos de autoria e co-autoria do bolsista, apresentados em eventos científicos durante o período de vigência da bolsa PIBIC/INPE - CNPq/MCT no CRS/CIE/INPE - MCT.

EVENTO: XXII Congresso Regional de Iniciação Científica e Tecnológica em Engenharia - CRICTE 2007, 29 a 31 de outubro de 2007 - Passo Fundo - RS.

1 - ESTUdO DA INFLUÊNCIA DAS QUEIMADAS NA REDUÇÃO DA RADIAÇÃO SOLAR INCIDENTE NO OBSERVATÓRIO ESPACIAL DO SUL OES/CRS/CIE/INPE - MCT.

Autores: Rodrigo Brackmann; Daniel V. Fiorin; Marcelo P. Pés; Ricardo A. Guarnieri.

2 - ANÁLISE DE RELAÇÕES EMPÍRICAS ENTRE A RADIAÇÃO SOLAR E FATORES DE NEBULOSIDADE

Autores: Daniel V. Fiorin; Fernando Ramos Martins; Nelson J. Schuch; Enio B. Pereira; rodrigo Brackmann; Marcelo Pizzuti Pes; Ricardo A. Guarnieri.

EVENTO: XXII Jornada Acadêmica Integrada - JAI, 22 a 25 de outubro de 2007 Santa Maria - RS.

\section{1 - ESTIMATIVAS DE MEDIDAS DA IRRADIAÇÃO SOLAR DIFUSA A PARTIR DA IRRADIAÇÃO SOLAR GLOBAL E DE DADOS DE NEBULOSIDADE}

Autores: Daniel Vinícius Fiorin; Nelson J. Schuch; Fernando Ramos Martins; Rodrigo Brackmann. 


\section{APÊDICE B}

\section{CERTIFICADOS}

Este Apêndice apresenta os certificados dos trabalhos apresentados pelos bolsistas em eventos científicos na qualidade de autor durante o período de vigência da Bolsa PIBIC/INPE -CNPq/MCT, no Laboratório de Energias Renováveis do Centro Regional Sul de Pesquisas Espaciais - CRS/CIE/INPE - MCT, em Santa Maria.RS. 


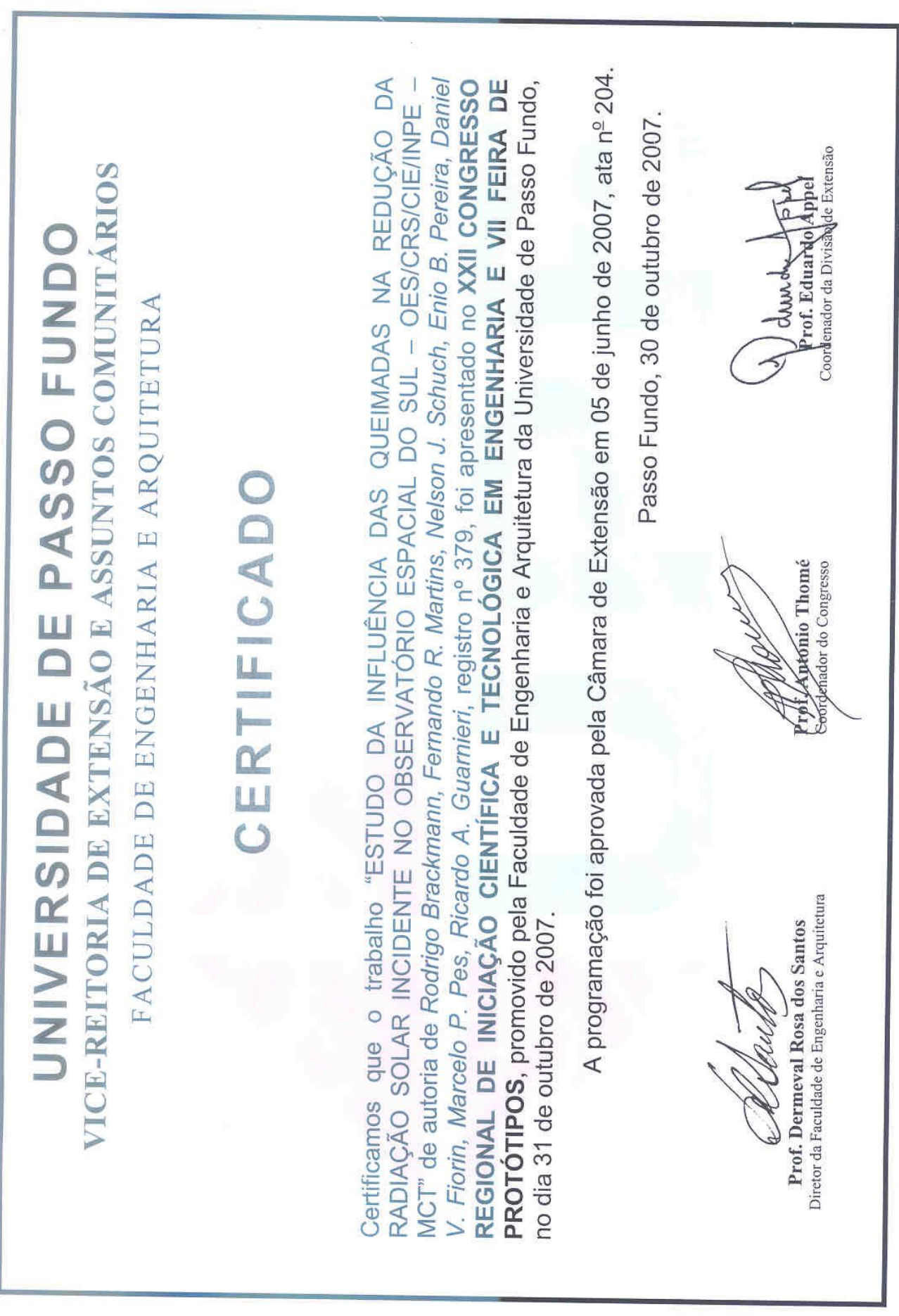




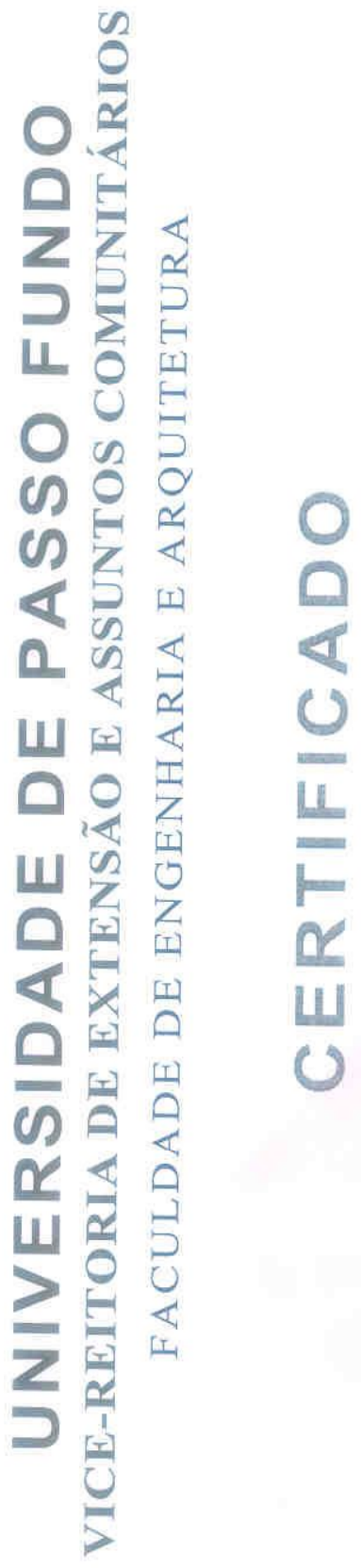

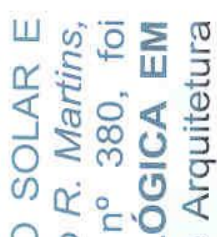

$<\frac{0}{0} \circ 0$

U.

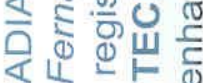

व

৫ 仓

山 ㅎํ웜

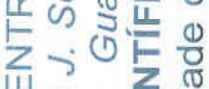

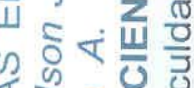

\& $\frac{0}{0}$ ग

는?

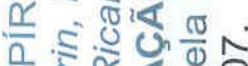

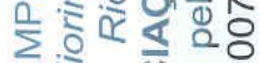

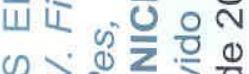

$\omega>0 \div$

Uू.

षक

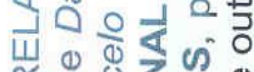

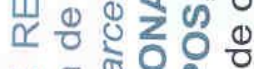

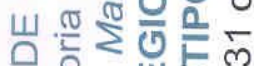

山

บ ชิㅇำ

होकी

ষ্ণ

它出山。

是向嵒茨

은

ॠ

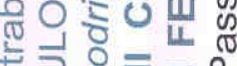

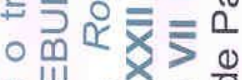

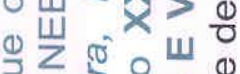

正

थ 5 के

$0<\frac{0}{4} \cdot \frac{0}{0}$

है山

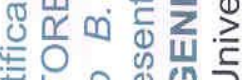

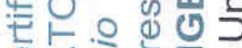

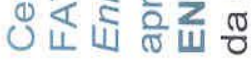
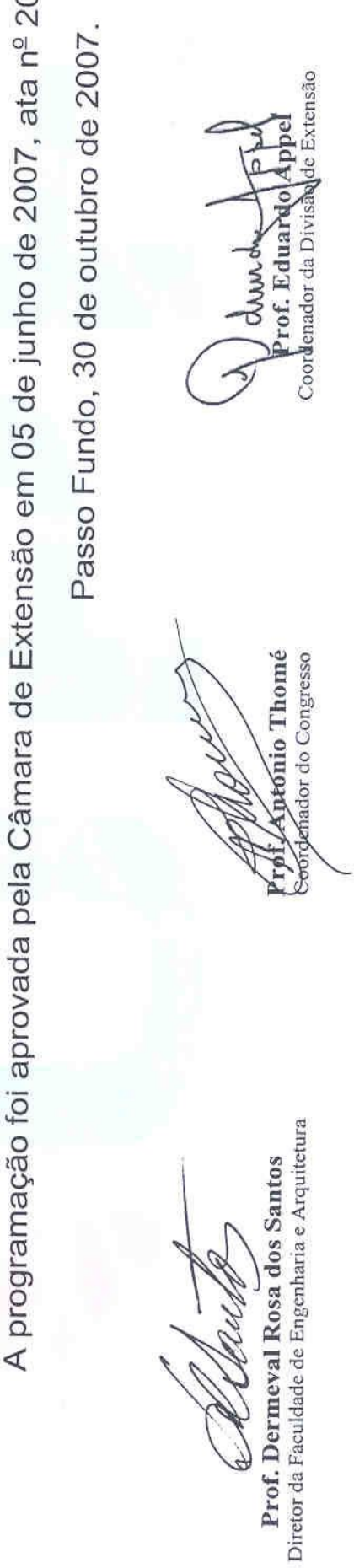


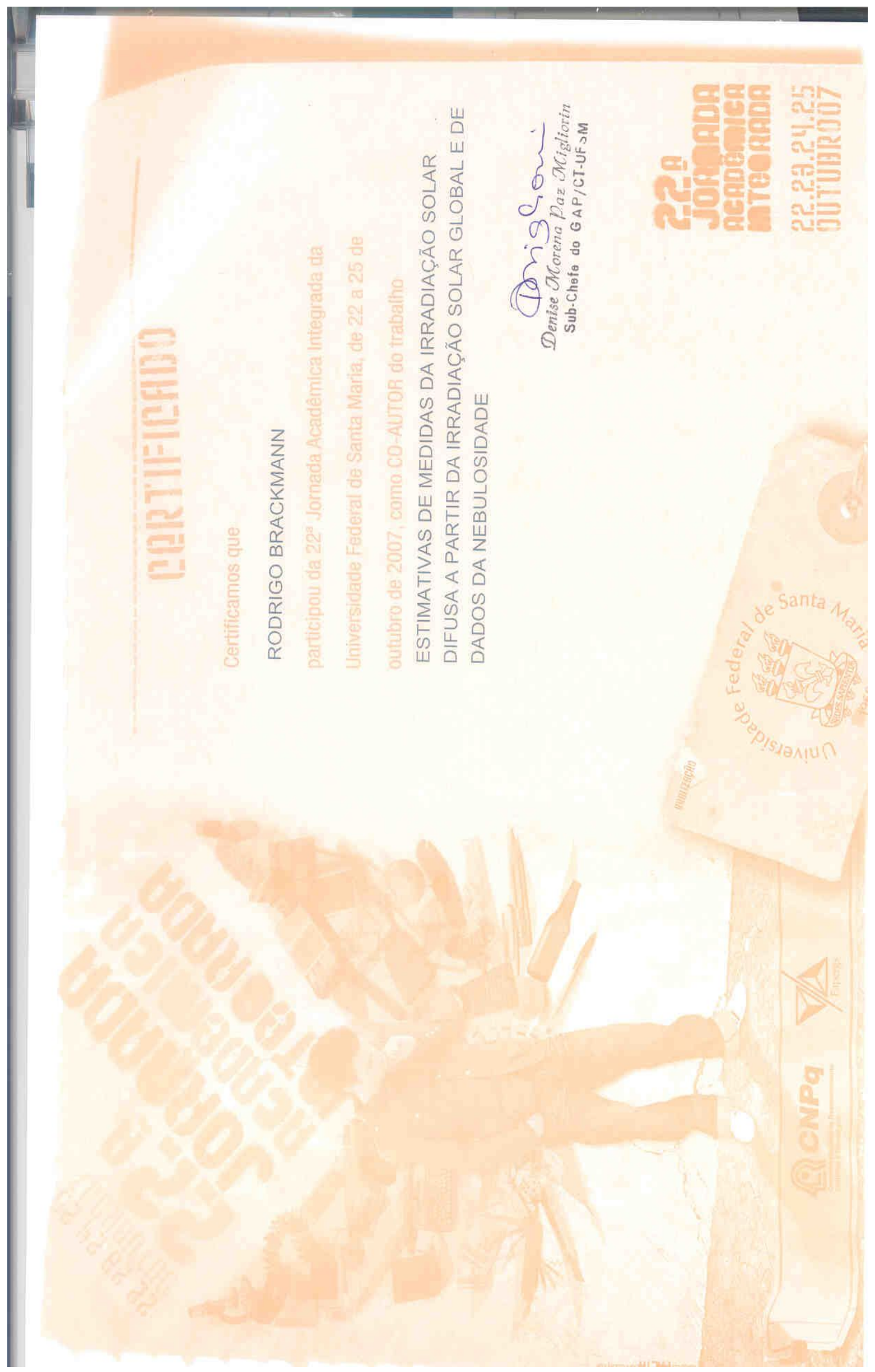

